Técnicas de visualização de informação para a análise de dados de sensores e biossensores

Eduardo Gonzalo Espinoza Carreon 
Data de Depósito:

Assinatura:

\title{
Técnicas de visualização de informação para a análise de dados de sensores e biossensores
}

\author{
Eduardo Gonzalo Espinoza Carreon
}

Orientador: Prof. Dr. Fernando V. Paulovich

Dissertação apresentada ao Instituto de Ciências Matemáticas e de Computação - ICMC-USP, como parte dos requisitos para obtenção do título de Mestre em Ciências - Ciências de Computação e Matemática Computacional. VERSÃO REVISADA

\section{USP - São Carlos}

Julho de 2013 
Ficha catalográfica elaborada pela Biblioteca Prof. Achille Bassi e Seção Técnica de Informática, ICMC/USP, com os dados fornecidos pelo(a) autor(a)

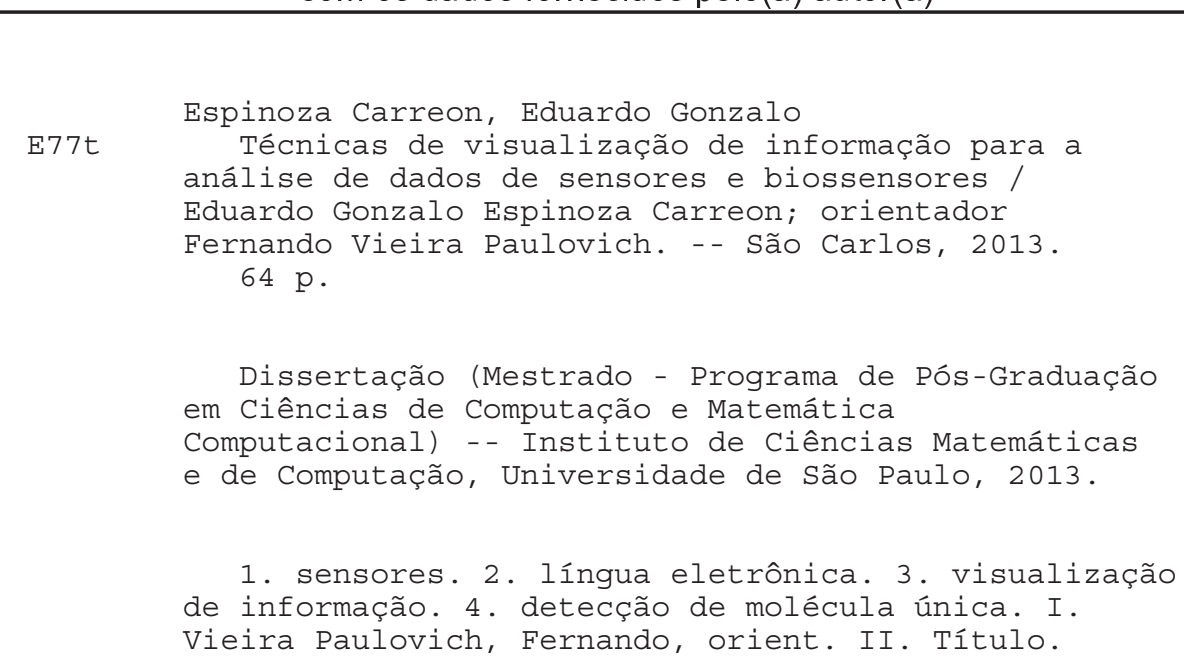




\section{Dedicatória}

Dedico este trabalho aos meu pais, Luis e Socorro;

e aos meus irmãos Pablo, Frank e Carolina. 


\section{Agradecimentos}

Gostaria de agradecer primeiramente a minha família, motivo pelo qual os primeiros parágrafos estão em espanhol.

Agradezco bastante a mis estimados padres, Luis y Socorro, por su apoyo, esfuerzo y cariño para que pudiese cumplir mis objetivos personales, académicos y profesionales. Muchas gracias por inspirarme a ser una mejor persona.

A mis queridos hermanos, Pablo, Frank y Carolina, porque a pesar del poco tiempo que pasamos juntos durante esta etapa hicieron mucha falta y sirvieron de motivación para poder concluir mis estudios.

Agradeço aos meus amigos e companheiros do laboratório VICG, pelo incentivo e companhia tanto nos momentos de estudo quanto nos momentos de lazer: Carlos, Vinicius, Thiago, Francisco, Renato, Christian, Aurea, Oscar, Samuel, Tácito, Danilo e Felipe.

Agradeço também aos grandes amigos que conheci aqui Rosi, Alceu, Ândrea, Pedro, Leonardo, Pedro, Jorge, Paola, Rose, Giovanna, Beatriz.

Agradeço às Republicas 7 eh Poko e Chiqueiro pela amizade e momentos de diversão nessa etapa.

Agradeço de forma especial ao pessoal da física Diogo e Pedro que tem me apoiado de maneira importante no desenvolvimento desse projeto.

Agradeço às instituições CNPq e FAPESP pelo apoio financeiro durante esse período.

Por último, porém não menos importante, quero agradecer ao meu orientador Prof. Fernando V. Paulovich, pelas suas conversas, conselhos, orientações e sugestões, sem os quais não seria possível o início e o término deste trabalho. Obrigado! 


\section{Conteúdo}

Dedicatória $\quad$ i

Agradecimentos $\quad$ iii

Lista de Figuras $\quad$ vii

Lista de Tabelas $\quad$ xii

Lista de Siglas $\quad$ Xv

Abstract $\quad$ Xv

Resumo xviii

1 Introdução 1

1.1 Organização da Dissertação . . . . . . . . . . . . . . . . . . . . 3

2 Visualização de informação 5

2.1 Sensores e biossensores . . . . . . . . . . . . . . . . . 5

2.1.1 Sensores do tipo SERS . . . . . . . . . . . . . . 6

2.1.2 Sensores de espectroscopia de impedância . . . . . . . . . . . . 7

2.2 Técnicas de visualização de Informação . . . . . . . . . . . . . . . . . . 8

2.2.1 Técnica de Projeção Multidimensional . . . . . . . . . . . . . . . 9

2.3 Outras técnicas de Visualização de Informação . . . . . . . . . . . . . . . . 13

2.3.1 Coordenadas Paralelas . . . . . . . . . . . . . . . . . . 13

2.3.2 Heatmap . . . . . . . . . . . . . . . . . . . 13

2.4 Aplicações . . . . . . . . . . . . . . . . . . . . . . . 14

2.5 Considerações finais . . . . . . . . . . . . . . . . . . . 20

3 Visualização de SERS $\quad 21$

3.1 Primeira abordagem . . . . . . . . . . . . . . . . . . . 22 
3.1.1 Resultados . . . . . . . . . . . . . . . . . . . 27

3.2 Segunda abordagem . . . . . . . . . . . . . . . . . . . . . . . . 29

3.2.1 Resultados . . . . . . . . . . . . . . . . . . 33

3.3 Considerações finais . . . . . . . . . . . . . . . . . . . . . 34

4 Troca de sensores em línguas eletrônicas 39

4.1 Processo para a substituição de sensores . . . . . . . . . . . . . . . 41

4.1.1 Etapa 1: Conversão para capacitância . . . . . . . . . . . . . . 41

4.1.2 Etapa 2: Conversão em circuito eletrônico equivalente de Taylor . . 43

4.1.3 Etapa 3: Substituição de sensores . . . . . . . . . . . . . . . . 46

4.2 Resultados . . . . . . . . . . . . . . . . . . . . . . . . . . 49

4.3 Considerações finais . . . . . . . . . . . . . . . . . . . . . . . . 52

5 Conclusões $\quad 55$

5.1 Detecção de molécula única em sensores do tipo SERS . . . . . . . . . 55

5.2 Substituição de sensores . . . . . . . . . . . . . . . . . 56

5.3 Limitações . . . . . . . . . . . . . . . . . . . . . . . . . 57

5.3 .1 Desenvolvimentos futuros . . . . . . . . . . . . 58

$\begin{array}{ll}\text { Referências Bibliográficas } & 64\end{array}$ 


\section{Lista de Figuras}

2.1 Exemplo da forma de coleta de espectros usado pelos sensores para os conjuntos de dados do sistema methylene blue (Aoki et al., 2013). Um laser é deslocado cada $3 \mu m$ (horizontal e verticalmente) seguindo um percurso snake-like em uma área $100 \mu m \times 100 \mu m . \ldots \ldots . \ldots . \ldots 6$

2.2 Sistema de espectroscopia por impedância que emprega um sensor interdigitado para reconhecer substâncias biológicas (figura extraída de Riul Jr. et al. (2010)) . . . . . . . . . . . . . . . . . . . . . .

2.3 Representação visual dos dados de capacitância obtidos por um sensor composto por um filme $P A H / P V S$ empregando a técnica Coordenadas paralelas. O eixo $x$ representa as frequências e o eixo $y$ constitui os valores de capacitância. As diferentes cores representam as diversas concentrações analisadas de ácido fítico. (figura extraída de Oliveira Jr et al. (2012)) . 14

2.4 Representação Heatmap para o conjunto de dados composto pelas medidas coletadas pelo sensor Eletrodo Puro na análise de ácido fítico. As amostras analisadas estão representadas pelas linhas, e cada coluna representa o valor de capacitância mensurado para uma frequência diferente. . . . . . . 15

2.5 Representações visuais de dados espectrais usando diferentes técnicas de Visualização de Informação expondo diversas características dos dados (figura extraída de Polder \& van der Heijden (2001)) . . . . . . . . . . . . . . 16

2.6 Visualização das medidas de impedância elétrica por uma unidade sensorial composta por um filme PAH/Phytase. Cada círculo representa as medidas coletadas por um sensor diferente e cada cor representa a concentração que foi mensurado (figura extraída de Moraes et al. (2010) ) . . . . . . . . . . . 17 
2.7 Projeção dos dados de impedância para amostras de Leishmania amazonensis e Trypanosoma cruzi (doença Chagas) com diferentes concentrações: serum $A$ (contendo anticorpos negativos), serum $B$ (contendo anticorpos anti-Leishmania), serum $C$ (contendo anticorpos anti-T. cruzi), mixture (mistura de anticorpos anti-T. cruzi e anti-Leishmania). A unidade sensorial usada foi um Eletrodo puro, ou seja, não era constituída por nenhum tipo de filme. (figura extraída de Paulovich et al. (2011a)) . . . . . . . . . 17

2.8 Resultados da análise dos sensores Eletrodo puro, PAH/Phytase e PAH/PVS. As medidas dos três sensores foram combinadas e projetadas as técnicas (a) IDMAP e (b) Coordenadas paralelas. Previamente foram selecionadas as 10 frequências mais representativas. (Figura extraída de Paulovich et al.

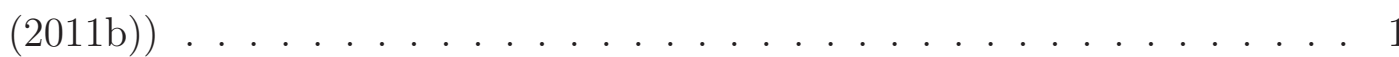

2.9 Representação visual da capacitância de unidades sensoriais constituídas por filmes PAH/Lipase e PAH/GOx. As projeções foram geradas com o intuito de detectar glucose e triclycerides em diferentes níveis de concentração. (Figura extraída de Moraes et al. (2012)) . . . . . . . . . . . . . . 19

2.10 Resultados obtidos por Moraes et al. (2012) na análise de diversas concentrações de glucose e triclycerides depois do uso de técnicas computacionais para selecionar as 10 frequências de maior relevância. Os resultados são apresentados duas técnicas de visualização de informação: (a) Projeção IDMAP e (b) Coordenadas paralelas

3.1 Aplicando o filtro de média num espectro sem tratamento de dados. A Figura (a) representa o espectro que exibe um valor espúrio, as outras figuras (b), (c) y (d) apresentam o espectro pré-processado usando o filtro de média com diferentes tamanhos de janela. O espectro tratado pertence ao conjunto de dados 10MB . . . . . . . . . . . . . . . . . . . 24

3.2 Resultado da aplicação da técnica detrending. Na esquerda é apresentado o espectro sem tratamento e na direita o resultado depois da aplicação do pré-processamento. O espectro processado corresponde ao conjunto de dados 100MB

3.3 Resultados da aplicação das duas abordagens de suavização sobre o espectro apresentado na Figura 3.1a. . . . . . . . . . . . . . . . . . 26

3.4 Resultados obtidos no processo manual de detecção de molécula únicas para os conjuntos de dados 100MB, 10MB e 1MB (figura extraída de Aoki et al. (2013))

3.5 Resultados obtidos no processo automático de detecção de molécula únicas para os conjuntos de dados 100MB, 10MB e 1MB (figura extraída de Aoki et al. (2013)) 
3.6 Resultados do processo de detecção de molécula única usando diferentes abordagens para o cálculo de dissimilaridade representadas usando o método de visualização Heatmap. Os pontos ressaltados em roxo indicam a presença dá molécula procurada enquanto os outros pontos claros representam falsos positivos. . . . . . . . . . . . . . . . . . . . . . . . 30

3.7 Faixa $\left[x_{1}, x_{2}\right]$ Full Width at Half Maximum (FWHM) indicada na área verde 31

3.8 Análise de deslocamentos horizontais entre os espectros (azul) e o espectro referência (vermelho) . . . . . . . . . . . . . . . . . . 32

3.9 Curvatura de um espectro expressada pela inclinação entre dois números de onda. . . . . . . . . . . . . . . . . . . . . . 33

3.10 Exemplo de falso positivo. A área verde indica a similaridade obtida usando a técnica de distância City-Block . . . . . . . . . . . . . . . . . . . . . 34

3.11 Comparativo de falsos positivos entre as duas abordagens: inicial (esquerda) e final (direita). São apresentados os 5 primeiros espectros classificados como molécula única e correspondem à analise do conjunto de dados $10 \mathrm{MB}$.

3.12 Análise do conjunto de dados R18, os pontos mais claros indicam a presença de um espectro classificado como molécula única . . . . . . . . . . . 3

3.13 Espectros (Figuras (b), (c) e (d)) do conjunto de dados R18 classificados como moléculas únicas. Os três espectros presentam um baixo grado de similaridade com o modelo de referencia (a) . . . . . . . . . . . . . .

4.1 Projeções para dados produzidos por diferentes unidades sensoriais para analisar diferentes concentrações de ácido fítico em que cada figura representa um material distinto usado na construção do sensor (figura extraída de Paulovich et al. (2011b)). . . . . . . . . . . . . . . . . . . . 40

4.2 Resumo do processo para analisar a reprodutibilidade de sensores composto por 3 etapas: (1) Pré-processamento dos dados (Seção 4.1.1) (2) Conversão em circuito eletrônico equivalente (Taylor \& Macdonald, 1987) (Seção 4.1.2) e (3) Substituição de sensores e avaliação dos resultados usando Técnicas de Projeção Multidimensional (Seção 4.1.3) . . . . . . . . . . . . . . . . . 42

4.3 Circuito eletrônico equivalente que representa um sensor (figura extraída de Taylor \& Macdonald (1987)) . . . . . . . . . . . . . . . .

4.4 Comparativo entre a curva de capacitância $C$ (linha vermelha) e a curva de capacitância sintética $C^{\prime}$ (linha cinza) gerada a partir do cálculo de parâmetros. A Figura (b) é apresentada com os eixos frequência e dissimilaridade em escala logarítmica para observar melhor a diferença presente entre as curvas. 
4.5 Projeções do resultado da substituição de um sensor deficiente no conjunto de dados PAH/Fitase. Na Figura (a) representa a projeção dos dados originais em que cada cor representa uma concentração diferente de ácido fítico. Na Figura (b) apresenta o resultado da substituição. Nessa ocasião os pontos vermelhos não representam uma concentração senão representam o novo sensor $S_{N O V O}$ após substituir o sensor deficiente $S_{D E F}$. Para uma melhor interpretação dos resultados, cada concentração é agrupada por um

4.6 Resultados da etapa de conversão das curvas de capacitância no circuito eletrônico equivalente de Taylor (Seção 4.1.2) para o conjunto de dados PAH/Phytase. A figura (a) apresenta a projeção dos dados originais com um valor de coeficiente de silhueta 0.82655245. A figura (b) apresenta a projeção dos dados após o cálculo de capacitores e resistores, o novo coeficiente é 0.551106150 . Todas as projeções foram geradas usando a técnica IDMAP e os parâmetros foram calculados com a técnica Sequential Linear Squares Programming. . . . . . . . . . . . . . . . . . . . 49

4.7 Resultados da etapa de conversão das curvas de capacitância no circuito eletrônico equivalente de Taylor (Seção 4.1.2) para o conjunto de dados PAH/PVS. A figura (a) apresenta a projeção dos dados originais com um valor de coeficiente de silhueta 0.70707214. A figura (b) apresenta a projeção dos dados após o cálculo de capacitores e resistores, o novo coeficiente é 0.540498260 . Todas as projeções foram geradas usando a técnica IDMAP e os parâmetros foram calculados com a técnica Sequential Linear Squares Programming. . . . . . . . . . . . . . . . . . . . . 50

4.8 Resultados da etapa de conversão das curvas de capacitância no circuito eletrônico equivalente de Taylor (Seção 4.1.2) para o conjunto de dados Eletrodo puro. A figura (a) apresenta a projeção dos dados originais com um valor de coeficiente de silhueta 0.6353018. A figura (b) apresenta a projeção dos dados após o cálculo de capacitores e resistores, o novo coeficiente é 0.488130060 . As projeções foram geradas usando a técnica IDMAP e os parâmetros foram calculados com a técnica Sequential Linear Squares Programming. . . . . . . . . . . . . . . . . 50 
4.9 Resultados da etapa de Substituição de sensores (Seção 4.1.3). O ponto vermelho representa o sensor substituído analisado em cada concentração. A Figura (a) exibe a projeção das curvas de capacitância originais. Já a Figura (b) apresenta a nova projeção gerada após a substituição. Observa-se como o novo sensor apresenta uma maior separação comparado com os dados originais. Por fim, a Figura (c) apresenta a projeção depois de aplicar a recalibração do sensor. Os parâmetros do sensor $S_{N O V O}$ são transformados nos parâmetros do sensor $S_{D E F} \ldots \ldots \ldots \ldots \ldots$

4.10 Resultados da etapa de Substituição de sensores na análise do conjunto PAH/PVS. As Figuras (b) e (c) representam o zoom da área indicada pelo retângulo preto na Figura (a). Observa-se como o sensor substituído, representado pelo círculo vermelho, é melhor agrupado após a etapa de transformação. . . . . . . . . . . . . . . . . . 52 


\section{Lista de Tabelas}

2.1 Símbolos usados e seus significados para o entendimento das Técnicas de Projeção Multidimensional. . . . . . . . . . . . . . . . . . . . . . . . . . 10

3.1 Símbolos usados e seus significados para o entendimento da abordagem proposta de Detecção de moléculas únicas. . . . . . . . . . . . . . . . . . . 23

4.1 Símbolos usados e seus significados para o entendimento da abordagem proposta para a Análise de Reprodutibilidade. . . . . . . . . . . . . . . . . 43

4.2 Resultados da aproximação no processo de cálculo de parâmetros $\left(G_{d}, G_{t}, G_{b}, C_{d}, C_{g}, C_{b}\right)$ do circuito equivalente a partir da curva de capacitância $C$ empregando as diferentes técnicas de ajuste de parâmetros. Um resultado mais próximo de zero indica uma maior precisão atingida por cada técnica. . . . . . . . 45

4.3 Representação original do conjunto de dados PAH/PVS. Cada linha representa uma curva de capacitância e está composta por 71 elementos para determinadas frequências. . . . . . . . . . . . . . . . . . . . . 46

4.4 Resultados da aproximação no processo de cálculo de parâmetros $\left(G_{d}, G_{t}, G_{b}, C_{d}, C_{g}, C_{b}\right)$ para o conjunto PAH/PVS . . . . . . . . . . . . . . . 46

4.5 Interpretação do Coeficiente de Silhueta proposta por Rousseeuw (1987). 48 


\section{Lista de Siglas}

DTW Dynamic Time Warping

FS Force Scheme

FWHM Full Width at Half Maximum.

GPA Generalized Procrustes Analysis

IDMAP Interactive Document Map

MB methylene blue

MDS Multidimensional Scaling

MMS Médias Móveis Simples

PCA Principal Component Analysis

R18 Octadecylrhodamine $B$

SERS Surface Enhanced Raman Spectroscopy

SG Savitzky-Golay

SM Sammon's Mapping

SMD Single Molecule Detection

TPM Técnica de Projeção Multidimensional

TRP Texas red tagged phospholipid 


\section{Abstract}

A sensor or biosensor is an analytical device that aims to identify substances and their concentrations. The efficient employment of sensors allows the solution of many problems in several fields such as chemistry, biology, medicine, pharmacology, environmental sciences, among others. Two problems were the main focus of this master's thesis: the diagnosis of diseases and the replacement of human beings by electronic tongues to avoid subjective analysis. The first problem is solved using single molecule detection but presents problems related to the large amount of data generated by sensors Surface Enhanced Raman Spectroscopy (SERS). The second one involves the recalibration of impedance spectroscopy sensors in electronic tongues for them to be replaced when one of them presents defficiencies.

We have developed two different approaches to handle these problems, both of them involve information visualization methods making the exploration of large amounts of data more efficiently. The first approach improved the execution time of the single molecule detection process compared to the manual analysis. The number of spectra classified as false positives was also reduced. The second approach, which is a candidate solution to the replacement of sensors in an electronic tongue, employs the definition of the equivalent circuit of Taylor along with Generalized Procrustes Analysis (GPA) to achieve the desired goal. This leads to the recalibration of one sensor into the response of another one, presenting good results. In the future, this could be potentially used to produce more reliable and reproducible systems. 


\section{Resumo}

Um sensor ou biossensor é um dispositivo analítico que tem por objetivo principal a identificação de substâncias e suas concentrações. O emprego efetivo dos sensores permite resolver diversos problemas em varias áreas como química, biologia, medicina, farmacologia, ciências ambientais, entre outras. Dentre desses problemas podemos ressaltar dois: o diagnóstico de doenças e a substituição de seres humanos por línguas eletrônicas para evitar as análises subjetivas. O primeiro problema é resolvido pela identificação de molécula única mas apresenta problemas relacionados à grande quantidade de dados gerados pelos sensores Surface Enhanced Raman Spectroscopy (SERS). Já o segundo problema envolve a recalibração de sensores de espectroscopia de impedância para que possam ser substituídos em línguas eletrônicas quando apresentem deficiências.

Em ambos casos foram desenvolvidas abordagens que empregaram técnicas de visualização de informação e permitem uma exploração eficiente da grande quantidade de dados produzidos. A primeira abordagem conseguiu melhorar o tempo de execução do processo de detecção de molécula única em contrapartida à análise manual atualmente empregada além de reduzir o número de falsos positivos. A segunda abordagem, a troca de sensores em línguas eletrônicas, mostrou resultados satisfatórios. O uso da definição do circuito eletrônico equivalente de Taylor em combinação com Generalized Procrustes Analysis (GPA) permitiu de forma adequada a troca de sensores por conseguir transformar a resposta de um sensor na resposta do outro, característica que no futuro poderá ser usada para conseguir produzir sistemas mais reprodutíveis e confiáveis. 


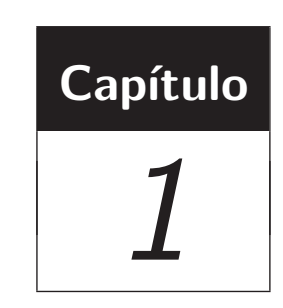

\section{Introdução}

$\mathrm{C}$

om o aumento da competitividade industrial nos últimos anos, em especial com a entrada no cenário produtivo global de países emergentes, cada vez mais se exige que o processo de produção seja aperfeiçoado com o intuito de resultar em produtos que sigam determinados padrões e que tenham maior qualidade. Nesse sentido, uma das atividades centrais é a capacidade de mensurar a qualidade do que foi produzido e realizar testes comparativos. Existem dispositivos de medição, conhecidos como sensores ou biossensores, que permitem realizar essa tarefa.

Um sensor ou biossensor é um dispositivo analítico que tem por objetivo principal a identificação de substâncias e suas concentrações (Mohanty \& Kougianos, 2006). Apesar de muito já ter sido feito na área de sensores e biossensores, ainda existem particularidades, do ponto de vista da análise dos dados gerados, que precisam ser tratadas.

Este trabalho se insere nesse contexto, propondo o estudo e implementação de técnicas de visualização de informação para a análise de dados gerados por sensores e biossensores. A visualização de informação (Grinstein et al., 2001; Oliveira \& Levkowitz, 2003) tira vantagem do sistema visual humano na tarefa de identificar padrões e tendências presentes nos dados (Card et al., 1999). Adicionalmente, o fator determinante para o sucesso atual dessas técnicas é a possibilidade de se analisar informação de forma muito mais rápida e confiável, o que as torna bastante indicadas para a exploração dos resultados produzidos por sensores e biossensores.

Nesse trabalho, foram propostas duas abordagens para resolver dois problemas presentes na análise de dados de sensores e biossensores: a detecção de molécula única (Single Molecule Detection (SMD)) em dados gerados por sensores do tipo Surface Enhanced Raman Spectroscopy (SERS)(Kneipp et al., 1997); e a substituição de sensores de espectroscopia de impedância (Pejcic \& Marco, 2006) em uma língua eletrônica. 
A primeira proposta, a detecção de uma única molécula, é um assunto de grande relevância e interesse científico em varias áreas como química, biologia, medicina, farmacologia e ciências ambientais (Barnes et al., 1995). Na detecção de molécula única, o intuito é encontrar as amostras ou espectros mais semelhantes a um espectro de referência que representa uma determinada substância ou analito. Atualmente, as abordagens empregadas para a solução desse problema são aplicadas de forma manual, comparando visualmente os espectros produzidos com o conjunto modelo de espectros de referência, buscando semelhanças. Como sensores mais modernos produzem dados em maior resolução e volume, a inspeção e comparação manual se mostram inviáveis, sendo atualmente necessário ferramentas especiais que deem suporte a exploração e interpretação de grandes massas de dados. Portanto, a análise manual dos dados gerados por sensores e biossensores é ineficiente quando milhares de espectros devem ser analisados.

A abordagem computacional desenvolvida nesse mestrado resolve de forma apropriada o problema de detecção de molécula única. Primeiro, os dados coletados são tratados já que geralmente dados do mundo real apresentam valores com ruído, incompletos e inconsistentes. Uma vez que os dados são pré-processados, é calculada a dissimilaridade presente entre os espectros analisados e as referências que representam a molécula procurada. Finalmente, os resultados são representados visualmente usando técnicas de visualização de informação. A técnica empregada escolhida para a representação dos resultados foi a Heatmap (Grinstein et al., 2001), pois assemelha-se à forma em que os dados são coletados. Nos experimentos, a nova ferramenta se mostrou eficiente ao analisar os conjuntos de dados sensoriais com uma maior precisão do que a análise manual.

A segunda proposta aborda a substituição de sensores em línguas eletrônicas. Uma língua eletrônica é um sensor capaz de distinguir líquidos muito similares utilizando as diferentes respostas elétricas dos materiais sendo analisados (Riul Jr. et al., 2010). As línguas eletrônicas vem sendo empregadas com sucesso na análise de diferentes substâncias como vinhos tintos (Parra et al., 2004), sucos de fruta, amostras de cerveja e chá (Kim et al., 2006), café, leite e derivados, além de detecção de traços de impurezas ou poluentes em água (Riul Jr. et al., 2010).

A ideia motora das línguas eletrônicas está na substituição das análises subjetivas gustativas produzidas por seres humanos, por uma ferramenta analítica confiável e reprodutível. Isso porque, mesmo se um grupo de pessoas for bem treinado, a avaliação continuará subjetiva, o que pode representar grande problema para aplicações industriais. Assim, grande interesse tem sido despertado tanto na comunidade científica como na industrial, em especial na industria de alimentos e farmacêutica, pois além da vantagem de evitar subjetivismos, problemas éticos e de segurança relacionados com toxicidade e exposição de humanos a fórmulas desagradáveis também são contornados (Riul Jr. et al., 2010).

Existem diferentes métodos para se construir as línguas eletrônicas (Riul Jr. et al., 
2010). Nesse trabalho, o foco foi dado às línguas baseadas no conceito de espectroscopia de impedância. As medidas de espectroscopia de impedância tem se mostrado de grande importância para investigar interações entre as substância analisadas e os materiais que constituem as unidades sensoriais (Pejcic \& Marco, 2006). Apesar disso, um dos maiores problemas com relação ao uso de espectroscopia de impedância em aplicações industriais diz respeito à reprodutividade dos dados obtidos. Isso porque mesmo sensores nominalmente idênticos dificilmente produzem a mesma resposta elétrica em toda a curva de impedância capturada (Paulovich et al., 2011b) o que acaba levando a construção de línguas eletrônicas não reprodutíveis .

Nesse sentido, foi desenvolvida uma abordagem computacional para encontrar uma transformação, ou escolha de parâmetros que torne as respostas de dois sensores mais semelhantes. Essa abordagem usa a definição do circuito eletrônico equivalente proposta por Taylor \& Macdonald (1987) para representar as curvas de impedância capturadas usando componentes eletrônicos. Essa representação permite reduzir a dimensionalidade dos dados e portanto a complexidade do problema. A abordagem desenvolvida faz uso das Técnicas de Projeção Multidimensional (TPMs) (Tejada et al., 2003) e do Coeficiente de Silhueta (Tan et al., 2005) para avaliar a qualidade dos resultados obtidos. Os resultados alcançados se mostraram promissores e abrem espaço para novos campos de pesquisa.

\subsection{Organização da Dissertação}

Esta dissertação está estruturada da seguinte maneira:

- No Capítulo 2 são apresentados os conceitos de sensores e biossensores assim como também é definida a forma em que eles produzem dados. Neste capítulo também é apresentada uma revisão das técnicas de visualização de informação e as aplicações que já vem sendo empregadas na análise de dados gerados pelos dispositivos mencionados;

- No Capítulo 3 é apresentada a abordagem computacional desenvolvida para a análise de dados gerados por sensores do tipo SERS e também um comparativo entre a nova técnica e o processo manual empregado atualmente;

- No Capítulo 4 é apresentada a abordagem desenvolvida para a substituição de sensores em línguas eletrônicas;

- Por fim, no Capítulo 5 apresenta-se as conclusões desse projeto de mestrado caracterizando as contribuições e limitações do trabalho, bem como sugestões de desenvolvimentos futuros das abordagens propostas. 


\section{Capítulo}

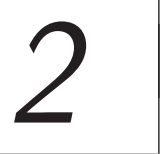

\section{Visualização de informação para dados de sensores e biossensores}

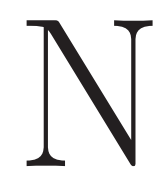

esse capítulo são apresentados os conceitos básicos sobre sensores e biossensores. Também é definida a forma em que esses dispositivos produzem dados. Por fim, é apresentada uma revisão das abordagens computacionais empregadas atualmente na análise de dados gerados por sensores e biossensores, dando um maior ênfase nas técnicas de visualização de informação.

A seguir apresentamos as definições de sensores e biossensores.

\subsection{Sensores e biossensores}

Um sensor ou biossensor é um dispositivo analítico que tem por objetivo distinguir diferentes substâncias e suas concentrações. É um dispositivo químico no qual uma entidade reconhecedora é acoplada a um transdutor para permitir a análise quantitativa de algum parâmetro complexo (Mohanty \& Kougianos, 2006). No caso específico de um biossensor, um determinado bio-elemento, tal como uma enzima, reconhece uma substância líquida (ou analito) específica e o elemento sensorial traduz as características dessa em sinais elétricos (Riul Jr. et al., 2010).

Nessa dissertação foram analisados dois tipos de sensores, os quais são apresentados a seguir: sensores do tipo Surface Enhanced Raman Spectroscopy (SERS) (Fleischmann et al., 1974) e sensores de espectroscopia de impedância (Riul et al., 2002). 


\subsubsection{Sensores do tipo SERS}

Nos sensores de tipo SERS (Fleischmann et al., 1974), uma superfície é dividida em uma matriz de células que depois é varrida por um sinal capturando espectros que representam as moléculas em cada uma dessas células. Um espectro é definido como um vetor de características que representam as intensidades de banda produzidas em função do número de onda (Aoki et al., 2013). O número de onda é definido como o valor inverso do comprimento de onda. Uma descrição mais detalhada do sistema empregado na coleta de dados por sensores do tipo SERS é apresentado na Figura 2.1. Em particular, a figura exibe a coleta empregada nos conjuntos pertencentes ao sistema methylene blue (Aoki et al., 2013). Um laser é deslocado cada $3 \mu m$ (horizontal e verticalmente) seguindo um percurso snake-like em uma área $100 \mu m \times 100 \mu m$. Com essas especificações são coletados 1156 espectros. Adicionalmente, os espectros são identificados pela posição $(X, Y)$ de deslocamento presente no momento da coleta. É importante notar que o ponto de partida para esse sistema é a coordenada $(-50,-50)$ devido a que o lado da área analisada mede $100 \mu m$.

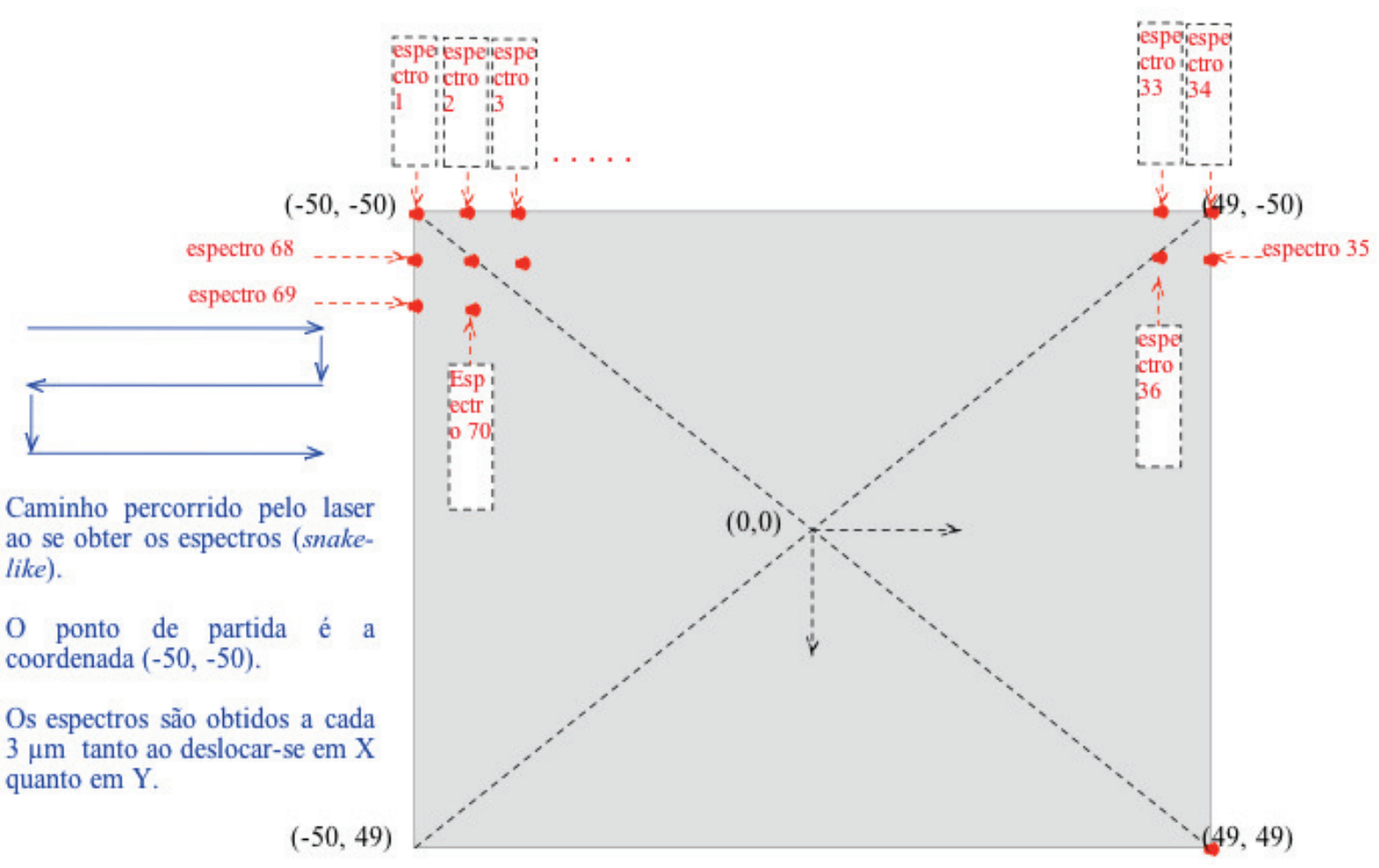

Figura 2.1: Exemplo da forma de coleta de espectros usado pelos sensores para os conjuntos de dados do sistema methylene blue (Aoki et al., 2013). Um laser é deslocado cada $3 \mu m$ (horizontal e verticalmente) seguindo um percurso snake-like em uma área $100 \mu m \times 100 \mu m$.

Os sensores do tipo SERS apresentam limitações por produzir uma grande quantidade de dados, difíceis de serem explorados. Atualmente, os dados produzidos por esse tipo de sensor são analisados manualmente, comparando de forma visual os espectros coletados 
com algum espectro de referência, ou conjunto de espectros de referência, buscando semelhanças. É fácil perceber que esse é um processo propenso a erros, demorado e fatigante. Diversos modelos estatísticos tem sido empregados para analisar dados SERS focados no processo de Detecção de molécula única (Single Molecule Detection (SMD)). Por exemplo, Sasic et al. (2006) empregaram Principal Component Analysis (PCA) para determinar o número de espécies quimicamente distinguíveis que contribuem para o espectro SERS medido.

\subsubsection{Sensores de espectroscopia de impedância}

Dentre os diferentes biossensores existentes, os relacionados ao conceito de língua eletrônica são de especial interesse para esse projeto de mestrado. As línguas eletrônicas (Riul Jr. et al., 2010) são sensores capazes de distinguir líquidos muito similares utilizando as diferentes respostas elétricas dos materiais sendo analisados. Exemplos de casos de sucesso do emprego da língua eletrônica para análise de diferentes substâncias envolvem a distinção de diferentes vinhos tintos (Parra et al., 2004), sucos de fruta, amostras de cerveja e chá (Kim et al., 2006), café, leite e derivados, além de detecção de traços de impurezas ou poluentes em água (Riul Jr. et al., 2010).

A ideia motora das línguas eletrônicas está na substituição das análises subjetivas gustativas produzidas por seres humanos, por uma ferramenta analítica confiável e reprodutível. Isso porque, mesmo se um grupo de pessoas for bem treinado, a avaliação continuará subjetiva, o que pode representar um grande problema para aplicações industriais. Assim, grande interesse tem sido despertado tanto na comunidade científica como na industrial, em especial na industria de alimentos e farmacêutica, pois além da vantagem de evitar subjetivismos, problemas éticos e de segurança relacionados com toxicidade e exposição de humanos a fórmulas desagradáveis também são contornados (Riul Jr. et al., 2010).

Existem diferentes métodos para se construir as línguas eletrônicas (Riul Jr. et al., 2010). Aqui o foco será dado às línguas baseadas no conceito de espectroscopia por impedância (Riul et al., 2002). Nesse método, o sensor possui como base um eletrodo cuja geometria sugere um capacitor planar, composto por dígitos de ouro igualmente separados que permitem a mensuração da sua interação com um analito. Cada eletrodo é construído em uma base de vidro, sobre o qual é depositado um filme nanoestruturado (Oliveira Jr et al., 2005). Os sensores baseados em espectroscopia por impedância empregam um sistema similar ao apresentado na Figura 2.2.

A técnica de espectroscopia de impedância consiste basicamente em fazer medidas utilizando uma tensão alternada $A C$ na entrada do circuito em estudo (unidades sensoriais no nosso caso) para obter valores de impedância. Dessa forma, um sensor é submergido num depósito contendo o analito, depois um sinal elétrico é aplicado sobre o eletrodo e a 


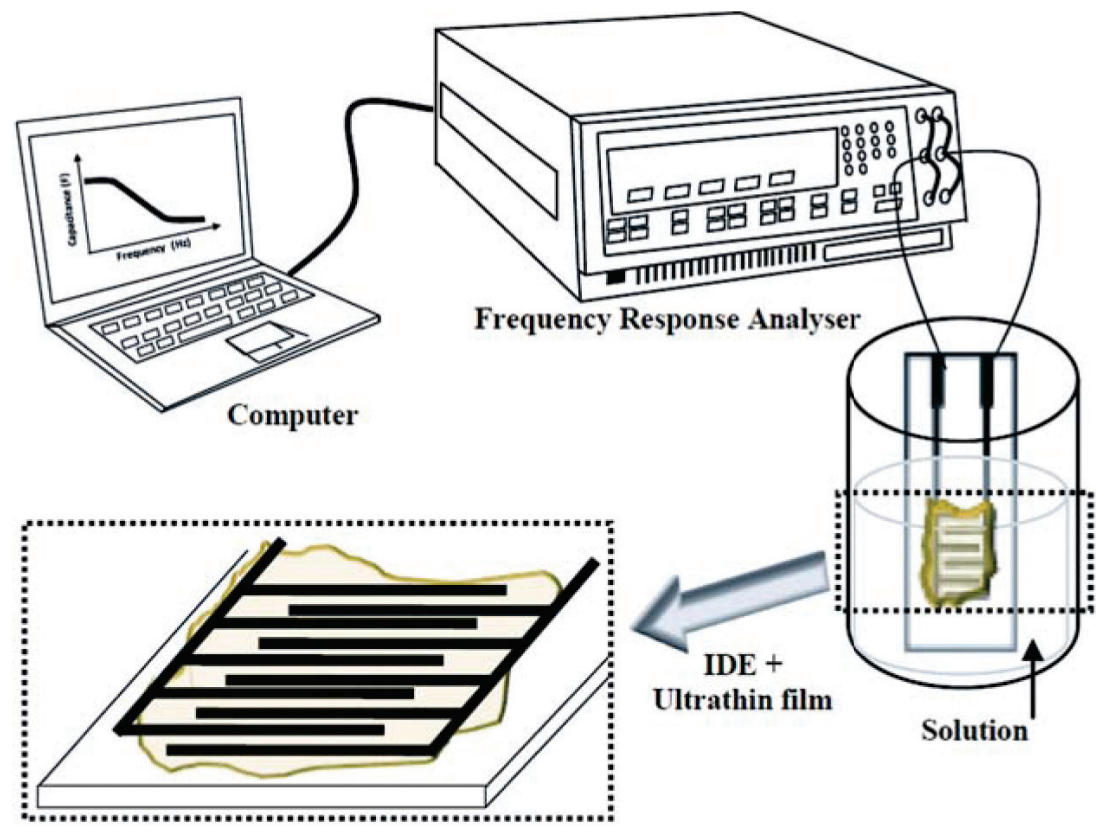

Figura 2.2: Sistema de espectroscopia por impedância que emprega um sensor interdigitado para reconhecer substâncias biológicas (figura extraída de Riul Jr. et al. (2010)).

impedância complexa do analito é medida variando-se a frequência do sinal, produzindo uma curva de impedância. A varredura de impedância ocorre para uma faixa de frequência relativamente ampla, geralmente entre $1 \mathrm{~Hz}$ e $1 \mathrm{MHz}$ (Chinaglia et al., 2008).

Diversas abordagens computacionais tem sido empregadas para analisar dados gerados por sensores e biossensores (Sasic et al., 2006; Legin et al., 2000; Moraes et al., 2010). Nessa dissertação foram empregadas um tipo específico de abordagens computacionais: técnicas de visualização de informação. Na próxima seção serão apresentadas as principais técnicas e as aplicações delas no campo de sensores e biossensores .

\subsection{Técnicas de visualização de Informação}

O processamento da informação atualmente disponível é percebido como um dos grandes desafios para as diferentes áreas do conhecimento (Keim, 2002). A visualização de informação tem se mostrado ferramental importante para lidar com essa massa de informação empregando o sistema visual humano no processo de reconhecimento e interpretação de padrões existentes em grandes conjuntos de dados. As técnicas de visualização de informação dependem de características básicas que o sistema perceptual humano inerentemente assimila de maneira rápida, como cor, tamanho, forma, proximidade e movimento. Porque percebemos tais características facilmente, e porque cada recurso pode ser usado para representar diferentes atributos de dados, boas visualizações permitem não só interpretar a informação de forma mais fácil, mas também permitem analisar maior quantidade de dados ao mesmo tempo. Podemos rapidamente reconhecer padrões nos dados 
que indicam tendências, lacunas, valores espúrios ou erros, valores mínimos e máximos, grupos, entre outras coisas. Como resultado, aplicações de visualização de informação nos permitem compreender melhor os sistemas complexos, tomar melhores decisões, e descobrir informações que poderiam permanecer desconhecidas.

\subsubsection{Técnica de Projeção Multidimensional}

Uma das principais técnicas de visualização de informação é a Técnica de Projeção Multidimensional (TPM). Uma TPM tipicamente mapeia instâncias de dados de um espaço multidimensional em elementos gráficos em um espaço visual de forma que a proximidade entre esses elementos reflita algum tipo de relacionamento entre as instâncias de dados, normalmente relacionamentos de similaridade (Tejada et al., 2003).

Formalmente, seja $\mathbf{X}$ um conjunto de $n$ instâncias de dados em $\mathbb{R}^{m} \operatorname{com} \delta: \mathbb{R}^{m} \times \mathbb{R}^{m} \rightarrow \mathbb{R}$ um critério de proximidade entre instâncias em $\mathbb{R}^{m}$, e $\mathbf{Y}$ um conjunto de pontos em $\mathbb{R}^{p}$, com $p \in\{1,2,3\}$, e $d: \mathbb{R}^{p} \times \mathbb{R}^{p} \rightarrow \mathbb{R}$ um critério de proximidade em $\mathbb{R}^{p}$. Uma TPM pode ser descrita como uma função $f: \mathbf{X} \rightarrow \mathbf{Y}$ que visa tornar a Equação 2.1:

$$
\left|\delta\left(\mathbf{x}_{i}, \mathbf{x}_{j}\right)-d\left(f\left(\mathbf{x}_{i}\right), f\left(\mathbf{x}_{j}\right)\right)\right|
$$

o mais próximo possível de zero, $\forall \mathbf{x}_{i}, \mathbf{x}_{j} \in \mathbf{X}$ (Tejada et al., 2003). Na Equação 2.1, $\delta\left(\mathbf{x}_{i}, \mathbf{x}_{j}\right)$ representa a dissimilaridade entre os objetos $i$ e $j$ no espaço original e $d\left(\mathbf{y}_{i}, \mathbf{y}_{j}\right)$ representa a distância entre os pontos $i$ e $j$ no espaço projetado.

Existem diferentes TPMs, as utilizadas nesse trabalho foram Multidimensional Scaling (MDS) (Young \& Householder, 1938), Sammon's Mapping (SM) (Sammon, 1969) e Interactive Document Map (IDMAP) (Minghim et al., 2006). Essas são descritas com maior detalhe na próxima seção. Para facilitar o entendimento dos conceitos apresentados, os símbolos mais frequentemente empregados nesse estudo e suas descrições podem ser encontrados na Tabela 2.1.

\subsubsection{Multidimensional Scaling}

A técnica Multidimensional Scaling (MDS) foi originada na década de 1930, quando Young \& Householder (1938) demostraram que, dada uma matriz de distâncias entre pontos em um espaço Euclideano, é possível extrair coordenadas tal que as distâncias sejam preservadas. Sejam $\mathbf{X}=\left[x_{1}, \cdots, x_{n}\right]^{T}$ um conjunto de $n$ pontos em um espaço Euclideano $m$-dimensional $\mathbb{R}^{m}$, com $\mathbf{x}_{i}=\left(x_{i 1}, x_{i 2}, \ldots, x_{i m}\right)^{T}$ as $m$ coordenadas do ponto $x_{I}$, o quadrado da distância Euclideana entre os $i$-ésimo e $j$-ésimo elementos é dada pela Equação 2.2: 
Tabela 2.1: Símbolos usados e seus significados para o entendimento das Técnicas de Projeção Multidimensional.

\begin{tabular}{|c||l|}
\hline Símbolo & Significado \\
\hline \hline $\mathbf{X}$ & Conjunto de objetos no espaço original $m$-dimensional. \\
\hline$m$ & Dimensão do espaço original. \\
\hline $\mathbf{X}_{i}$ & $\begin{array}{l}i \text {-ésimo objeto do espaço original. } \\
\text { A representação vetorial } \mathbf{X}_{i}=\left(x_{i 1}, x_{i 2}, \ldots, x_{i m}\right) \text { representa suas coordenadas. }\end{array}$ \\
\hline $\mathbf{Y}$ & Conjunto de pontos no espaço projetado $p$-dimensional. \\
\hline$p$ & Dimensão do espaço projetado. \\
\hline $\mathbf{Y}_{i}$ & $\begin{array}{l}i \text {-ésimo objeto do espaço projetado. } \\
\text { A representação vetorial } \mathbf{y}_{i}=\left(y_{i 1}, y_{i 2}, \ldots, y_{i p}\right) \text { representa suas coordenadas. }\end{array}$ \\
\hline$n$ & Número de objetos no espaço original e no projetado. \\
\hline$\delta\left(\mathbf{x}_{i}, \mathbf{x}_{j}\right)$ & Dissimilaridade entre os objetos $i$ e $j$ no espaço original. \\
\hline$d\left(\mathbf{y}_{i}, \mathbf{y}_{j}\right)$ & Distância entre os pontos $i$ e $j$ no espaço projetado. \\
\hline
\end{tabular}

$$
\hat{\delta}\left(\mathbf{x}_{i}, \mathbf{x}_{j}\right)=\left(\mathbf{x}_{i}-\mathbf{x}_{j}\right)^{T}\left(\mathbf{x}_{i}-\mathbf{x}_{j}\right)
$$

Seja $\mathbf{B}$ a matriz do produto interno em que o elemento $i j$ é dado por $[\mathbf{B}]_{i j}=b_{i j}=\mathbf{x}_{i}^{T} \mathbf{x}_{j}$. Dada a matriz de distâncias quadradas $\left\{\hat{\delta}\left(\mathbf{x}_{i}, \mathbf{x}_{j}\right)\right\}$, a matriz do produto interno é definida pela Equação 2.3 (para maiores detalhes ver Cox \& Cox (2000)):

$$
\mathbf{B}=\mathbf{H A H}
$$

em que A é a matriz $[\mathbf{A}]_{i j}=a_{i j}=-\frac{1}{2} \hat{\delta}\left(\mathbf{x}_{i}, \mathbf{x}_{j}\right)$, e $\mathbf{H}$ é a matriz de centragem,

$$
\mathbf{H}=\mathbf{I}-n^{-1} \mathbf{1} \mathbf{1}^{T}
$$

com $\mathbf{1}=(1,1,1, \ldots, 1)^{T}$ um vetor com $n$ coordenadas iguais a 1 . Também temos que $\mathbf{B}$ pode ser expressa como $\mathbf{B}=\mathbf{X X}^{T}$. O rank de $\mathbf{B}$, será:

$$
\operatorname{rank}(\mathbf{B})=\operatorname{rank}(\mathbf{X X})^{T}=\operatorname{rank}(\mathbf{X})=m
$$

Dessa forma a matriz do produto interno B é simétrica, positiva, semi-definida, e com rank $m$. Portanto, B tem $m$ autovalores não negativos e $n-m$ autovalores nulos. A matriz $\mathbf{B}$ pode então ser escrita em termos de sua decomposição espectral como:

$$
\mathbf{B}=\mathbf{V} \Lambda \mathbf{V}^{T}
$$

em que $\Lambda=\operatorname{diag}\left(\lambda_{1}, \ldots, \lambda_{n}\right)$ é a matriz diagonal dos autovalores de $\mathbf{B}$, e $\mathbf{V}=\left[\mathbf{v}_{1}, \ldots, \mathbf{v}_{n}\right]$ é a matriz dos autovetores correspondentes, normalizados de forma que $\mathbf{v}_{i}^{T} \mathbf{v}_{i}=1$. Por conveniência, os autovalores de $\mathbf{B}$ são rotulados de forma que $\lambda_{1} \geq \lambda_{2} \geq \ldots \geq \lambda_{n} \geq 0$. Como existem $n-m$ autovalores nulos, $\mathbf{B}$ pode ser reescrita como:

$$
\mathbf{B}=\mathbf{V}_{1} \Lambda_{1} \mathbf{V}_{1}^{T}
$$


em que $\Lambda_{1}=\operatorname{diag}\left(\lambda_{1}, \lambda_{2}, \ldots, \lambda_{m}\right)$, e $\mathbf{V}_{1}=\left[\mathbf{v}_{1}, \ldots, \mathbf{v}_{m}\right]$. Dessa forma, como $\mathbf{B}=\mathbf{X X}^{T}$, a matriz de coordenadas $\mathbf{X}$ é dada por:

$$
\mathbf{X}=\mathbf{V}_{1} \Lambda_{1}^{\frac{1}{2}}
$$

em que $\Lambda^{\frac{1}{2}}=\operatorname{diag}\left(\lambda_{1}^{\frac{1}{2}}, \ldots, \lambda_{m}^{\frac{1}{2}}\right)$ e assim as coordenadas dos pontos foram recuperadas a partir das distâncias entre os pontos. Geralmente a matriz de distâncias $\hat{\delta}\left(\mathbf{x}_{i}, \mathbf{x}_{j}\right)$ é Euclideana, no caso que as dissimilaridades $\delta\left(\mathbf{x}_{i}, \mathbf{x}_{j}\right)$ não configurem uma métrica, duas opções são possíveis: (i) descartar os autovetores cujos autovalores são não positivos ; ou (ii) adicionar uma constante apropriada $c$ às dissimilaridades e repetir o processo novamente (Cox \& Cox, 2000). Assim, os pontos $\mathbf{X}$ residirão em um espaço $m$-dimensional no caso das distâncias Euclideanas, ou próximo disso para outras dissimilaridades, formando o espaço de menor dimensão que consegue representar os pontos preservando as distâncias fornecidas como entrada. Caso se queira que $\mathbf{X}$ seja um espaço $p$-dimensional, com $p<m$, os $p$ autovetores que apresentarem os $p$ maiores autovalores devem ser utilizados. Assim, no caso de uma projeção bi-dimensional, os dois autovetores com maiores autovalores são empregados.

\subsubsection{Sammon's Mapping}

Uma das primeiras TPMs baseadas em otimização não-linear, conhecida como Sammon's Mapping (SM), foi proposta por Sammon (1969). Considere um conjunto X de $n$ objetos no espaço m-dimensional. O objetivo da abordagem Sammon's Mapping é encontrar $n$ pontos em um espaço $p$-dimensional (com $p<m$ ), com $n$ pontos $\mathbf{y}_{i}$ de modo que as distâncias entre pontos $d\left(\mathbf{y}_{i}, \mathbf{y}_{j}\right)$ no espaço $p$-dimensional se aproximem o mais possível às distâncias entre os objetos $\delta\left(\mathbf{x}_{i}, \mathbf{x}_{j}\right)$ correspondentes no espaço $m$-dimensional. Isto é conseguido através da minimização de um critério de erro, chamado Sammon's stress dado por:

$$
S=\frac{1}{\sum_{i<j} \delta\left(\mathbf{x}_{i}, \mathbf{x}_{j}\right)} \sum_{i<j} \frac{\left(d\left(\mathbf{y}_{i}, \mathbf{y}_{j}\right)-\delta\left(\mathbf{x}_{i}, \mathbf{x}_{j}\right)\right)^{2}}{\delta\left(\mathbf{x}_{i}, \mathbf{x}_{j}\right)}
$$

A técnica Sammon's Mapping aplica o método de gradiente descendente para minimizar esta função, com a estimativa de $y_{p q}$, na $t$-ésima iteração dada por

$$
y_{p q}(t+1)=y_{p q}(t)-\alpha\left[\frac{\frac{\partial S(t)}{\partial y_{p q}(t)}}{\frac{\partial^{2} S(t)}{\partial y_{p q}^{2}(t)}}\right]
$$

em que $\alpha$ é um fator de convergência determinado empiricamente (recomenda-se um valor $\alpha \approx 0.3$ a 0.4 ) e as derivadas parciais da equação 2.10 são dadas por: 


$$
\begin{gathered}
\frac{\partial S(t)}{\partial y_{p q}(t)}=-\frac{2}{\lambda} \sum_{k=1, k \neq i}^{n}\left[\frac{d_{k p}-d_{k p}^{*}}{d_{k p} d_{k p}^{*}}\right]\left(y_{p q}-y_{k q}\right) \\
\frac{\partial^{2} S(t)}{\partial^{2} y_{p q}(t)}=-\frac{2}{\lambda} \sum_{k=1, k \neq i}^{n} \frac{1}{d_{k p} d_{k p}^{*}}\left[\left(d_{k p}-d_{k p}^{*}\right)-\left(\frac{\left(y_{p q}-y_{k q}\right)^{2}}{d_{k p}^{*}}\right)\left(1+\frac{d_{k p}-d_{k p}^{*}}{d_{k p}}\right)\right]
\end{gathered}
$$

O mapeamento não linear dos dados de entrada é obtido pela atualização de cada coordenada projetada usando a Equação 2.10 em um processo iterativo até que um valor limite de convergência seja atingido ou um número máximo de iterações seja executado.

\subsubsection{Interactive Document Map}

A técnica Interactive Document Map (IDMAP) (Minghim et al., 2006), originalmente desenvolvida para mapear coleções de documentos, projeta as amostras num espaço visual de baixa dimensionalidade com uma técnica de redução de dimensionalidade de custo computacional pequeno, como FastMap (Faloutsos \& Lin, 1995) e melhora o posicionamento inicial obtido com uma estratégia precisa conhecida como Force Scheme. A Force Scheme (FS), proposta por Tejada et al. (2003), baseia-se no conceito de atração e repulsão de forças proporcionais à diferença entre as distâncias no espaço projetado e as distâncias no espaço original. O processo empregado pode ser descrito como: para cada ponto projetado $\mathbf{y}_{i} \in \mathbf{Y}$, calcula-se um vetor $\overrightarrow{\mathbf{v}}_{i j}=\left(\mathbf{y}_{j}-\mathbf{y}_{i}\right) \forall \mathbf{y}_{j} \neq \mathbf{y}_{i}$. Então, uma perturbação em $\mathbf{y}_{i}$ é aplicada na direção de $\overrightarrow{\mathbf{v}}_{i j}$. A força dessa perturbação é expressa pela Equação 2.13.

$$
S_{I D M A P}=\frac{\delta\left(\mathbf{x}_{i}, \mathbf{x}_{j}\right)-\delta_{\min }}{\delta_{\max }-\delta_{\min }}-d\left(\mathbf{y}_{i}, \mathbf{y}_{j}\right)
$$

em que $\delta_{\min }$ e $\delta_{\max }$ representam a mínima e a máxima distância entre os objetos no espaço original. Aplicando esse processo de forma iterativa para cada uma das amostras, a diferença $\left|\delta\left(\mathbf{x}_{i}, \mathbf{x}_{j}\right)-d\left(\mathbf{y}_{i}, \mathbf{y}_{j}\right)\right| \forall \mathbf{x}_{i}, \mathbf{x}_{j}$ é reduzida, resultando em um posicionamento mais preciso dos pontos. No entanto, é necessário trabalhar com distâncias normalizadas para evitar inconsistências derivadas da diferença entre as faixas de valores do espaço multidimensional original e do espaço projetado.

As Técnicas de Projeção Multidimensional vem sendo empregadas com sucesso na análise de dados de sensores e biossensores, mas outras também vem sendo utilizadas. Na próxima seção, outras técnicas de visualização de informação são apresentadas. 


\subsection{Outras técnicas de Visualização de Informação}

As técnicas apresentadas na seção anterior servem para a interpretação das relações de similaridade entre instâncias de dados. Nesta seção, são apresentadas técnicas que proveem suporte à interpretação das relações presentes nos atributos dos dados.

\subsubsection{Coordenadas Paralelas}

A técnica de coordenadas paralelas, desenvolvida por Inselberg (1985); Inselberg \& Dimsdale (1987), muda o conceito da representação dos eixos de coordenadas perpendiculares, alinhando-os entre si sobre um plano. Esta representação permite a visualização de todos os atributos em um único plano, permitindo observar localmente as tendências nos valores dos atributos das instâncias. A capacidade dessa técnica para mostrar as relações entre os atributos é afetada pela ordem em que eles são atribuídos aos eixos paralelos. Diferentes extensões para permitir uma melhor interpretação, como interação e seleção de intervalos, foram propostas na literatura (Keim, 2002).

As coordenadas paralelas já vem sendo empregadas na análise de dados de sensores e biossensores. Oliveira Jr et al. (2012) empregaram Coordenadas paralelas para analisar diferentes concentrações de ácido fítico usando um sensor composto por um filme $P A H / P V S$, que gerou dados de capacitância correspondentes a determinadas frequências. A Figura 2.3 apresenta o resultado dessa análise, em que cada concentração está representada por uma cor diferente. Os eixos $x$ e $y$ representam as frequências e as capacitâncias respectivamente.

\subsubsection{Heatmap}

Um Heatmap é uma matriz de células coloridas com base nos valores de algum atributo dos dados. O método é uma generalização do Scatterplot 2D (Grinstein et al., 2001). Nessa técnica de visualização, todos os valores dos dados são mapeados na mesma escala de cor normalizada, e cada valor é representado por um quadrado ou retângulo colorido. Geralmente, cada coluna representa uma dimensão e cada linha representa uma instância do conjunto de dados. A Figura 2.4 ilustra um exemplo dessa técnica aplicada aos dados gerados por um sensor do tipo Eletrodo Puro. Esse sensor é denominado dessa forma pois não é constituído por nenhum tipo de filme. Os dados coletados correspondem a medidas de capacitância produzidas por esse sensor na análise de diversas concentrações de ácido fítico. Note que são analisadas 6 concentrações, sendo que uma delas apresenta características totalmente diferentes das outras, indicada na figura pelo retângulo vermelho . Cada linha do Heatmap representa uma amostra de ácido fítico e as colunas representam as frequências analisadas. As células são coloridas segundo o valor de capacitância medido para cada frequência. 


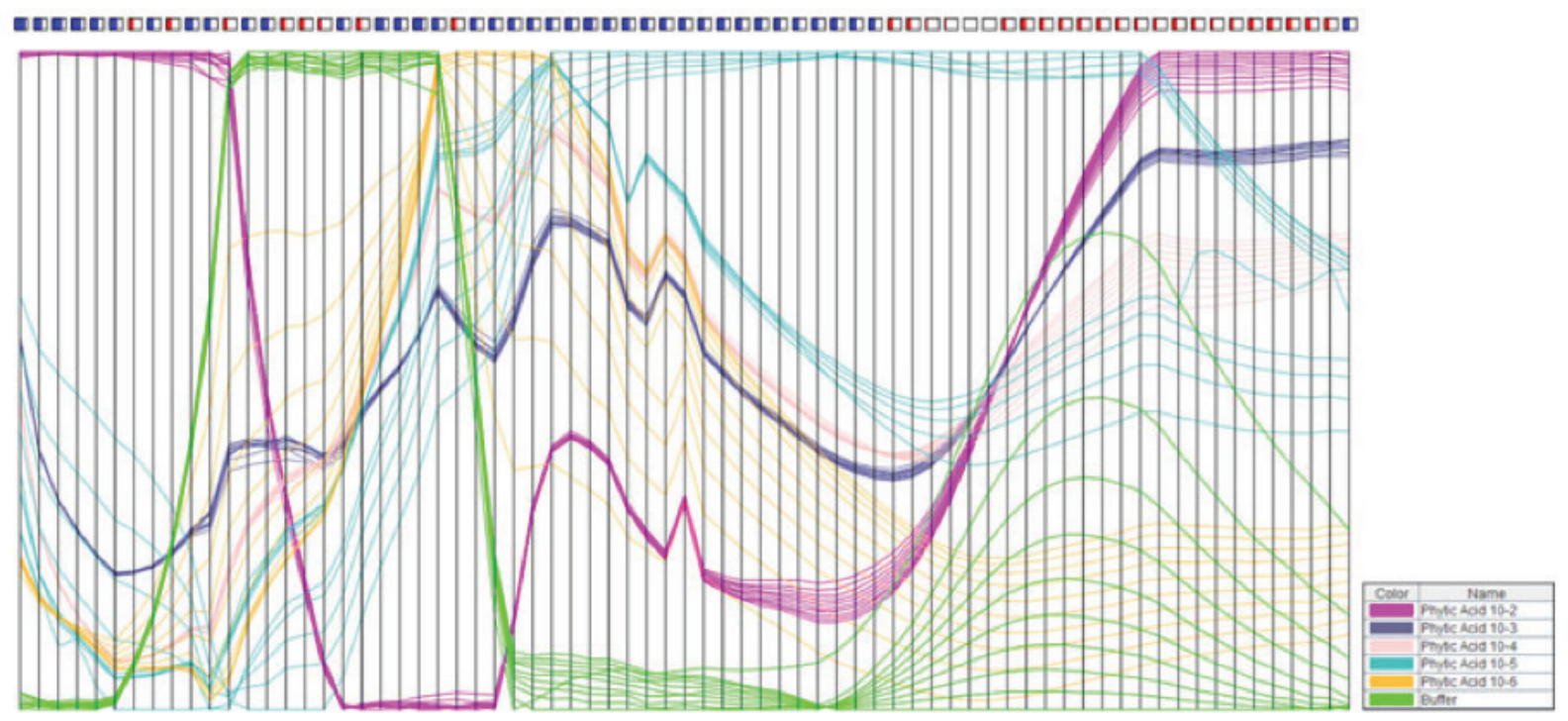

Figura 2.3: Representação visual dos dados de capacitância obtidos por um sensor composto por um filme $P A H / P V S$ empregando a técnica Coordenadas paralelas. O eixo $x$ representa as frequências e o eixo $y$ constitui os valores de capacitância. As diferentes cores representam as diversas concentrações analisadas de ácido fítico. (figura extraída de Oliveira Jr et al. (2012))

Na próxima seção são apresentadas diversas aplicações das técnicas de visualização de informação para tratamento e análise de dados produzidos por sensores e biossensores.

\subsection{Aplicações das técnicas de visualização de informação para dados de sensores e biossensores}

Landgrebe (1997) é um dos pioneiros na análise de dados provindos de sensores. Nesse trabalho foram propostas 3 tipos de representações visuais para dados espectrais: (1) como espectro, que é representado a través de pontos em função do número de onda, (2) em forma de imagem, em que cada pixel representa a relação existente entre as instâncias e (3) em forma de um espaço de características, as quais são representadas pelos pixels. Polder \& van der Heijden (2001) empregaram essa classificação e utilizaram diversas técnicas de visualização para analisar dados espectrais. A Figura 2.5 apresenta os resultados dessa análise. A Figura 2.5a exibe a representação espectral dos dados, em que cada espectro é analisado de forma individual expondo as suas características mais representativas. Nessa ocasião, os dados correspondem a análise feita por sensores avaliando o amadurecimento de tomates. Já nas Figuras 2.5b e 2.5c, outro conjunto de dados é analisado. Os dados foram produzidos por sensores avaliando 5 tipos diferentes de rosas. A Figura 2.5b ilustra o segundo tipo de representação, as distâncias entre os elementos expõem o relacionamento entre eles, da mesma forma que as Técnicas de Projeção Multidimensional (TPMs). O último tipo de representação visual para dados espectrais é apresentado na Figura 2.5c. 


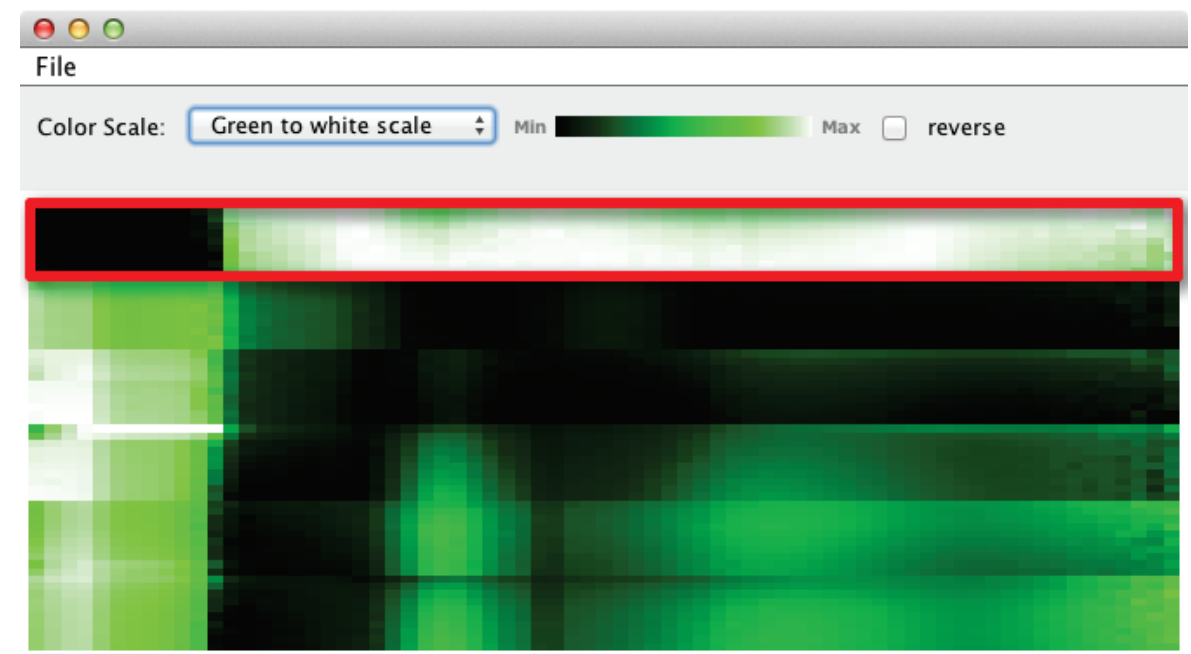

Figura 2.4: Representação Heatmap para o conjunto de dados composto pelas medidas coletadas pelo sensor Eletrodo Puro na análise de ácido fítico. As amostras analisadas estão representadas pelas linhas, e cada coluna representa o valor de capacitância mensurado para uma frequência diferente.

$\mathrm{Na}$ imagem são expostas as características de cada elemento e como elas se comportam em relação aos outros elementos.

Moraes et al. (2010) empregaram Técnicas de Projeção Multidimensional para analisar dados de língua eletrônica. Nos experimentos foi utilizada a técnica Sammon's Mapping para explorar biossensores compostos por filmes de material PAH/PVS e PAH/Phytase. O uso de TPMs permitiu melhorar a seletividade de biossensores baseados em espectroscopia por impedância além de simplificar a análise de grandes quantidades de dados como apresentado na Figura 2.6. Na figura é analisado o comportamento de um sensor fabricado com um filme PAH/Phytase, e como ele responde às diferentes concentrações de ácido fítico. Comprova-se que os grupos apresentam uma boa separação entre eles. É importante definir que a classificação dos sensores está dada pelo tipo de filme usado: Eletrodo Puro (Bare) (sem uso de filme), Hydrochloride and Phytase (PAH/Phyitase), Hydrochloride and Polyvinyl sulfonate (PAH/PVS), Glucose oxidase and Lipase (GOx/Lipase), Hydrochloride and Glucose oxidase (PAH/GOx) e Hydrochloride and Lipase (PAH/Lipase), entre outros. Uma descrição mais detalhada dos tipos de filmes e os usos encontra-se em Moraes et al. (2010).

Em Paulovich et al. (2011a) foi demonstrado que é possível classificar diferentes analitos usando técnicas de projeção multidimensional ao contrario dos tradicionais métodos estatísticos. Nesse trabalho, os autores conseguiram uma excelente distinção entre as amostras reais para as doenças de Chagas e Leishmaniose. O uso de técnicas de visualização de informação permitiu empregar a curva de impedância completa em lugar de selecionar determinadas frequências. As técnicas de projeção multidimensionais Multidimensional Scaling, Interactive Document Map (IDMAP) e Sammon's Mapping (SM) foram combinadas com a técnica de redução de dimensionalidade Principal Component Analysis (PCA) 


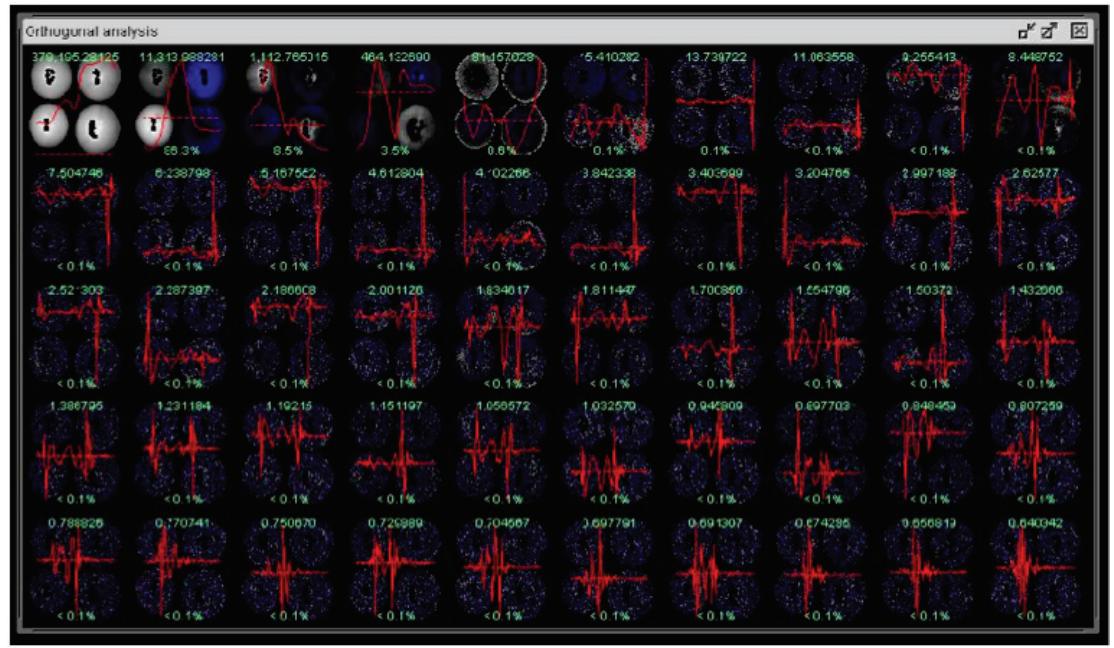

(a) Representação espectral: os dados são apresentados em função do número de onda

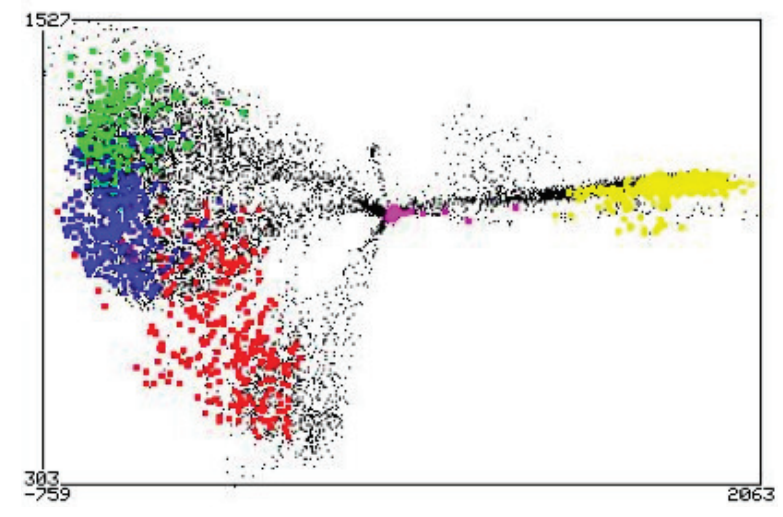

(b) Representação em forma de imagem que representa a relação entre as instâncias

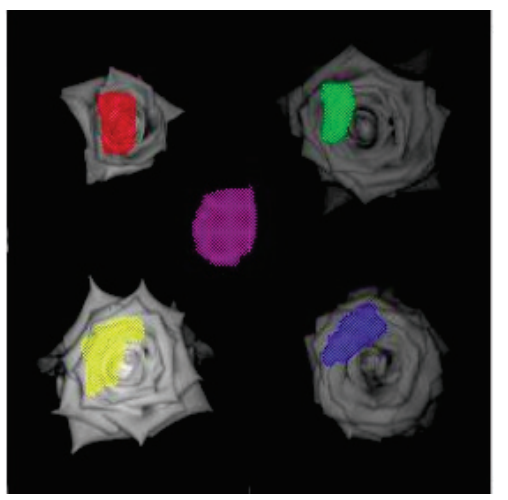

(c) Representação visual que exibe as características apresentadas em cada instância

Figura 2.5: Representações visuais de dados espectrais usando diferentes técnicas de Visualização de Informação expondo diversas características dos dados (figura extraída de Polder \& van der Heijden (2001)).

(Katsube et al., 2005; Gil et al., 2006) para melhorar o critério de discriminação para a seletividade. As diferentes técnicas de projeção tem propriedades específicas que as fazem mais o menos eficientes, dependendo das características do conjunto de dados analisados. Nos experimentos, a abordagem PCA não apresentou bons resultados enquanto as técnicas IDMAP e Sammon's mapping exibiram resultados similares, sendo que a última abordagem mencionada apresentou melhores resultados em algumas situações. As técnicas de projeção mencionadas e outras foram implementadas numa nova ferramenta denominada PEx-Sensors. Esta ferramenta também incorpora várias técnicas de pré-processamento de dados requeridos para poder lidar com dados de sensores e biossensores. PEx-Sensors encontra-se disponível em http://www.icmc.usp.br/ paulovic/pexsensors/. Com a ferramenta PEx-Sensors é factível criar e explorar interativamente representações visuais de conjuntos de dados multidimensionais permitindo que analistas de dados empreguem 


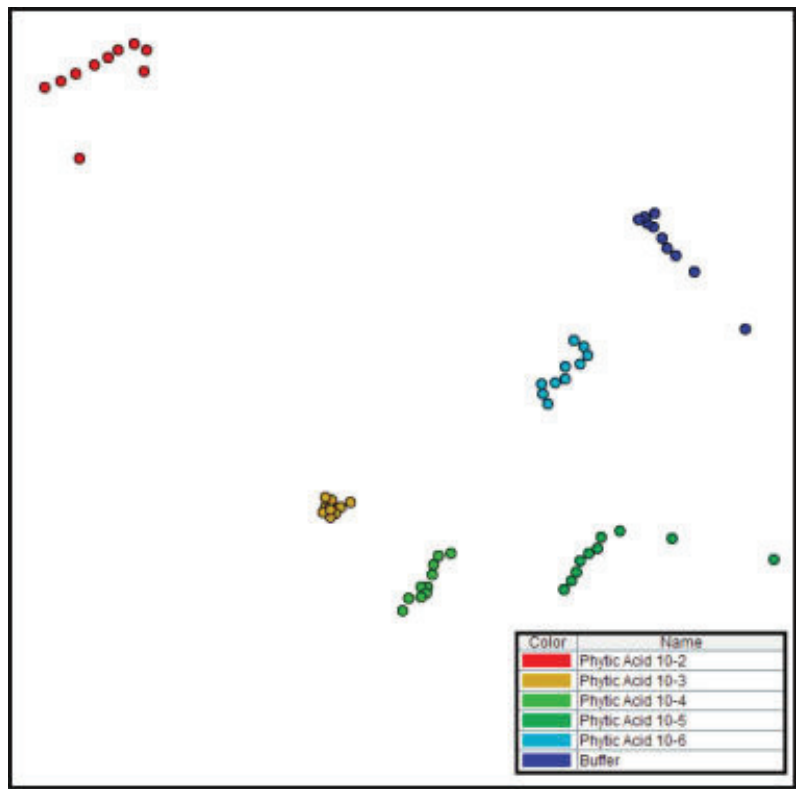

Figura 2.6: Visualização das medidas de impedância elétrica por uma unidade sensorial composta por um filme PAH/Phytase. Cada círculo representa as medidas coletadas por um sensor diferente e cada cor representa a concentração que foi mensurado (figura extraída de Moraes et al. (2010))

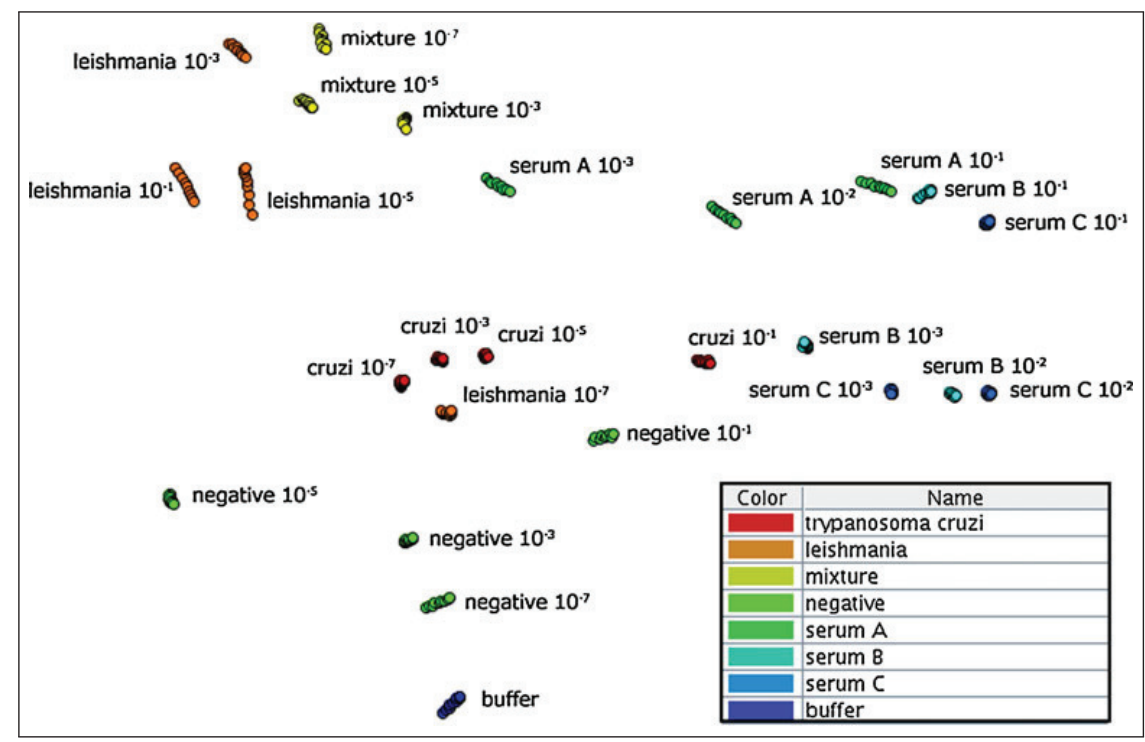

Figura 2.7: Projeção dos dados de impedância para amostras de Leishmania amazonensis e Trypanosoma cruzi (doença Chagas) com diferentes concentrações: serum $A$ (contendo anticorpos negativos), serum $B$ (contendo anticorpos anti-Leishmania), serum $C$ (contendo anticorpos anti-T. cruzi), mixture (mistura de anticorpos anti-T. cruzi e antiLeishmania). A unidade sensorial usada foi um Eletrodo puro, ou seja, não era constituída por nenhum tipo de filme. (figura extraída de Paulovich et al. (2011a))

suas habilidades visuais para reconhecer estruturas ou padrões baseados em similaridade.

Paulovich et al. (2011b) fizeram uso da ferramenta PEx-Sensors para analisar dados de espectroscopia de impedância gerados por línguas eletrônicas e outras unidades sensoriais. Foram avaliados três tipos de sensores : Eletrodo puro, PAH/Phytase e 
PAH/PVS. Nesse trabalho, foram empregadas técnicas de Coordenadas paralelas, Algoritmos genéticos (Goldberg, 1989) e Coeficiente de Silhueta (Tan et al., 2005) para selecionar as 10 frequências mais representativas com o intuito de atingir uma boa separação entre as concentrações. Nos experimentos conseguiram uma melhora de até $30 \%$ na distinção de diferentes concentrações de ácido fítico. O resultado da análise é exposto na Figura 2.8, que exibe as representações usando as abordagens IDMAP e Coordenadas paralelas. Em ambas figuras é apresentado um bom agrupamento para cada concentração, determinada pela cor usada. É importante ressaltar que para atingir essa melhora as medidas dos três tipos de sensores foram combinadas e consideradas como um único conjunto.

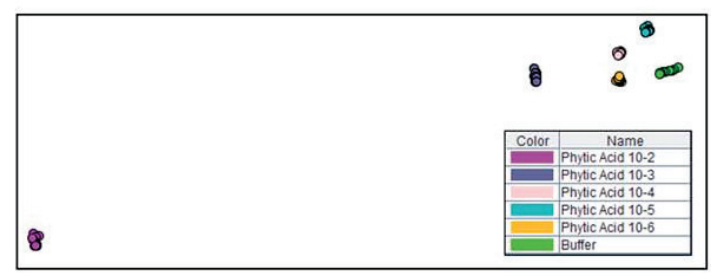

(a) Projeção IDMAP

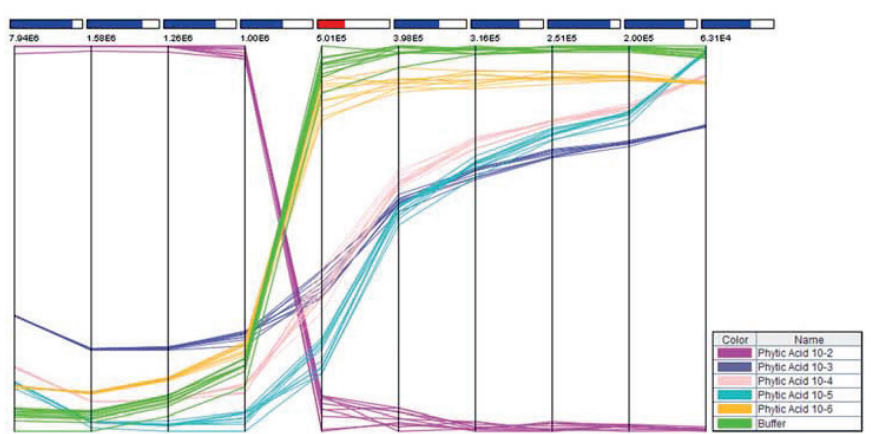

(b) Coordenadas paralelas

Figura 2.8: Resultados da análise dos sensores Eletrodo puro, PAH/Phytase e PAH/PVS. As medidas dos três sensores foram combinadas e projetadas as técnicas (a) IDMAP e (b) Coordenadas paralelas. Previamente foram selecionadas as 10 frequências mais representativas. (Figura extraída de Paulovich et al. (2011b))

Moraes et al. (2012) também fizeram uso dos métodos de visualização de informação para análise de dados produzidos por sensores e biossensores. Nessa ocasião, foram usadas amostras de moléculas de glucose e triclycerides em diferentes concentrações. A descoberta deste tipo de moléculas é importante porque as altas concentrações das moléculas mencionadas podem causar disfunções coronárias e doenças, incluindo diabetes mellitus nefrose, obstrução do fígado e patologias endócrinas (Avramoglu et al., 2006; Solanki et al., 2009; Vijayalakshmi et al., 2008). Na análise foram considerados sensores constituídos por filmes PAH/Lipase e PAH/GOx. Da mesma forma que Paulovich et al. (2011b), a sensibilidade das unidades sensoriais foi avaliada usando as técnicas IDMAP e Coordenadas paralelas em conjunto com Algoritmos genéticos e Coeficiente de Silhueta para escolher as frequências de maior relevância. Nos experimentos conseguiram uma melhora de até $17 \%$ na distinção entre as diferentes concentrações de glucose e triclycerides comparados com os resultados originais (Figura 2.9). Os novos resultados são apresentados nas Figuras 2.10a (Projeção IDMAP) e 2.10b (Coordenadas paralelas). Na Figura 2.10a as unidades sensoriais que representam a mesma concentração (mesma cor) exibem um bom agrupamento. Adicionalmente, na outra representação (Figura 2.10b) os diferentes grupos de linhas estão bem separadas. Desta forma, verifica-se que o sensor analisado consegue 


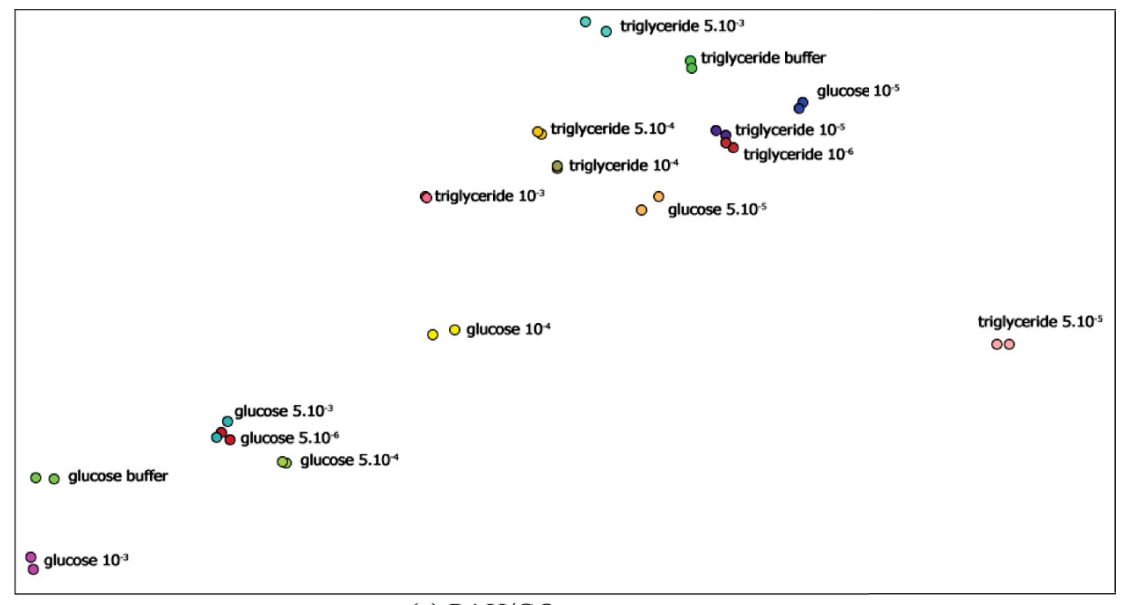

(a) PAH/GOx sensor

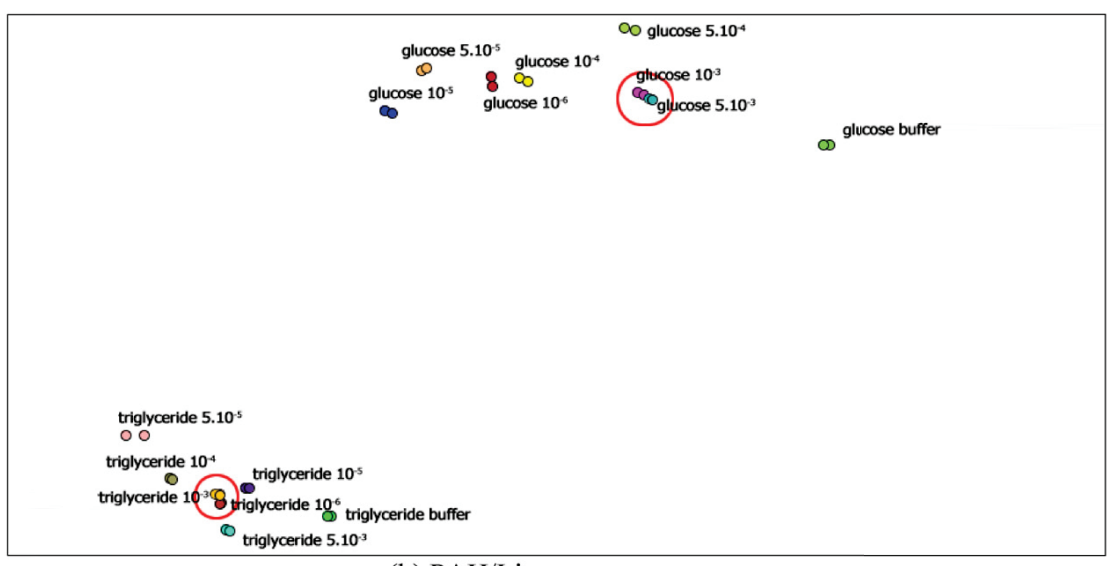

(b) PAH/Lipase sensor

Figura 2.9: Representação visual da capacitância de unidades sensoriais constituídas por filmes PAH/Lipase e PAH/GOx. As projeções foram geradas com o intuito de detectar glucose e triclycerides em diferentes níveis de concentração. (Figura extraída de Moraes et al. (2012))

boa discriminação entre as diferentes substâncias e concentrações analisadas.

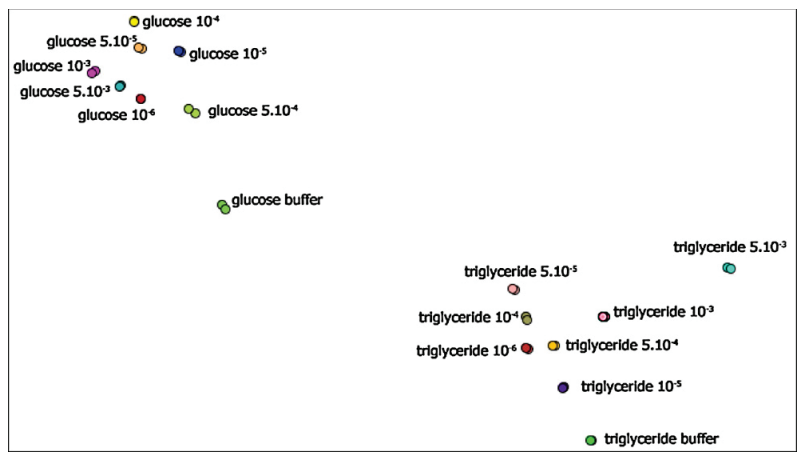

(a) Projeção usando a técnica IDMAP

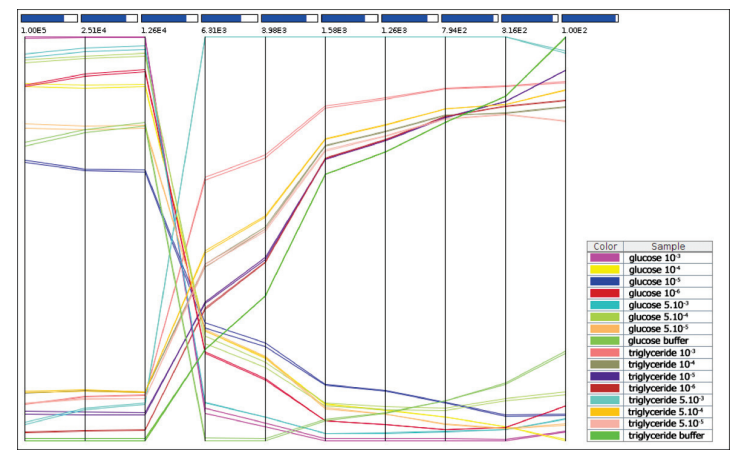

(b) Gráfico de Coordenadas paralelas

Figura 2.10: Resultados obtidos por Moraes et al. (2012) na análise de diversas concentrações de glucose e triclycerides depois do uso de técnicas computacionais para selecionar as 10 frequências de maior relevância. Os resultados são apresentados duas técnicas de visualização de informação: (a) Projeção IDMAP e (b) Coordenadas paralelas 
Por fim, Oliveira Jr et al. (2012) analisaram as vantagens e limitações apresentadas pelas técnicas computacionais empregadas atualmente na análise de dados sensoriais, com maior ênfase nas técnicas de visualização de informação. Entre as vantagens consideradas, três foram definidas como principais: (1) oferecem a possibilidade de explorar conjuntos de dados completos de forma rápida, (2) existem diversas técnicas de projeção para analisar os diferentes tipos de dados dados, pois cada técnica tem propriedades específicas que as fazem mais o menos eficientes e (3) em combinação com outras técnicas computacionais podem otimizar a eficiência da sensibilidade das unidades sensoriais.

\subsection{Considerações finais}

Nesse capítulo foram definidos os conceitos básicos de sensores, biossensores e a importância da análise dos dados gerados por eles tanto na comunidade industrial como na científica. Também foram apresentados métodos computacionais, especialmente as técnicas de visualização de informação, para tratar as grandes quantidades de dados normalmente geradas por esses dispositivos. O emprego desse tipo de técnicas permitiu a descoberta de novas informações como padrões, tendências, grupos, etc. presentes nos dados.

Nos próximos capítulos serão apresentadas as abordagens propostas para resolver dois problemas relacionados com a análise de dados de sensores e biossensores: (1) Tratamento de grandes conjuntos de dados SERS e (2) Troca de sensores em línguas eletrônicas . 


\section{Capítulo 3 \\ Visualização de dados gerados por sensores do tipo SERS}

A detecção de uma única molécula (Single Molecule Detection (SMD)) é um assunto de grande relevância e interesse científico em varias áreas como química,

biologia, medicina, farmacologia e ciências ambientais (Barnes et al., 1995). Apesar de muito já ter sido feito ainda existem particularidades, do ponto de vista da análise dos dados gerados, que precisam ser tratadas. Normalmente, a detecção de moléculas únicas usando a técnica Surface Enhanced Raman Spectroscopy (SERS) é feita de forma manual comparando visualmente os espectros produzidos com o conjunto modelo de espectros de referência, buscando semelhanças. Nesse processo é empregada a intensidade de uma banda representativa do espectro coletado para identificar a molécula alvo. Por ser um processo manual, é ineficiente quando milhares de espectros devem ser analisados. Usualmente, são gerados cerca de 1.200 espectros em uma única coleta de dados. Porém, aparelhos mais modernos e de melhor precisão, geram mais de 30.000 espectros por coleta de dados.

A grande quantidade de dados envolvidos nos experimentos cria a necessidade de utilizar métodos estatísticos e computacionais para tratá-los em substituição da abordagem manual. Dentre as principais abordagens candidatas, a visualização de informação tem se mostrado uma ferramenta importante ao conseguir lidar com grandes conjuntos de dados (Keim, 2002).

Nesse projeto de mestrado, foram analisados 5 conjuntos de dados para 3 sistemas diferentes de sensores usando técnicas de visualização de informação: methylene blue (MB), Texas red tagged phospholipid (TRP) e Octadecylrhodamine B (R18) correspondentes aos espectros do tipo SERS; sendo que o sistema MB tem 3 conjun- 
tos diferentes 1MB, 10MB e 100MB, que representam a concentração de moléculas detectadas, sendo de 1, 10 e 100 moléculas por $\mu m^{2}$ respectivamente. Cada um desses 3 conjuntos de dados é composto por 1156 espectros (instâncias). O conjunto de dados TRP apresenta 6804 espectros e o conjunto R18 contem 37848 espectros. Cada espectro destes conjuntos (MB, TRP e R18) de dados tem 393 atributos que representam as intensidades de banda em um determinado intervalo de números de onda. No sistema MB os números de onda encontram-se no intervalo $\left[1048 \mathrm{~cm}^{-1} ; 1651 \mathrm{~cm}^{-1}\right]$; no sistema TRP está no intervalo $\left[1126.58 \mathrm{~cm}^{-1} ; 1723.64 \mathrm{~cm}^{-1}\right]$ e no sistema $\mathbf{R} 18$ no intervalo $\left[1152.37 \mathrm{~cm}^{-1} ; 1747.64 \mathrm{~cm}^{-1}\right]$. Além disso, cada conjunto de dados tem associado espectros de referência (modelos padrão) usados no processo de detecção de moléculas únicas valores que são usados para fazer as comparações e os cálculos de dissimilaridade (Aoki et al., 2013).

A seguir são apresentadas as duas abordagens propostas que visam resolver o problema de detecção de moléculas únicas, sendo que a segunda é uma evolução da primeira, corrigindo algumas deficiências apresentadas.

\subsection{Primeira abordagem}

Na primeira abordagem, o processo para a identificação de um espectro de molécula única consiste em cinco etapas: (1) Filtragem, (2) Detrending, (3) Suavização, (4) Cálculo de dissimilaridade e (5) Visualização. As três primeiras etapas focam-se no pré-processamento dos dados e as duas últimas definem a visualização.

A primeira etapa, filtragem, transforma os espectros para a remoção de valores espúrios que podem influenciar nas comparações entre um espectro dado e a referência. Para isso é, nesse trabalho aplicamos um filtro de média (Quinn, 2000). Seja $S=\left\{y_{1}, y_{2}, y_{3}, \cdots, y_{m}\right\}$ um espectro, em que cada valor $y_{i}$ representa uma intensidade de banda de dispersão localizada no número de onda $i$, e $m$ o número de ondas analisadas. Cada valor $y_{i}$ é verificado usando uma janela de tamanho $w<<m$ centrado em $y_{i}$, calculando-se a média usando a seguinte equação:

$$
m_{i w}=\frac{y_{i-w}+\cdots+y_{i}+\cdots+y_{i+w}}{2 w+1}
$$

nessa janela, verifica-se se o critério $S_{i} \times L \leq\left|y_{i}-m_{i w}\right|$ é satisfeito para cada $y_{i}$ dentro da janela, em que $S_{i}$ representa o desvio padrão de $y_{i-w}+\cdots+y_{i}+\cdots+y_{i+w}$, e $L$ é um limiar. Se o critério não é satisfeito, é assumido que a medida $y_{i}$ trata-se de um valor espúrio e deve ser substituído por $m_{i w}$.

Os resultados da primeira etapa podem ser vistos na Figura 3.1, onde são usados diferentes tamanhos de janela, $w=\{3,5,7\}$. O resultado para cada uma dessas ja- 
Tabela 3.1: Símbolos usados e seus significados para o entendimento da abordagem proposta de Detecção de moléculas únicas.

\begin{tabular}{|c||l|}
\hline Símbolo & Significado \\
\hline \hline$S$ & $\begin{array}{l}\text { Espectro Raman. A representação vetorial } S=\left\{y_{1}, y_{2}, \ldots, y_{n}\right\} \text { representa as } \\
\text { intensidades de banda Raman. }\end{array}$ \\
\hline$m$ & Número de intensidades Raman por espectro \\
\hline$y_{i}$ & $i$-ésima intensidade Raman no número de onda $i$ \\
\hline$w$ & Tamanho da janela \\
\hline$m_{i w}$ & Média com tamanho de janela $w$ e centrada em $y_{i}$ \\
\hline $\operatorname{diss}\left(S_{i}, S_{j}\right)$ & Dissimilaridade entre dois espectros $S_{i}, S_{j}$ \\
\hline
\end{tabular}

nelas é observado nas Figuras 3.1b, 3.1c e 3.1d respectivamente. O espectro sem pré-processamento é observado na Figura 3.1a. A área vermelha indica a presença de um dado espúrio, e como ele desaparece com a aplicação do filtro de média. Os experimentos apresentados correspondem à análise do conjunto de dados 10MB.

A segunda etapa, detrending (Barnes et al., 1989), consiste em uma operação estatística ou matemática usada para remover tendências presentes nas séries. Geralmente é aplicada para eliminar detalhes que podem estar ocultando relações de interesse. No caso de tratamento de espectros serve para corrigir a linha de base. Um método simples para aplicar detrending consiste em subtrair a média para cada valor no conjunto de dados como apresentado na seguinte equação:

$$
y_{i}=y_{i}-m_{i w}
$$

em que $m_{i w}$ é a média em uma janela de tamanho $w$ e centrada em $y_{i}$, calculada pela Equação 3.1. Os resultados dessa etapa podem ser observados na Figura 3.2b. Na Figura 3.2a é apresentado um espectro que exibe a presença de uma tendência crescente indicado pela linha vermelha. Por outro lado, a Figura 3.2b apresenta o espectro préprocessado pela técnica detrending e verifica-se que a tendência presente é removida.

Após o detrending, segue a etapa da suavização dos espectros. Nesta etapa foram testadas duas técnicas: Médias Móveis Simples (MMS) (Morettin \& Toloi, 2004) e SavitzkyGolay (SG) (Savitzky \& Golay, 1964; Steinier et al., 1972). A abordagem MMS é um das técnicas mais simples de suavização, pois suaviza um espectro calculando uma média dos valores e da vizinhança definida por uma janela a partir da equação:

$$
y_{i}^{\prime}=m_{i w}, \quad i=0, \cdots, n
$$

em que $y_{i}^{\prime}$ é denominado valor exponencialmente suavizado. A MMS aplica pesos iguais aos valores vizinhos e requer a definição dos limites de vizinhança (parâmetro $w$ ). Por outro lado, na técnica SG, o espectro é o resultado da convolução de uma janela contendo $2 w+1$ pontos, onde a janela é usada para a estimativa do ponto central (com $w$ pontos em cada lado). Esses $2 w+1$ pontos são ajustados por um polinômio de ordem determinada, e 


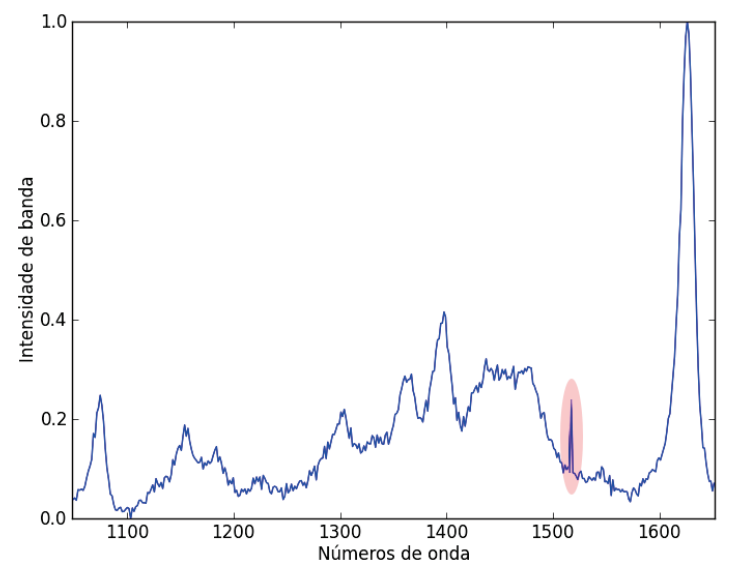

(a) Espectro não pré-processado. A área vermelha indica a presença de um dado espúrio

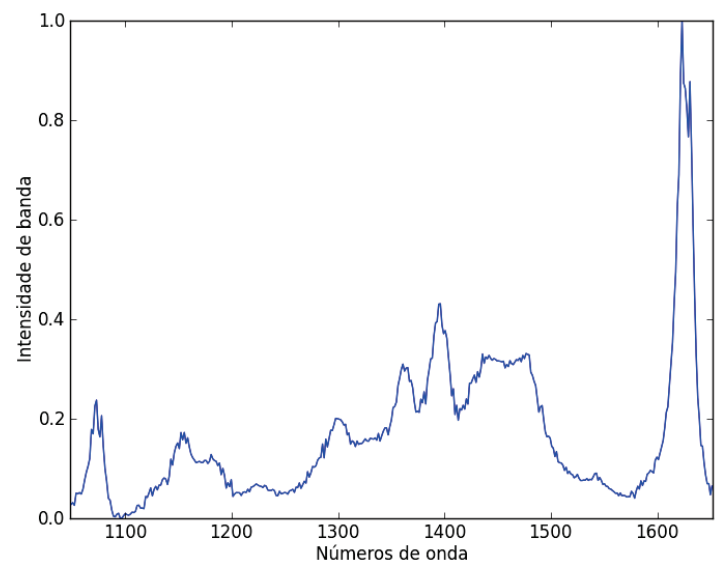

(c) Janela de tamanho 5

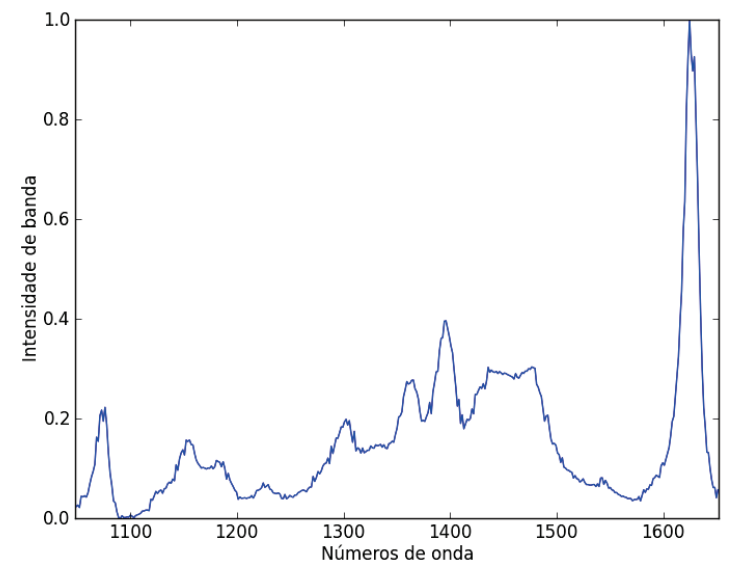

(b) Janela de tamanho 3

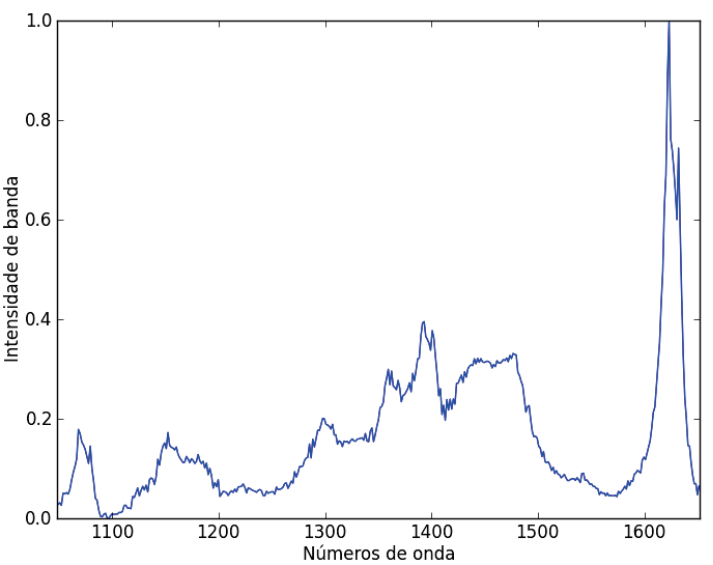

(d) Janela de tamanho 7

Figura 3.1: Aplicando o filtro de média num espectro sem tratamento de dados. A Figura (a) representa o espectro que exibe um valor espúrio, as outras figuras (b), (c) y (d) apresentam o espectro pré-processado usando o filtro de média com diferentes tamanhos de janela. O espectro tratado pertence ao conjunto de dados 10MB 


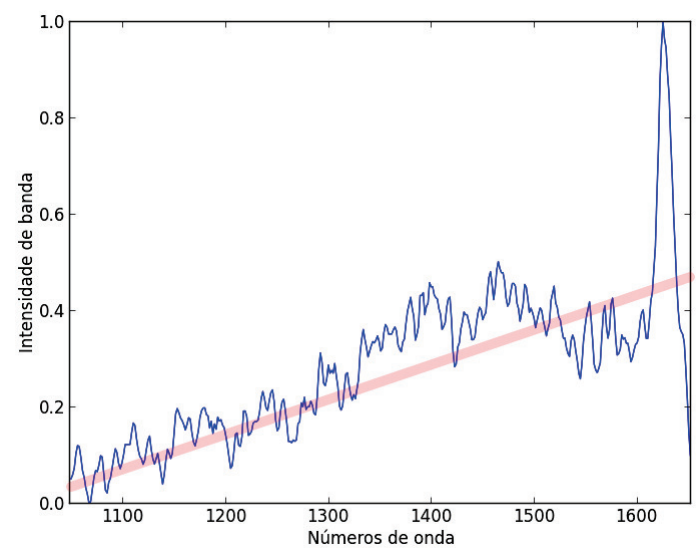

(a) Espectro não processado. A linha vermelha indica a presença de uma tendência

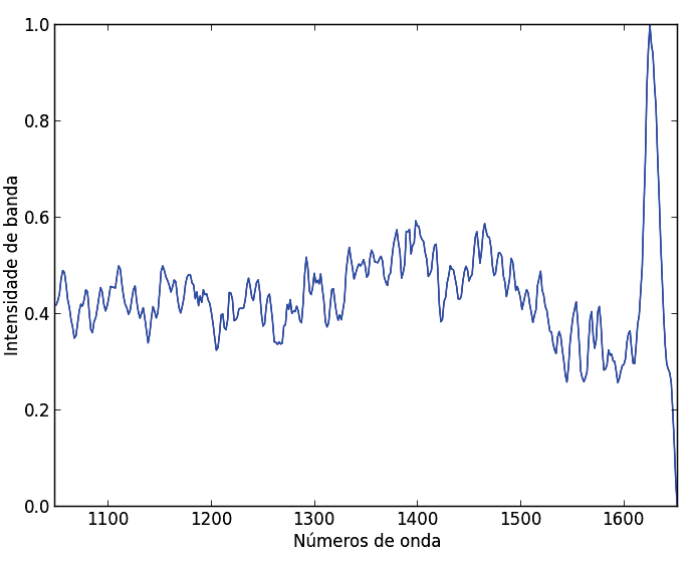

(b) Resultado da aplicação de detrending ao espectro

Figura 3.2: Resultado da aplicação da técnica detrending. Na esquerda é apresentado o espectro sem tratamento e na direita o resultado depois da aplicação do pré-processamento. O espectro processado corresponde ao conjunto de dados $100 \mathrm{MB}$

os coeficientes encontrados por este ajuste são utilizados na estimativa do novo valor deste comprimento de onda. Assim, os $w$ pontos em cada extremidade do espectro são perdidos. Gorry (1990) propôs um método para contornar o problema da perda de pontos usando janelas assimétricas. No entanto, esse método perde estrutura fina nas extremidades do espectro, ou seja não consegue suavizar com a mesma eficiência as extremidades, a menos que o ajuste polinomial seja de ordem maior (Sun, 2008).

A estimativa do coeficiente polinomial é, a princípio, feita apenas uma vez, pois os coeficientes não mudam de uma janela para outra. Isto significa que o mesmo vetor de coeficientes pode ser usado em todo o espectro (menos os dois conjuntos de $g$ pontos nas extremidades do espectro), tornando a execução mais eficiente. No trabalho original de Savitzky \& Golay (1964) foram apresentadas tabelas com os coeficientes para várias derivações e suavização para muitos ajustes polinomiais diferentes. No entanto, existem erros nessas tabelas, como apontado e corrigido por Steinier et al. (1972). Hoje não há necessidade para essas tabelas, pois os coeficientes podem ser facilmente encontrados através da inversão da matriz $C$ :

$$
C=\left[\begin{array}{cccc}
1 & -w & \cdots & (-w)^{i} \\
1 & -(w-1) & \cdots & {[-(w-1)]^{i}} \\
\vdots & \vdots & 0 & \vdots \\
1 & w-1 & \cdots & (w-1)^{i} \\
1 & w & \cdots & w^{i}
\end{array}\right]
$$

em que $i$ é a ordem polinomial para o qual os pontos são ajustados. Dessa forma, o tamanho desta matriz será $(2 w+1) \times(i+1)$ e portanto simples para calcular.

O resultado desse passo de suavização é a remoção dos sinais de alta frequência, 


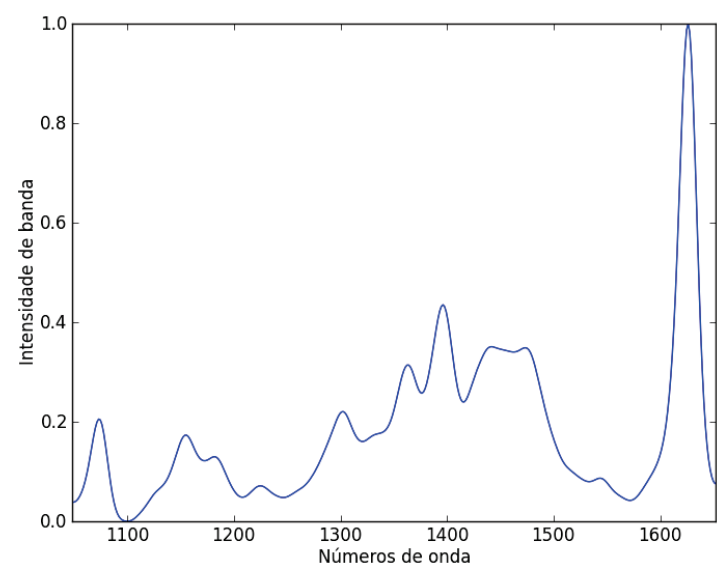

(a) Suavizado usando Médias Móveis Simples

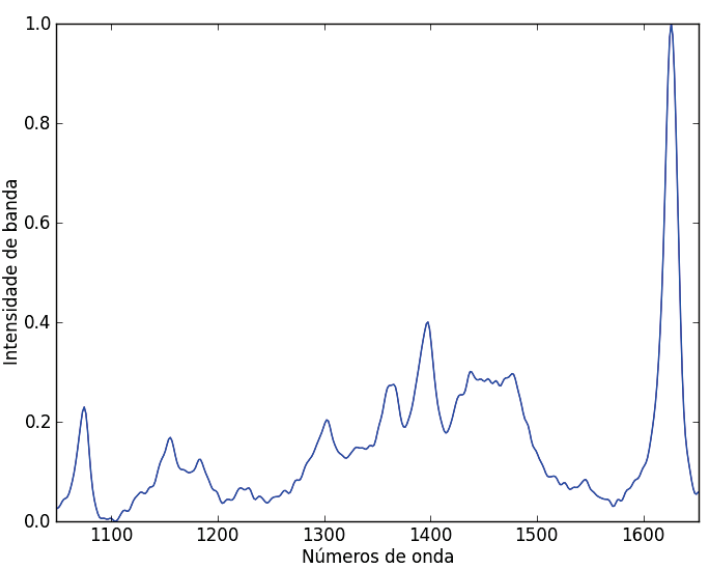

(b) Suavizado usando Savitzky-Golay

Figura 3.3: Resultados da aplicação das duas abordagens de suavização sobre o espectro apresentado na Figura 3.1a.

preservando a forma geral do espectro. As Figuras 3.3a e 3.3b apresentam os resultados da aplicação de MMS e SG respectivamente. Nas figuras é possível perceber que ambos tipos de suavização fornecem resultados parecidos. Nos experimentos a técnica SG apresentou os resultados mais próximos aos da análise manual e por esse motivo foi escolhida como a técnica a ser usada no processo de suavização. A etapa de suavização é necessária porque o ruído de alta frequência afeta o cálculo de dissimilaridade, apresentado a seguir.

Finalmente, antes da visualização é feito o cálculo de dissimilaridade analisando possíveis deslocamentos e adaptando os cálculos caso necessário. Foram aplicadas 4 abordagens diferentes: (1) Dynamic Time Warping (DTW) (Morettin \& Toloi, 2004) que emparelha duas curvas representadas por sequências de pontos de dados de modo que a soma das distâncias quadradas euclidianas entre os pontos de dados encontrados é minimizada, (2) aplicando a Transformada de Fourier (Cooley \& Tukey, 1965) em cada um dos espectros para depois calcular a dissimilaridade entre os espectro; (3) Max Moving Euclidean e (4) Min Moving Euclidean. Estas duas últimas fazem o cálculo de dissimilaridade usando a seguinte equação:

$$
\operatorname{diss}\left(s_{1}, s_{2}\right)=\sqrt{\sum_{t=1}^{m}\left(D_{t}\right)^{2}}
$$

em que $D_{t}$ é calculado como $D_{t}=\max (\operatorname{diss}(t, w))$ para Max Moving Euclidean e $D_{t}=$ $\min (\operatorname{diss}(t, w))$ para Min Moving Euclidean, $w$ representa o tamanho da janela, diss $(t, w)$ é definido como o conjunto de distâncias $\left\{\operatorname{diss}\left(x_{t-w}, y_{t}\right), \cdots, \operatorname{diss}\left(x_{t}, y_{t}\right), \cdots, \operatorname{diss}\left(x_{t+w}, y_{t}\right)\right\}$, $s_{1}$ e $s_{2}$ são dois espectros definidos como $s_{1}=\left\{x_{1}, x_{2}, x_{3}, \cdots, x_{n}\right\}$ e $s_{2}=\left\{y_{1}, y_{2}, y_{3}, \cdots, y_{n}\right\}$ e diss representa o cálculo de dissimilaridade. Nos nossos experimentos foi empregada a técnica City-Block pois ela apresentou os melhores resultados.

O resultado desta abordagem é uma representação visual das diferenças entre o con- 
junto de espectros e os valores de referências. A técnica de visualização de informação escolhida foi o Heatmap (Grinstein et al., 2001), pois apresenta uma relação direita com o esquema de captura dos dados em um sensor SERS, como discutido no Capítulo 2. Neste modelo, cada célula do Heatmap representa a dissimilaridade encontrada entre um espectro analisado e o espectro de referência. As células mais claras apresentam os espectros mais próximos das referências e são coloridas segundo a escala apresentada na Figura 3.6a.

\subsubsection{Resultados}

Na Figura 3.4 são apresentados os resultados do processo manual de detecção de moléculas únicas para os conjuntos de dados 100MB, 10MB e 1MB em que os pontos mais claros correspondem às moléculas únicas detectadas. Os espectros classificados como molécula única foram selecionados nos resultados e comparados com o espectro referência apresentado na parte de baixo da Figura 3.4.
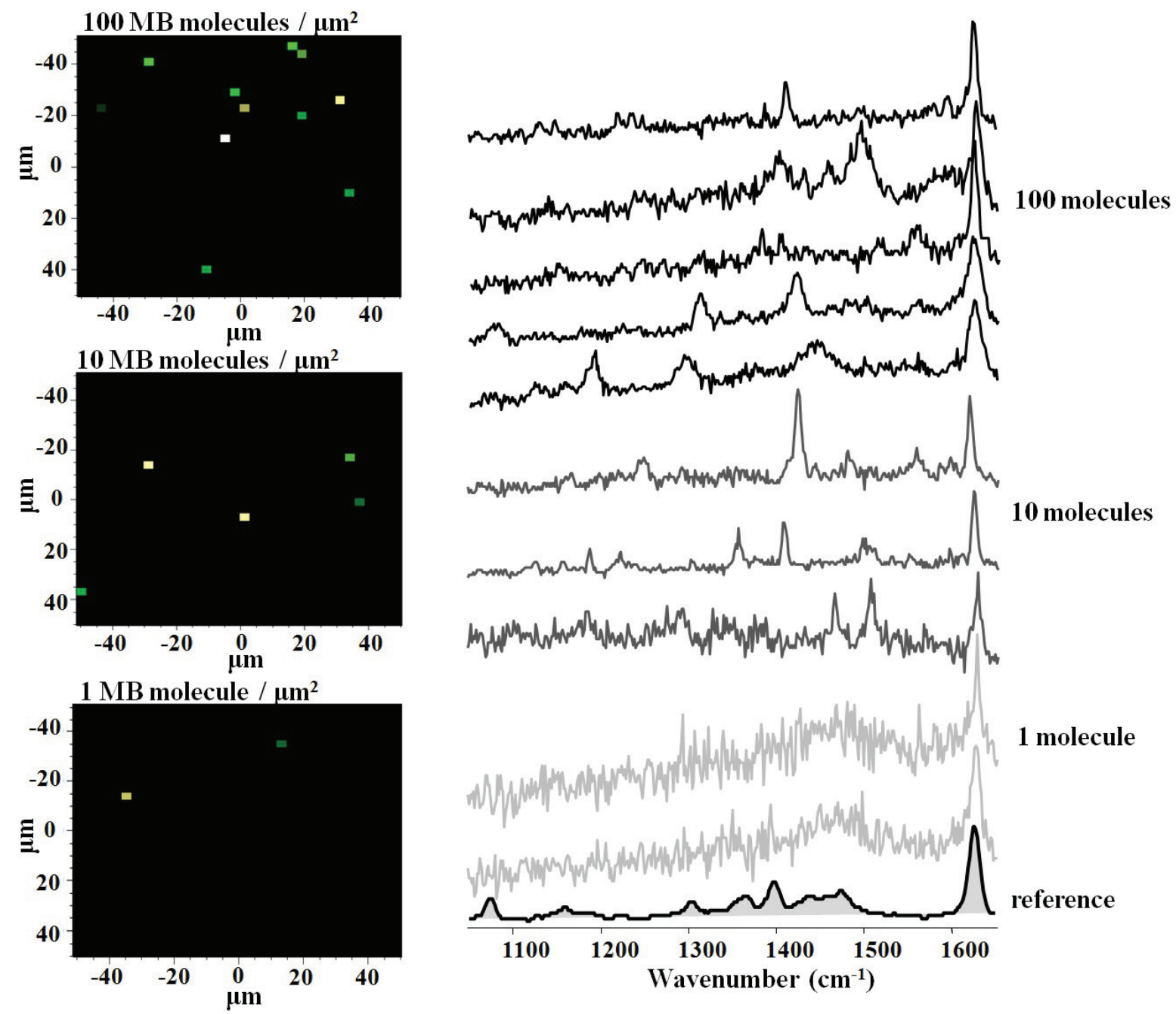

Figura 3.4: Resultados obtidos no processo manual de detecção de molécula únicas para os conjuntos de dados 100MB, 10MB e 1MB (figura extraída de Aoki et al. (2013)) 
A Figura 3.5 apresenta os resultados da abordagem computacional. Na maioria dos casos, o posicionamento das moléculas achadas tem concordância com os resultados do processo manual (Figura 3.4). Note que na Figura 3.5, no resultado correspondente ao conjunto $10 \mathrm{MB}$, existe uma molécula faltante se o comparamos com o resultado manual do mesmo conjunto de dados. O espectro foi analisado com maior detalhe e verificou-se que embora a faixa importante do espectro tenha coincidido com a referência, existem outras zonas bem diferentes do espectro. Portanto esse espectro deve ser classificado como falso positivo na análise manual.

Embora a abordagem computacional proposta tenha conseguido identificar corretamente alguns dos espectros classificados como molécula única no processo manual, ainda apresentava deficiências. Um exemplo disso é apresentado na Figura 3.6, em que os resultados correspondem ao comparativo das 4 técnicas propostas para o cálculo de dissimilaridade. É possível verificar que os resultados das 4 abordagens empregadas: Dynamic Time Warping (Figura 3.6b), aplicando a Transformada de Fourier (Figura 3.6c); Max Moving Euclidean (Figura 3.6d) e Min Moving Euclidean (Figura 3.6e) são parecidos. Os quadrados roxos representam os espectros identificados como molécula única, enquanto o resto é detectado como falso positivo, algo que deveria ser minimizado

O caso de resolução de falsos positivos será detalhado na próxima Seção 3.2 junto com a descrição da segunda abordagem que visa corrigir esta e outras imperfeições constatadas. 

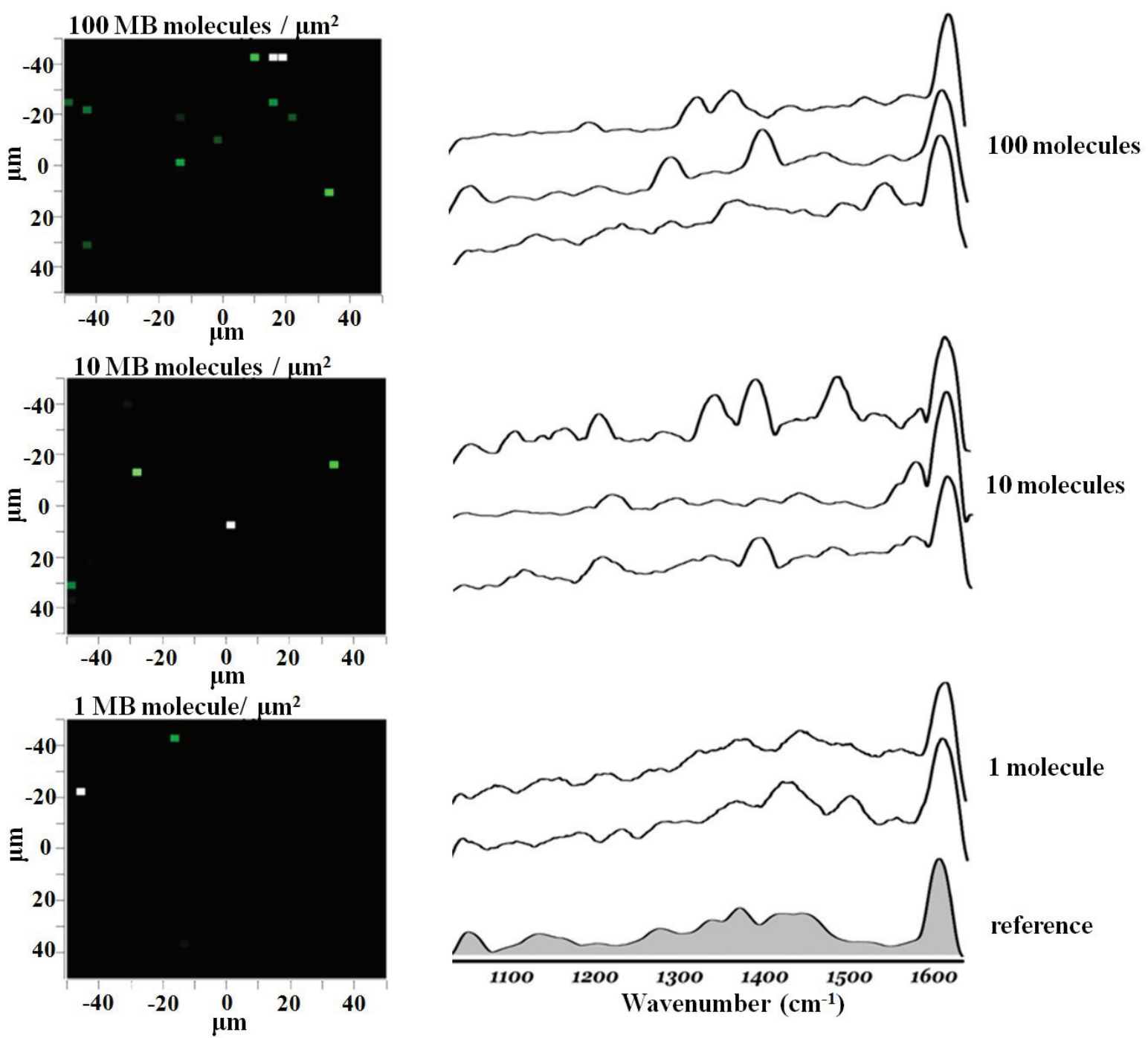

Figura 3.5: Resultados obtidos no processo automático de detecção de molécula únicas para os conjuntos de dados 100MB, 10MB e 1MB (figura extraída de Aoki et al. (2013))

\subsection{Segunda abordagem}

Apesar dos bons resultados, o número de falsos positivos na primeira abordagem é consideravelmente alto. Por este motivo, a etapa do cálculo de dissimilaridade sofreu algumas mudanças a fim de reduzir esse número. A primeira mudança baseia-se no fato de que certas faixas dos números de onda tem maior relevância no processo de detecção de molécula única (Pieczonka \& Aroca, 2008). Geralmente essa faixa encontra-se na zona Full Width at Half Maximum (FWHM) (Pieczonka \& Aroca, 2008). A faixa FWHM é considerada a medida da largura de um pico de espalhamento no ponto onde a intensidade cai para a metade (ver Figura 3.7). Deste modo, o novo cálculo de dissimilaridade dá maior relevância à análise nesta faixa. O cálculo é definido como $\delta_{f w h m}(e, r)$, em que e representa o espectro analisado e $r$, a referência. De forma resumida, este cálculo determina se algum pico do espectro analisado existe na zona FWHM da referência. Em caso existir, o valor 
Min

Max

(a) Escala de cor usada no desenho dad grades

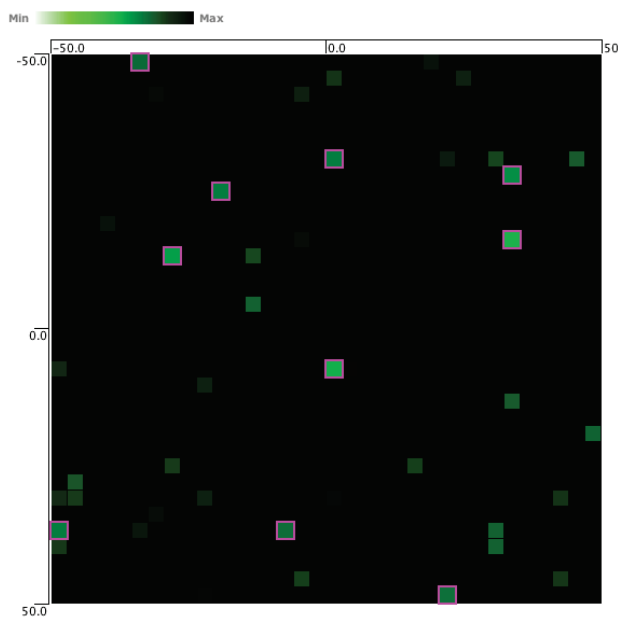

(b) Dynamic Time Warping

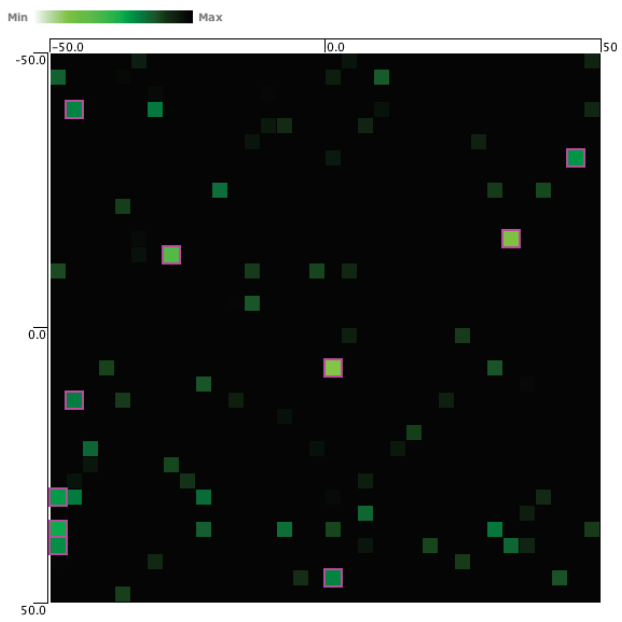

(d) Max Moving Euclidean

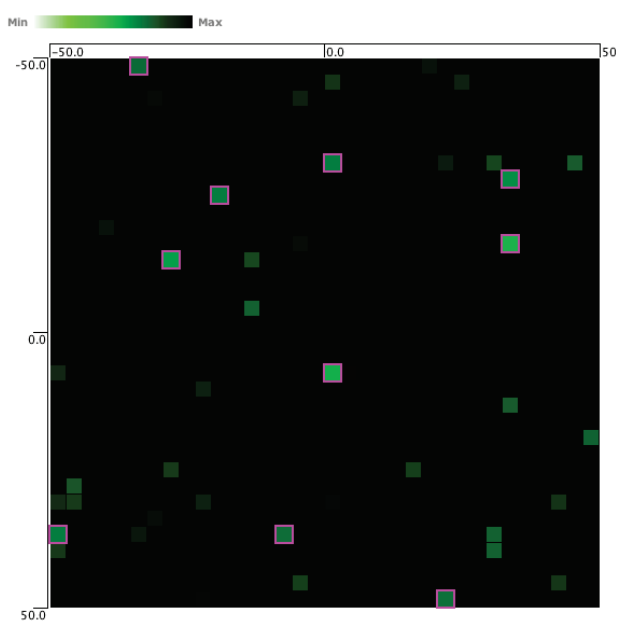

(c) Usando transformada de Fourier

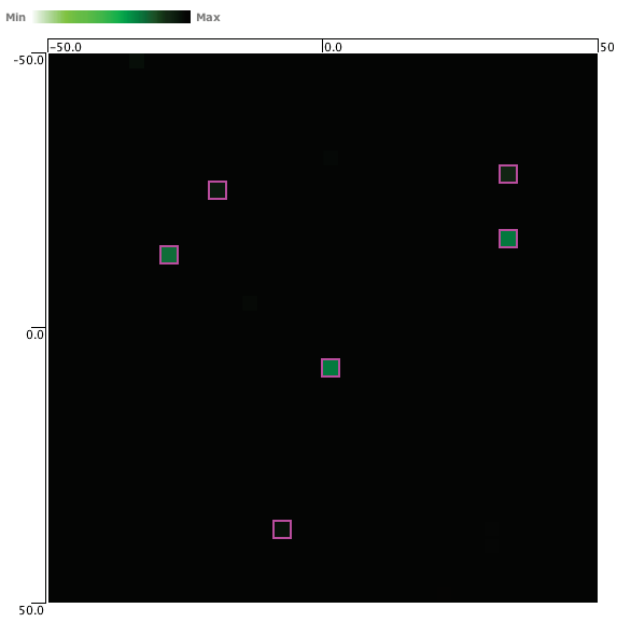

(e) Min Moving Euclidean

Figura 3.6: Resultados do processo de detecção de molécula única usando diferentes abordagens para o cálculo de dissimilaridade representadas usando o método de visualização Heatmap. Os pontos ressaltados em roxo indicam a presença dá molécula procurada enquanto os outros pontos claros representam falsos positivos.

de dissimilaridade é definido pelo deslocamento presente entre o pico FWHM e o pico encontrado.

Outra mudança refere-se ao tratamento dos deslocamentos nos espectros. Na nova abordagem, os deslocamentos são tratados de duas formas diferentes:

1. Os deslocamentos horizontais tem um limite máximo (5\%), e também não podem ser aplicados se alguma intensidade de banda representativa é apresentada dentro da faixa FWHM. Um exemplo é apresentado na Figura 3.8c. É possível observar que existe uma área verde que indica a presença de um pico destacável na faixa FWHM, 


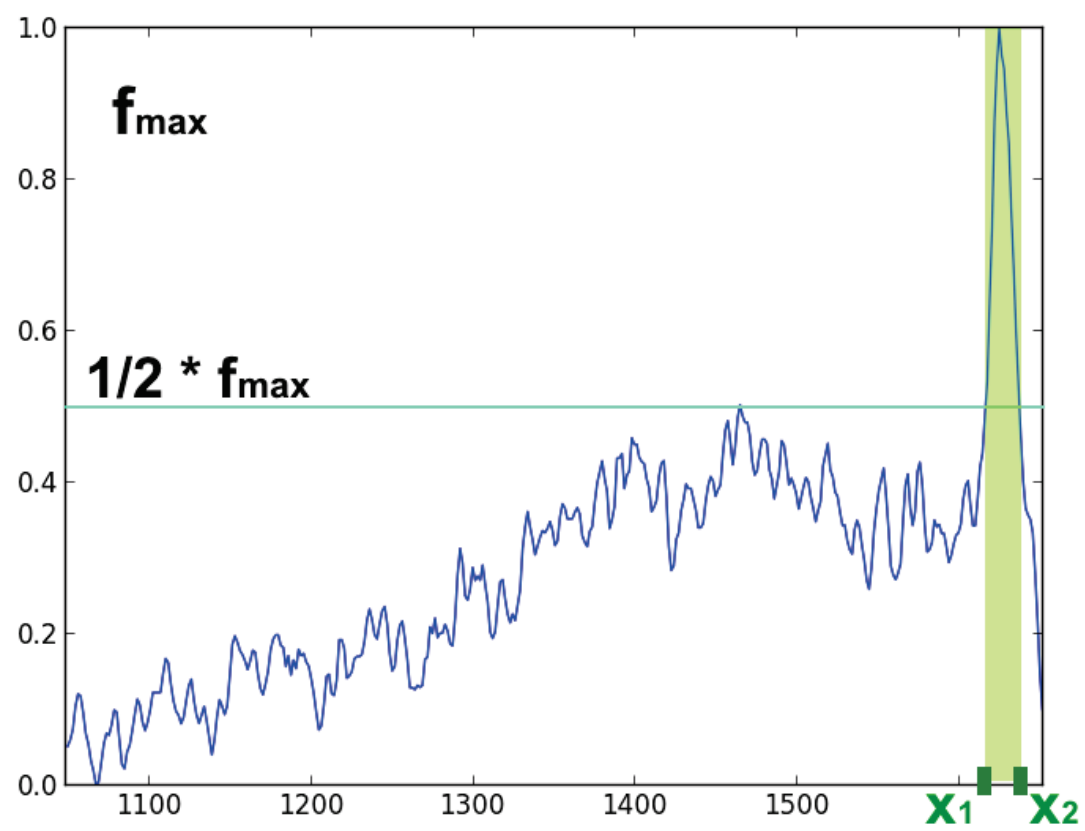

Figura 3.7: Faixa $\left[x_{1}, x_{2}\right]$ Full Width at Half Maximum (FWHM) indicada na área verde por consequência o espectro não pode ser deslocado horizontalmente. Este cálculo de dissimilaridade será definido como $\delta_{\text {hor }}(e, r)$, em que e representa o espectro analisado e $r$, a referência.

2. Uma análise da curvatura é feita para tratar os deslocamentos verticais. Para cada espectro é gerado um vetor de características definido como $C=\left\{a_{1}, a_{2}, a_{2}, \cdots, a_{m-1}\right\}$ em que $a_{i}$ representa a inclinação entre as intensidades de bandas nos números de onda $x_{i}$ e $x_{i+1}$. Logo, os vetores de características gerados para cada espectro são comparados com o vetor obtido a partir do espectro de referência usando a técnica de distância euclidiana. Este cálculo de curvatura é denominado $\delta_{v e r}(e, r)$. Da mesma forma que no cálculo $\delta_{f w h m}(e, r)$, e representa o espectro analisado e $r$, o espectro de referência. Um modelo visual para a análise de curvatura é apresentado na Figura 3.9. 


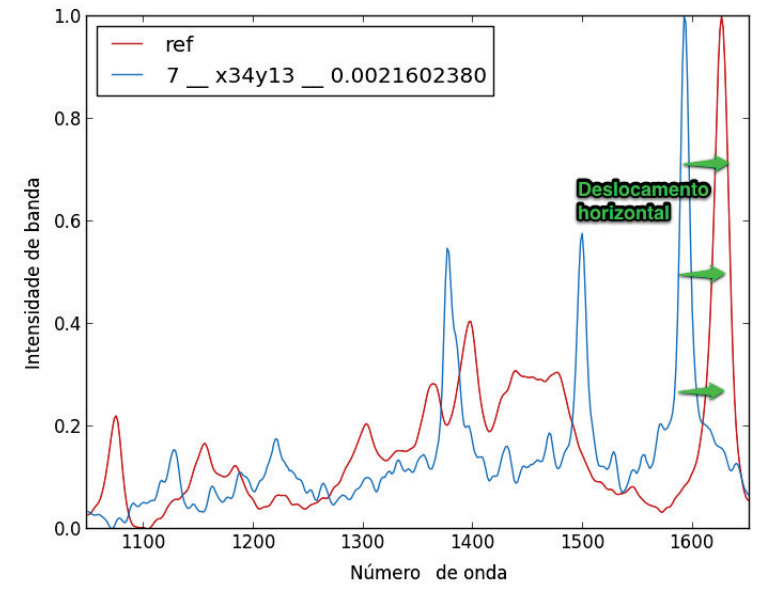

(a) Analise de possível deslocamento horizontal

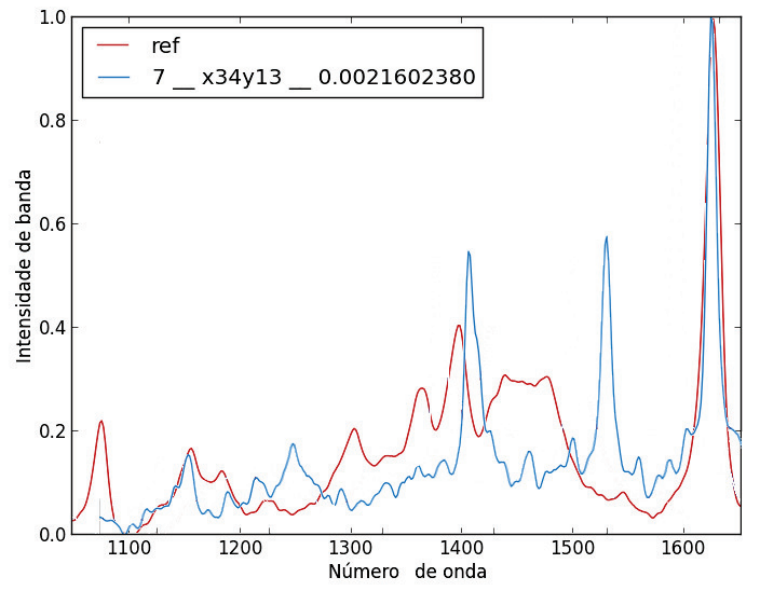

(b) Efetuando o deslocamento horizontal

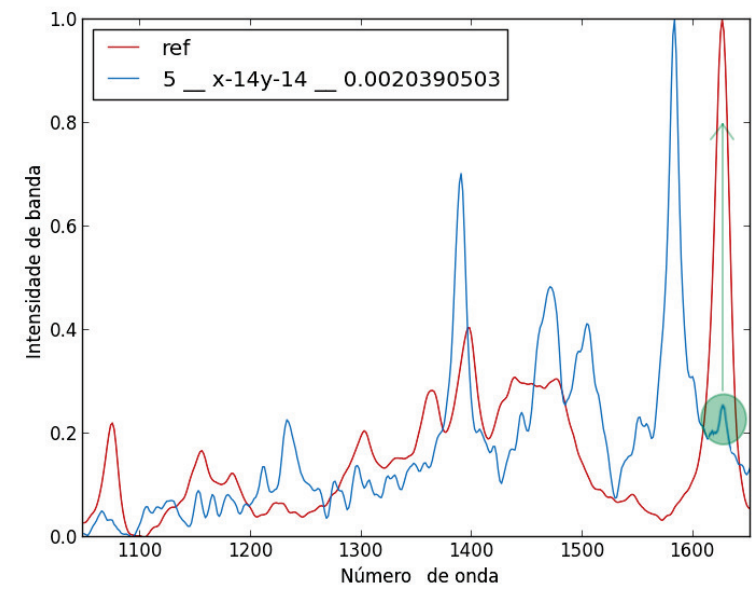

(c) Exemplo de um espectro que não pode ser deslocado horizontalmente pois apresenta um pico na zona FWHM

Figura 3.8: Análise de deslocamentos horizontais entre os espectros (azul) e o espectro referência (vermelho) 


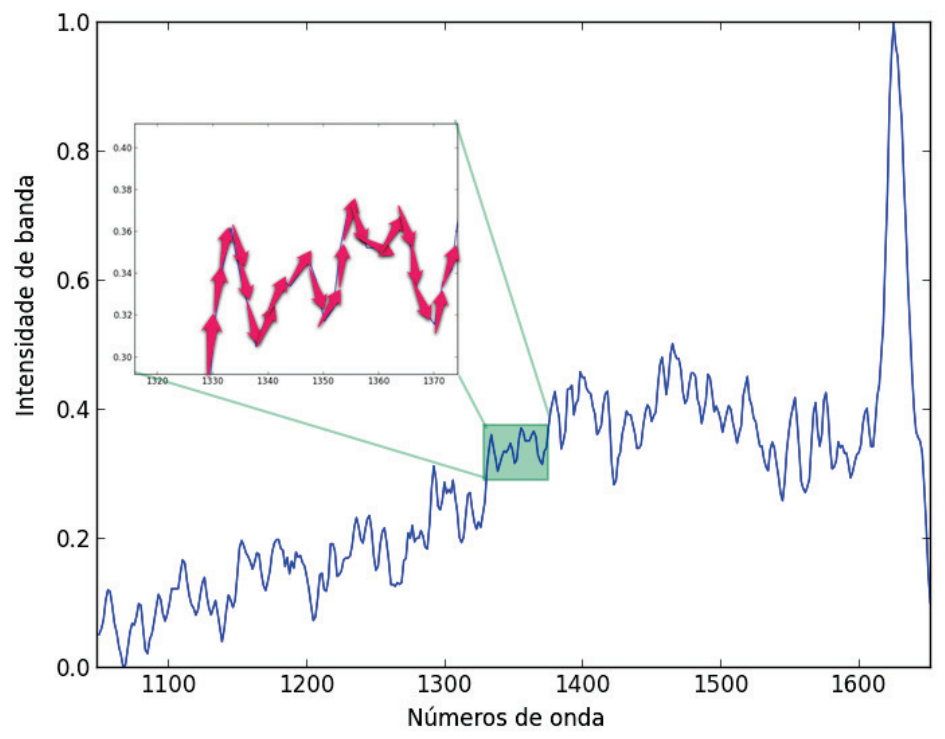

Figura 3.9: Curvatura de um espectro expressada pela inclinação entre dois números de onda.

Finalmente, o novo cálculo de dissimilaridade é dado pela fórmula:

$$
\delta(e, r)=w_{1} \delta_{f w h m}(e, r)+w_{2} \delta_{v e r}(e, r)+w_{3} \delta_{h o r}(e, r)
$$

em que $e$ representa o espectro, $r$ a referência, $\delta_{f w h m}(e, r)$ representa o cálculo de dissimilaridade que dá maior importância à faixa $\mathrm{FWHM}, \delta_{v e r}(e, r)$ representa o cálculo de dissimilaridade usando a análise de curvatura para deslocamentos verticais e $\delta_{\text {hor }}(e, r)$ representa o cálculo de dissimilaridade considerando os possíveis deslocamentos horizontais; $\left(w_{1}, w_{2}, w_{3}\right) \in[0,1]$ são os valores dos pesos correspondente a cada cálculo de dissimilaridade. Nos experimentos foram usados os seguintes pesos: $w_{1}=0.8, w_{2}=0.1$ e $w_{3}=0.1$ pois apresentaram os melhores resultados.

A seguir é apresentado um comparativo entre a primeira e segunda abordagens, conjuntamente é apresentado um caso de uso que exemplifica o potencial do uso das técnicas propostas para resolver o problema de detecção de molécula única.

\subsubsection{Resultados}

Os novos resultados apresentaram grandes melhorias em termos da redução de falsos positivos. Um comparativo entre as duas abordagens propostas aplicadas ao conjunto de dados 10MB é apresentado na Figura 3.11. Na primeira abordagem, entre os 5 primeiros espectros classificados como molécula única existe um falso positivo (Figura 3.11 (I4)). Na abordagem final, esse espectro é descartado. Um espectro é classificado como altamente similar se apresenta ao menos $90 \%$ de similaridade com o modelo de referência. $(\leq 0.1$ usando a dissimilaridade como classificador no intervalo $[0,1]$ sendo que zero representaria o valor ótimo) 
Na Figura 3.10 é apresentado um falso positivo usando a primeira abordagem, onde a área verde indica a dissimilaridade calculada. Como o valor da área é pequeno, a similaridade do espectro com a referência é grande, portanto o espectro analisado é classificado como molécula única. Porém, considerando o pico presente no intervalo de números de onda [1048, 1100], o espectro é descartado. Na segunda abordagem, os falsos positivos são reduzidos.

A análise do conjunto e R18 ilustra o potencial das técnicas de visualização de informação para identificar moléculas únicas eliminando falsos positivos, uma vez que demanda apenas alguns segundos para a classificação em contrapartida à análise manual. É importante destacar que o número de espectros do conjunto R18 é 37848, portanto o processo de detecção manual seria de fato impraticável. O resultado do processamento sobre o conjunto R18 pode ser visto na Figura 3.12 e os espectros classificados como molécula única são exibidos na Figura 3.13. Os três espectros (Figuras 3.13b, 3.13c e $3.13 \mathrm{~d})$ apresentaram um baixo grau de dissimilaridade $(\leq 0.1)$ quando foram comparados com o espectro de referência (Figura 3.13a)

\subsection{Considerações finais}

O desenvolvimento de uma nova ferramenta computacional para apoiar a detecção de moléculas únicas trouxe resultados bastante promissores. Nos experimentos, a nova ferramenta se mostrou eficiente ao analisar os conjuntos de dados espectrais com uma maior precisão do que a análise manual. Um dos motivos que possibilitam essa melhora encontra-se na análise de faixas específicas dos números de onda que tem maior relevância em relação às outras faixas.

Outras questões importantes a destacar são a rapidez e simplicidade da análise computacional. A análise do conjunto de dados espectrais R18 é um exemplo a destacar uma

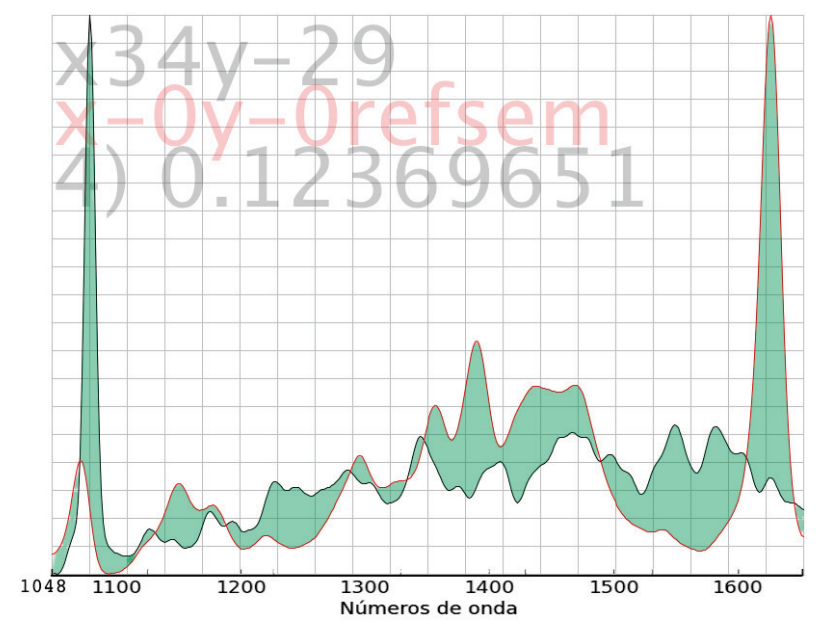

Figura 3.10: Exemplo de falso positivo. A área verde indica a similaridade obtida usando a técnica de distância City-Block 


\section{(I1)}
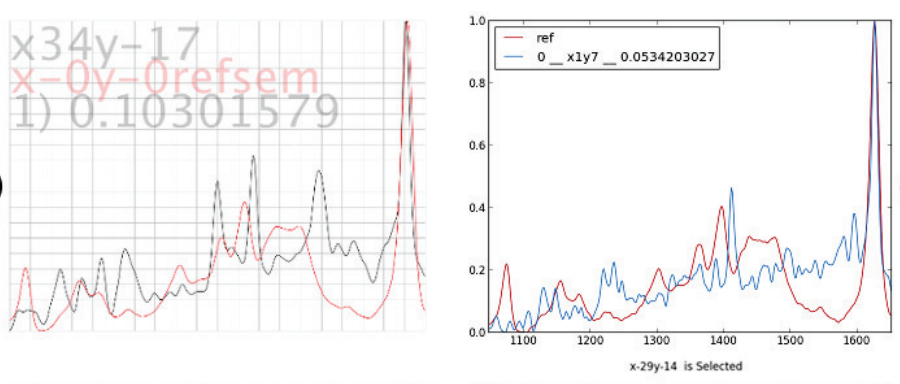

(F1)

(I2)
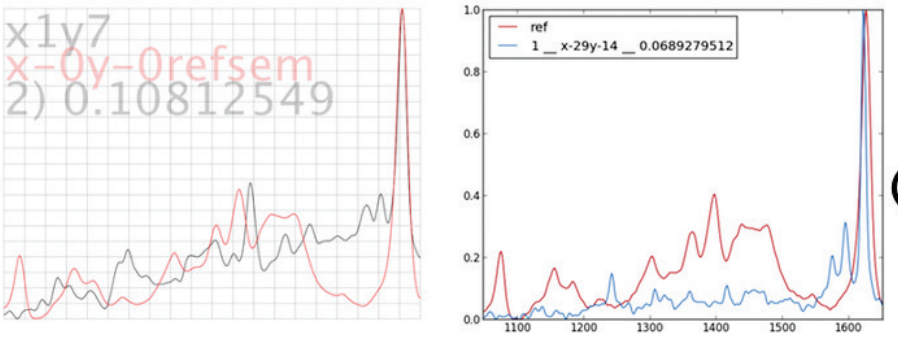

(F2)

\section{(I3)}

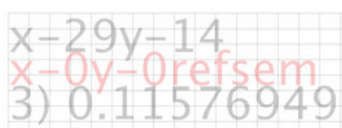

(I4)
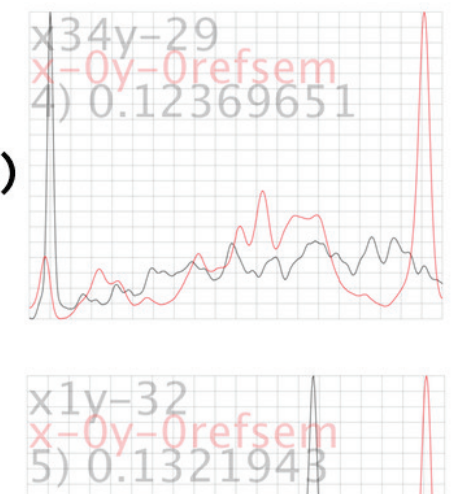

(I5)

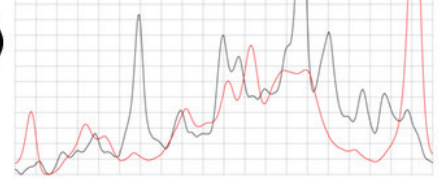

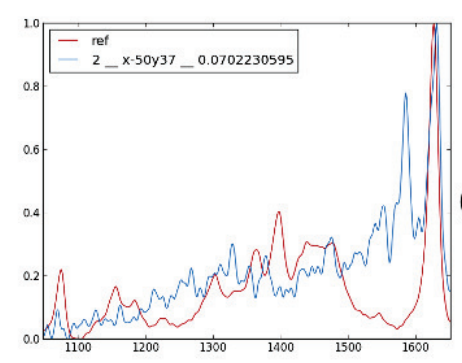

(F3)

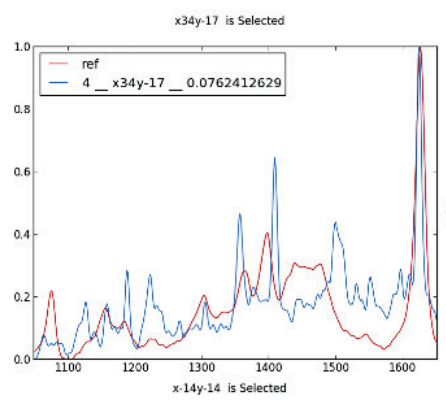

(F4)

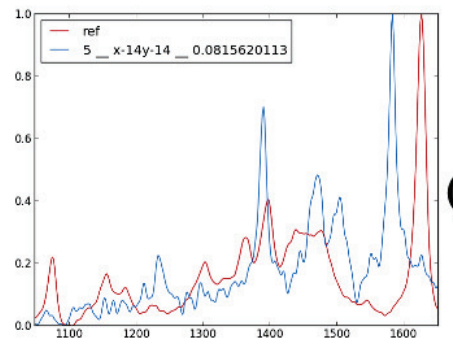

Figura 3.11: Comparativo de falsos positivos entre as duas abordagens: inicial (esquerda) e final (direita). São apresentados os 5 primeiros espectros classificados como molécula única e correspondem à analise do conjunto de dados 10MB. 


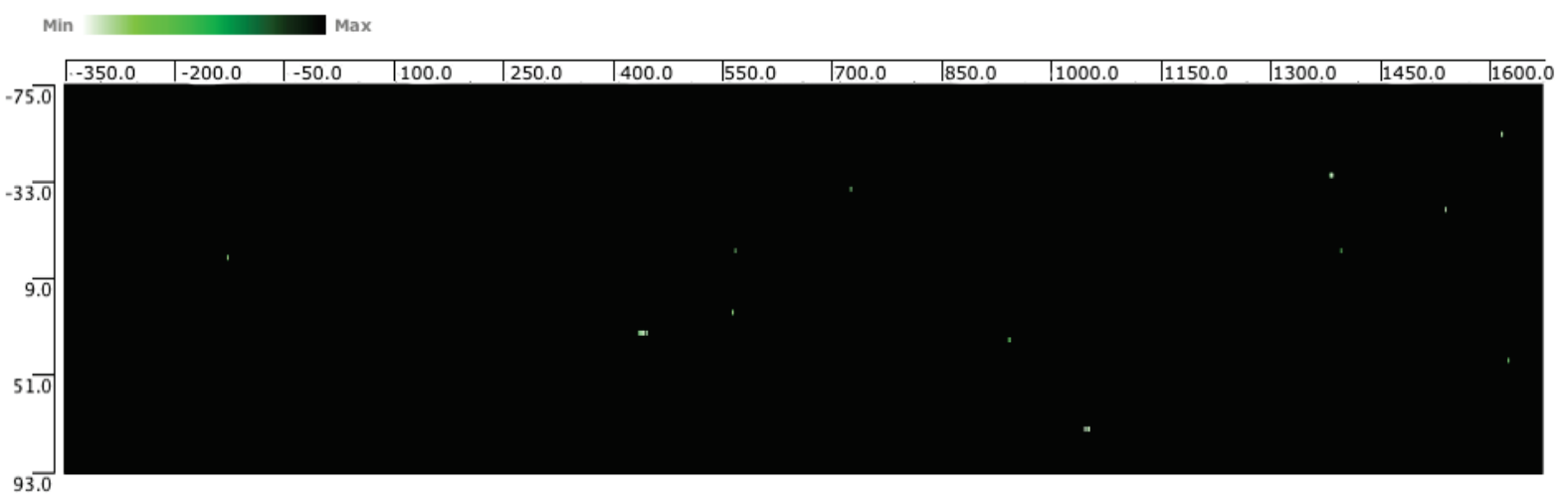

Figura 3.12: Análise do conjunto de dados R18, os pontos mais claros indicam a presença de um espectro classificado como molécula única

vez que seu número grande de espectros (37848) dificulta a análise manual. O uso da abordagem computacional proposta torna a análise manual em um processo rápido e simples. Nos experimentos foi usado um computador Intel Core ir com $24 \mathrm{~GB}$ de memoria e um HD de estádo sólido (SSD) de 120GB. Nesse computador o processamento do conjunto R18 levou aproximadamente $\sim 10$ segundos. É importante ressaltar esta característica pois com a rapidez que avança a tecnologia, os futuros aparelhos para análise sensorial estarão preparados para gerar milhões de dados espectrais em lugar dos milhares que são gerados atualmente. 


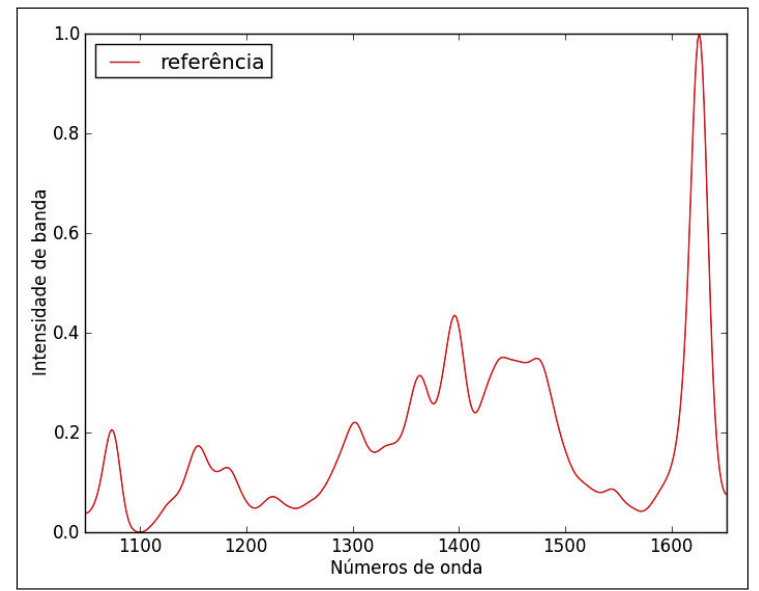

(a) Espectro referência

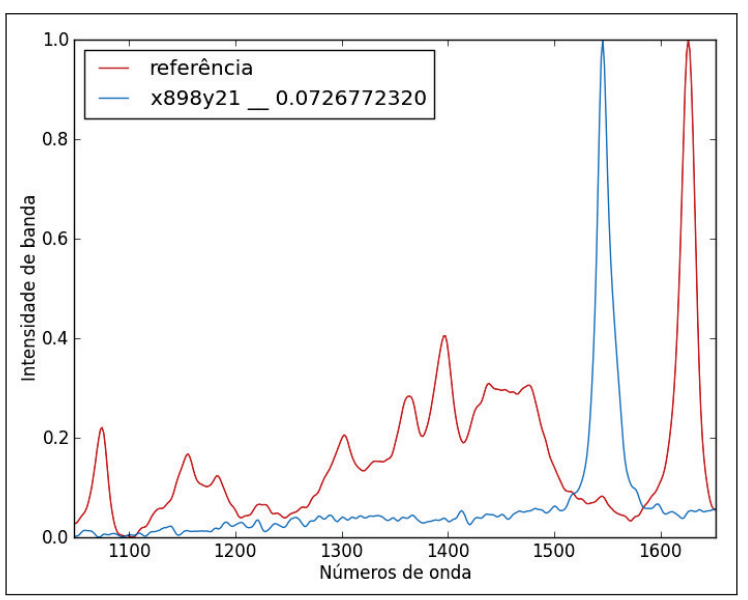

(c) Espectro $(\mathrm{X}: 898, \mathrm{Y}: 21)$

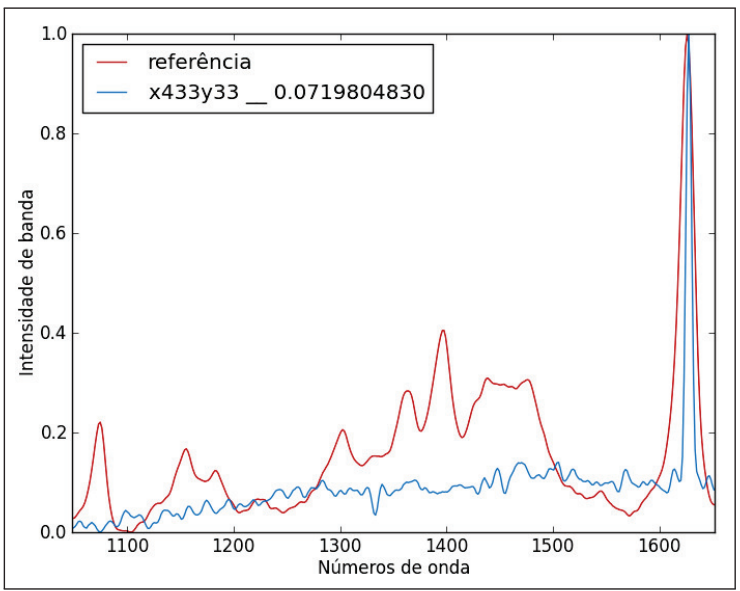

(b) Espectro (X:443, Y:33)

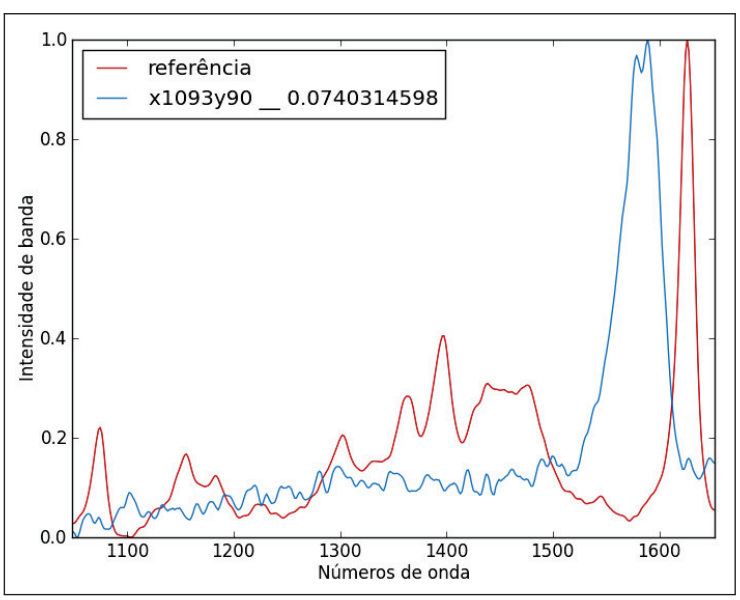

(d) Espectro (X:1093,Y:90)

Figura 3.13: Espectros (Figuras (b), (c) e (d)) do conjunto de dados R18 classificados como moléculas únicas. Os três espectros presentam um baixo grado de similaridade com o modelo de referencia (a). 


\section{Capítulo 4 \\ Troca de sensores em línguas eletrônicas}

s medidas de espectroscopia de impedância tem se mostrado de grande im-
portância para investigar interações entre analitos, as substâncias analisada, e os
materiais que constituem as unidades sensoriais (Pejcic \& Marco, 2006). Porém, um dos maiores problemas com relação ao uso de espectroscopia de impedância em aplicações industriais diz respeito à reprodutividade dos dados obtidos quando sensores são substituídos em uma língua eletrônica. Isso porque mesmo sensores nominalmente idênticos, ou seja sensores fabricados com materiais altamente similares, dificilmente produzem a mesma resposta elétrica em toda a curva de impedância capturada (Paulovich et al., 2011b) afetando a resposta da língua eletrônica. Assim, se em um arranjo de sensores, que foi calibrado para dar uma certa resposta, por exemplo, a classificação da qualidade de café (uma aplicação real que já vem sendo explorada), algum sensor precisar ser trocado, é altamente provável que a resposta dada pelo novo arranjo seja diferente da original, o que impossibilita a comercialização em grande escala desse tipo de aparelho.

A Figura 4.1 apresenta projeções para dados produzidos por três sensores com diferentes arquiteturas de construção. Nesse experimento identificaram-se diferentes concentrações de ácido fítico em uma solução aquosa. Os círculos representam as amostras de ácido, onde círculos de mesma cor representam amostras da mesma concentração. Observe que há uma boa separação das amostras em diferentes concentrações. Porém, o que se busca idealmente é que os círculos de mesma cor fiquem não somente agrupados, mas sobrepostos, indicando que o sensor responde sempre da mesma forma - o que se esperaria de uma ferramenta industrial reprodutível. Porém, é de conhecimento que sensores nominalmente iguais podem responder de forma diferente se a curva completa de impedância 


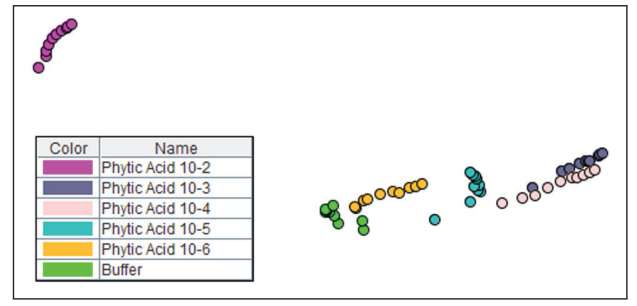

(a) Sensor de eletrodo puro.

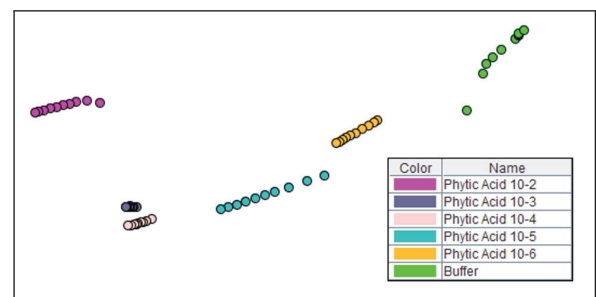

(b) Sensor coberto com PAH/Phytase.

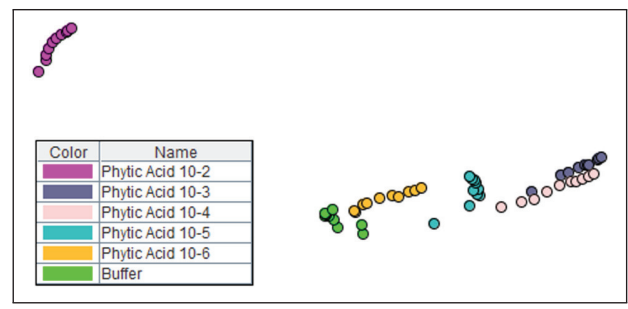

(c) Sensor coberto com PAH/PVS.

Figura 4.1: Projeções para dados produzidos por diferentes unidades sensoriais para analisar diferentes concentrações de ácido fítico em que cada figura representa um material distinto usado na construção do sensor (figura extraída de Paulovich et al. (2011b)).

é empregada na medição (Moraes et al., 2010), o que pode ser verificado no exemplo dos três sensores na Figura 4.1 já que existe um espalhamento dos círculos de mesma cor.

Com relação à reprodutibilidade de sensores nominalmente iguais, deseja-se definir uma forma de verificar visualmente as diferenças entre as medidas geradas por dois sensores e tentar definir uma forma de encontrar alguma transformação, ou escolha de parâmetros que torne as respostas mais semelhantes. Para determinar a possibilidade de fabricar sensores reprodutíveis, os seguintes conjuntos de dados foram utilizados nos experimentos: Hydrochloride and Phytase (PAH/Phytase), Hydrochloride and Polyvinyl sulfonate (PAH/PVS), Eletrodo Puro (Bare) que são compostos por 6 concentrações com 10 sensores avaliados para cada concentração e com uma curva de impedância composta por elementos complexos para 71 frequências no intervalo $[1 \mathrm{~Hz}, 1 \mathrm{MHz}]$. Outros conjuntos de dados também foram analisados: Glucose oxidase and Lipase (GOx/Lipase), Hydrochloride and Glucose oxidase (PAH/GOx) e Hydrochloride and Lipase (PAH/Lipase). Cada um desses conjuntos apresenta 17 concentrações com 2 sensores para cada concentração e curvas de impedância correspondentes a 142 frequências no mesmo intervalo do que os conjuntos anteriores: [1 $\mathrm{Hz}, 1 \mathrm{M} \mathrm{Hz}$ ]. Uma descrição mais detalhada dos conjuntos de dados mencionados pode ser consultado em Moraes et al. (2009).

Na seguinte seção será detalhada a abordagem proposta para a substituição de sensores em uma língua eletrônica. Será apresentada nossa metodologia para abordar esse problema. 


\subsection{Processo para a substituição de sensores}

A fim de propor uma metodologia para a substituição de sensores foi desenvolvida uma abordagem que consiste em 3 etapas: (1) pré-processamento dos conjuntos de dados, (2) conversão da curva de capacitância em valores de resistores e capacitores, que representam os componentes do circuito eletrônico equivalente de Taylor (Taylor \& Macdonald, 1987), (3) substituição de um sensor deficiente por um sensor novo recalibrado.

Uma visão geral do processo para substituição de sensores é explicada na Figura 4.2. Em resumo, a primeira etapa (Figura 4.2(1)) transforma o conjunto de dados composto por valores de impedância (Figura 4.2(a)) em valores de capacitância (Figura 4.2(b)). A segunda etapa (Figura 4.2(2)) converte os valores de capacitância nos parâmetros correspondentes do circuito de Taylor (Figura 4.2(c)). Finalmente, a última etapa (Figura 4.2(3)) adapta um sensor $S_{N O V O}$ às características de um sensor deficiente $S_{D E F}$ e que precise ser substituído (Figura 4.2(d)). Os resultados da terceira etapa servem para verificar a eficiência da abordagem proposta e são avaliados usando Técnicas de Projeção Multidimensional (Tejada et al., 2003) e Coeficiente de silhueta (Tan et al., 2005). Verifica-se como o bom agrupamento da projeção dos dados de capacitância dos sensores para diferentes concentrações (Figura 4.2(e)) é mantida após a substituição (Figura 4.2(f)).

A seguir cada uma das etapas do processo para reprodutibilidade será detalhada.

\subsubsection{Etapa 1: Conversão para capacitância}

A primeira etapa consiste em transformar as curvas de impedância completas fornecidas por sensores de espectroscopia de impedância nos conjuntos de dados em curvas de capacitância. Cada elemento da curva de impedância é representado por um elemento complexo z. Assim, um elemento é composto por dois valores: real $\left(z_{r}\right)$ e imaginário $\left(z_{i}\right)$. A partir desses valores de impedância é possível calcular o valor real de capacitância usando a seguinte equação:

$$
c=\frac{1}{w}\left(\frac{-z_{i}}{\left(z_{r}\right)^{2}+\left(z_{i}\right)^{2}}\right)
$$

em que $w$ representa o valor de frequência angular $(\operatorname{com} w=2 \pi f$, sendo que $f$ é a frequência usada na coleta de dados). Para facilitar o entendimento da abordagem, os símbolos mais frequentemente empregados nesse capítulo e suas descrições podem ser encontrados na Tabela 4.1. 

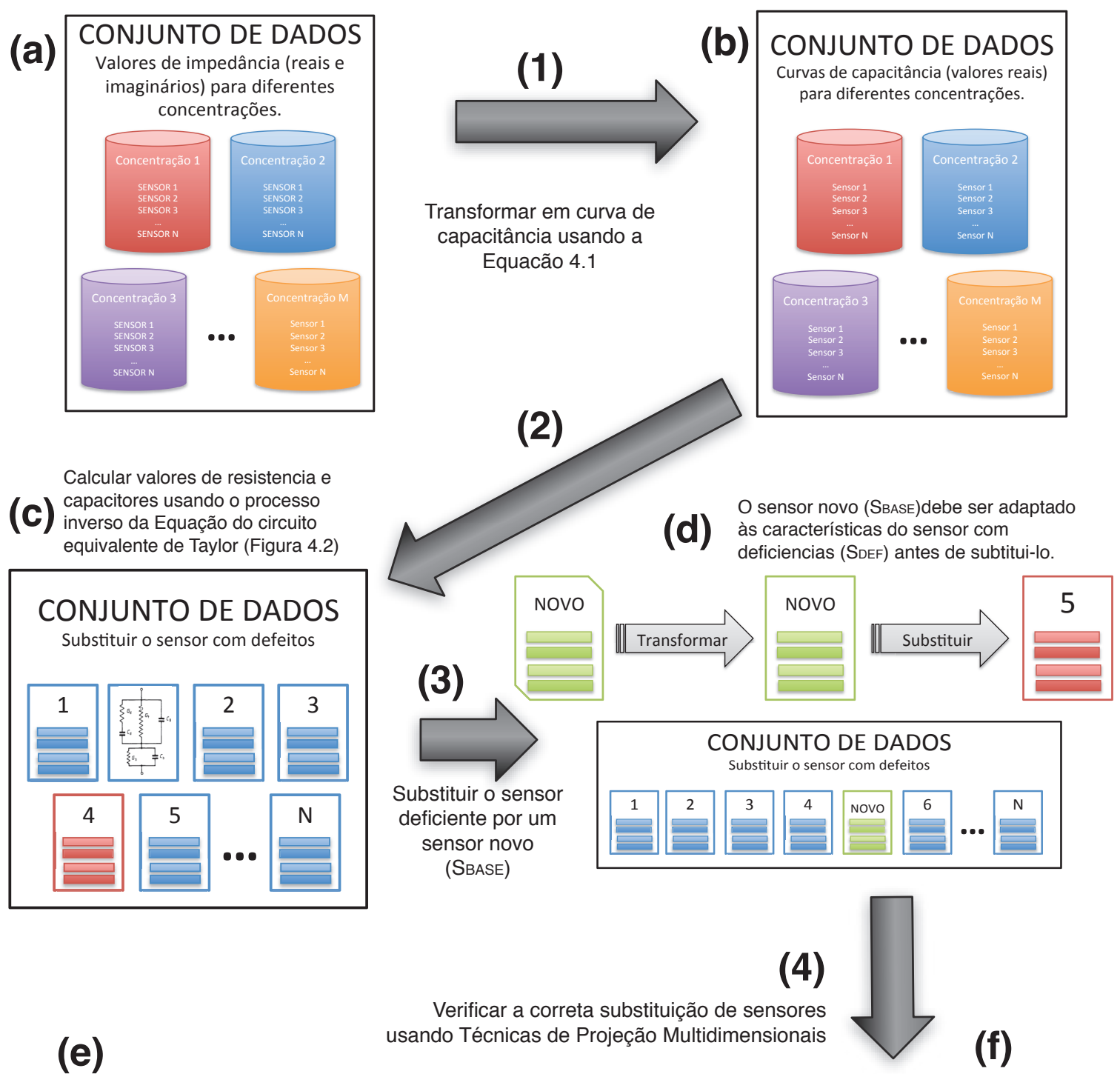

(e) (C) inverso da Equação do circuito equivalente de Taylor (Figura 4.2)

\section{CONJUNTO DE DADOS \\ Substituir o sensor com defeitos}
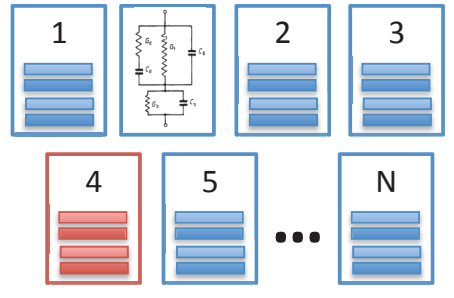

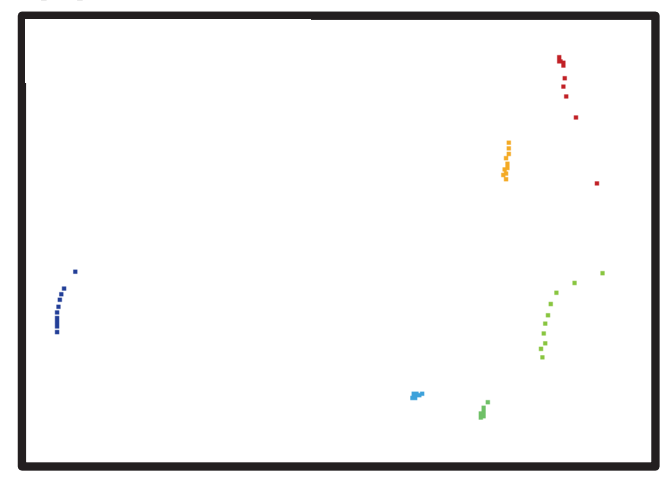

Projeção dos conjuntos de dados originais (curva de capacitância $C$ )

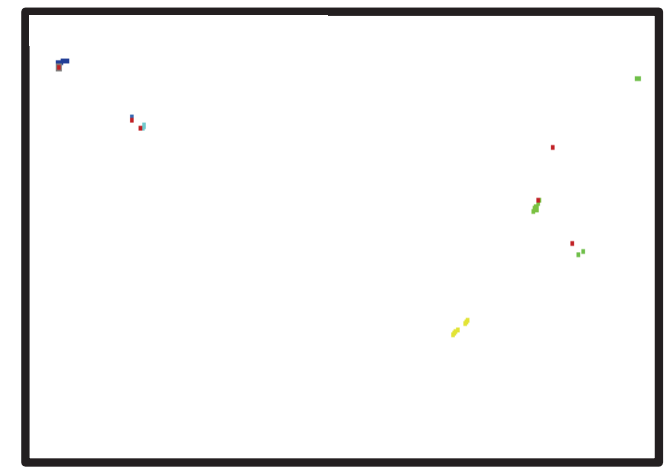

Projeção das resultados após a substituição (curva de capacitância sintética $C^{\prime}$ )

Figura 4.2: Resumo do processo para analisar a reprodutibilidade de sensores composto por 3 etapas: (1) Pré-processamento dos dados (Seção 4.1.1) (2) Conversão em circuito eletrônico equivalente (Taylor \& Macdonald, 1987) (Seção 4.1.2) e (3) Substituição de sensores e avaliação dos resultados usando Técnicas de Projeção Multidimensional (Seção 4.1.3) 
Tabela 4.1: Símbolos usados e seus significados para o entendimento da abordagem proposta para a Análise de Reprodutibilidade.

\begin{tabular}{|c||l|}
\hline \multicolumn{1}{|c|}{ Símbolo } & Significado \\
\hline \hline$f$ & Frequência . \\
\hline$w$ & Frequência angular $(w=2 \pi f)$. \\
\hline$z$ & Elemento complexo de impedância. \\
\hline$z_{r}$ & Parte real em um elemento de impedância. \\
\hline$z_{i}$ & Parte imaginária em um elemento de impedância. \\
\hline$G_{d}, G_{t}, G_{b}$ & $\begin{array}{l}\text { Valores das resistências correspondentes ao circuito eletrônico equivalente de } \\
\text { Taylor }\end{array}$ \\
\hline$C_{d}, C_{g}, C_{b}$ & $\begin{array}{l}\text { Valores dos capacitores correspondentes ao circuito eletrônico equivalente de } \\
\text { Taylor }\end{array}$ \\
\hline$C$ & $\begin{array}{l}\text { Curva de capacitância. A representação vetorial } C=\left\{c_{1}, c_{2}, \ldots, c_{n}\right\} \text { representa } \\
\text { os valores de capacitância para determinadas frequências } f .\end{array}$ \\
\hline$C^{\prime}$ & $\begin{array}{l}\text { Curva de capacitância sintética. Essa curva é o resultado do cálculo da capa- } \\
\text { citância a partir do circuito eletrônico equivalente de Taylor. }\end{array}$ \\
\hline Silh & $\begin{array}{l}\text { Valor de coeficiente silhueta calculado para uma projeção multidimensional. } \\
\text { Usado para avaliar a qualidade de uma projeção. }\end{array}$ \\
\hline
\end{tabular}

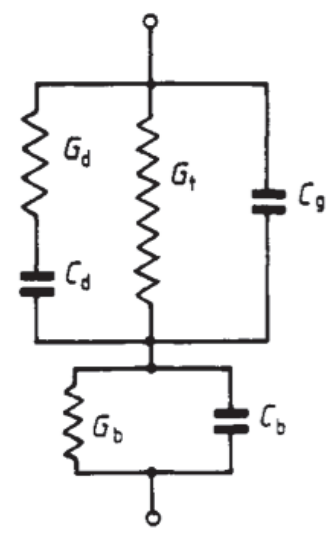

Figura 4.3: Circuito eletrônico equivalente que representa um sensor (figura extraída de Taylor \& Macdonald (1987))

\subsubsection{Etapa 2: Conversão em circuito eletrônico equivalente de Taylor}

Após a conversão de curvas de impedância em curvas de capacitância podemos representar um sensor por um circuito eletrônico equivalente (Taylor \& Macdonald, 1987) como apresentado na Figura 4.3. Esse circuito é composto por 3 resistores $\left(G_{d}, G_{t}, G_{b}\right)$ e 3 capacitores $\left(C_{d}, C_{g}, C_{b}\right)$ que usam como parâmetro a frequência $f$ e dão como resposta um valor de capacitância $c$. Desta forma, o processo de substituição de sensores diminui a complexidade. A transformação procurada seria calculada baseada nos seis valores mencionados em lugar de utilizar a curva de capacitância completa. Por fim, o cálculo de capacitância $c$ é dado pela Equação 4.2: 


$$
c=\left[\left(C_{b} G^{2}+C G_{b}^{2}\right)+\omega^{2}\left(C_{b} C^{2}+C_{b}^{2} C\right)\right] \times\left[\left(G_{b}+G\right)^{2}+\omega^{2}\left(C_{b}+C\right)^{2}\right]^{-1}
$$

em que $C$ é calculado usando a Equação 4.3:

$$
C=C_{g}+\left\{C_{d} G_{d}^{2} /\left(G_{d}^{2}+\omega^{2} C_{d}^{2}\right)\right\}
$$

e $G$ é calculado pela Equação 4.4 :

$$
G=G_{t}+\left\{\omega^{2} C_{d}^{2} G_{d} /\left(G_{d}^{2}+\omega^{2} C_{d}^{2}\right)\right\}
$$

Usando a Equação 4.2 do circuito eletrônico equivalente como referência, foi desenvolvida uma técnica que executa o processo inverso, ou seja, calcula os valores dos capacitores e resistores correspondentes ao circuito a partir da curva de capacitância resultante da execução da primeira etapa. O ajuste de parâmetros faz uso de técnicas de otimização a fim de definir com maior precisão os valores dos capacitores e resistores. Aqui nos testamos as técnicas Levenberg-Marquardt (LM) (Moré, 1978), Nelder-Mead (Olsson \& Nelson, 1975), Simulated Annealing (Kirkpatrick et al., 1983), Powell (Powell, 1964), Constraint Optimization By Linear Approximation(COByLA) (Powell, 1994) e Sequential Linear Squares Programming (SLSQP) (Kraft, 1988). As técnicas de otimização precisam de um valor base para cada parâmetro e um intervalo definido para obter os melhores parâmetros para uma função de ajuste (ROSSI, 2009). Geralmente, os valores dos resistores encontram-se no intervalo [10E3, 10E8] e os valores dos capacitores encontram-se no intervalo [10E-10, 10E-6].

A Figura 4.4 apresenta o resultado da aproximação da nova curva de capacitância $C^{\prime}$ gerada a partir dos parâmetros calculados (linha cinza) com a curva de capacitância original $C$ (linha vermelha). O ajuste de parâmetros atingiu uma grande precisão sendo que um resultado próximo de zero indica uma maior aproximação no cálculo dos valores. No exemplo, a dissimilaridade conseguida entre as duas curvas foi 5.71899688575E-08 usando a técnica de otimização SLSQP. Na Figura 4.4b os eixos frequência e dissimilaridade são apresentados em escala logarítmica. De outra forma, a diferença entre ambas curvas de capacitância não poderia ser percebida de forma visual, como ilustrado na Figura 4.4a.

Um comparativo dos resultados obtidos pelas diferentes técnicas de otimização empregadas no ajuste de parâmetros é apresentado na Tabela 4.2. Na tabela são exploradas as precisões atingidas para cada um dos conjuntos de dados analisados. Os valores exibidos correspondem à média dos valores de precisão atingidos pela conversão para cada curva de capacitância. Para uma melhor compreensão, os valores apresentados foram normalizados. Observa-se que todas as técnicas de otimização apresentaram bons resultados. O valor mínimo de aproximação atingido é menor do que 4.856E-05, um valor relativa- 

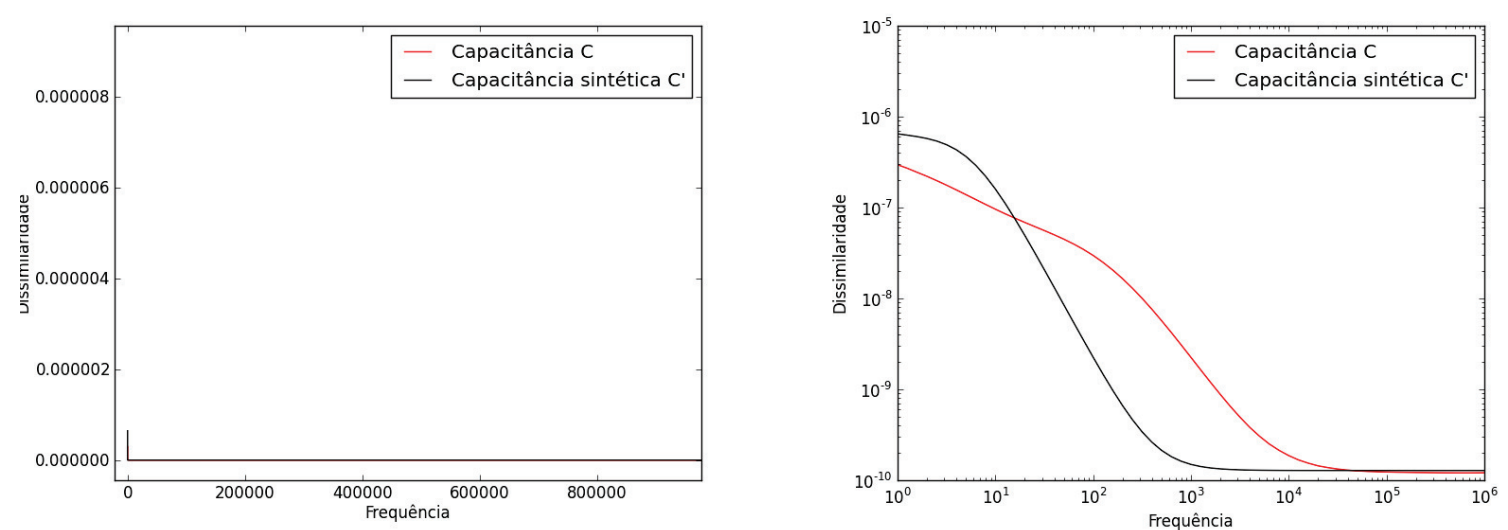

(a) Comparativo das duas curvas de capacitância $y$ (b) Aplicando escala logarítmica em ambos eixos $x$ e $y$

Figura 4.4: Comparativo entre a curva de capacitância $C$ (linha vermelha) e a curva de capacitância sintética $C^{\prime}$ (linha cinza) gerada a partir do cálculo de parâmetros. A Figura (b) é apresentada com os eixos frequência e dissimilaridade em escala logarítmica para observar melhor a diferença presente entre as curvas.

mente baixo. Esse resultado é conseguido pela técnica Simulated Annealing no ajuste do conjunto GOx/Lipase. Os melhores resultados foram conseguidos pelas técnicas COByLA, nos conjuntos de dados PAH/Phytase (8.462E-09), PAH/PVS (2.230E-09) e Eletrodo Puro (5.852E-09), e Nelder-Mead, nos conjuntos PAH/GOx (4.8093E-12), GOx/Lipase (1.7624E-11) e PAH/Lipase (1.6586E-10).

Tabela 4.2: Resultados da aproximação no processo de cálculo de parâmetros $\left(G_{d}, G_{t}, G_{b}, C_{d}, C_{g}, C_{b}\right)$ do circuito equivalente a partir da curva de capacitância $C$ empregando as diferentes técnicas de ajuste de parâmetros. Um resultado mais próximo de zero indica uma maior precisão atingida por cada técnica.

\begin{tabular}{|c|c|c|c|c|c|c|}
\hline & LM & Nelder & Powell & COByLA & SLSQP & S. Annealing \\
\hline \hline PAH/Phytase & $263.70 \mathrm{E}-08$ & $2.5185 \mathrm{E}-08$ & $3.5635 \mathrm{E}-08$ & $\mathbf{0 . 8 4 6 2 E - 0 8}$ & $263.93 \mathrm{E}-08$ & $2864.8 \mathrm{E}-08$ \\
\hline PAH/PVS & $252.94 \mathrm{E}-08$ & $5.4389 \mathrm{E}-08$ & $5.5666 \mathrm{E}-08$ & $\mathbf{0 . 2 2 3 0 E}-08$ & $151.06 \mathrm{E}-08$ & $2980.8 \mathrm{E}-08$ \\
\hline PAH/GOx & $1.2583 \mathrm{E}-08$ & $\mathbf{0 . 0 0 0 4 E - 1 8}$ & $4.7678 \mathrm{E}-08$ & $0.7377 \mathrm{E}-08$ & $1291.4 \mathrm{E}-08$ & $3704.9 \mathrm{E}-08$ \\
\hline Gox/Lipase & $5.6086 \mathrm{E}-08$ & $\mathbf{0 . 0 0 0 1 E - 0 8}$ & $12.229 \mathrm{E}-08$ & $1.4517 \mathrm{E}-08$ & $2539.9 \mathrm{E}-08$ & $4856.6 \mathrm{E}-08$ \\
\hline Eletrodo puro & $0.8793 \mathrm{E}-08$ & $0.9195 \mathrm{E}-08$ & $1.0873 \mathrm{E}-08$ & $\mathbf{0 . 5 8 5 2 E}-\mathbf{0 8}$ & $103.16 \mathrm{E}-08$ & $1625.0 \mathrm{E}-08$ \\
\hline PAH/Lipase & $13.882 \mathrm{E}-08$ & $\mathbf{0 . 0 1 6 5 E - 0 8}$ & $9.2212 \mathrm{E}-08$ & $1.3259 \mathrm{E}-08$ & $923.22 \mathrm{E}-08$ & $3456.6 \mathrm{E}-08$ \\
\hline
\end{tabular}

A fim de apresentar os resultados dessa etapa são apresentadas as Tabelas 4.3 e 4.4. A Tabela 4.3 apresenta o conjunto de dados PAH/PVS em forma de curvas de capacitância, cada uma composta por 72 valores de capacitância correspondentes a determinadas frequências (exibidas na primeira linha). O resultado do processo de conversão é apresentado na Tabela 4.4, que exibe os seis parâmetros calculados para cada curva de capacitância, conseguindo a redução de dimensionalidade desejada. As novas curvas de capacitância geradas usando os parâmetros apresentam uma diferencia menor do que 9.74096135567E-08 para o conjunto de dados inteiro. 
Tabela 4.3: Representação original do conjunto de dados PAH/PVS. Cada linha representa uma curva de capacitância e está composta por 71 elementos para determinadas frequências.

\begin{tabular}{|c|c|c|c|c|c|c|}
\hline Frequência & $1.000 \mathrm{E}+07$ & $7.943 \mathrm{E}+06$ & $6.309 \mathrm{E}+06$ & $5.011 \mathrm{E}+06$ & $3.981 \mathrm{E}+06$ & $\ldots$ \\
\hline af2A.z & $2.786593 \mathrm{E}-10$ & $3.7946948 \mathrm{E}-10$ & $4.603013 \mathrm{E}-10$ & $5.0877397 \mathrm{E}-10$ & $5.1901894 \mathrm{E}-10$ & $\ldots$ \\
\hline af2B.z & $2.8512756 \mathrm{E}-10$ & $3.80261 \mathrm{E}-10$ & $4.6127743 \mathrm{E}-10$ & $5.1000054 \mathrm{E}-10$ & $5.2054777 \mathrm{E}-10$ & $\ldots$ \\
\hline af2C.z & $2.8518168 \mathrm{E}-10$ & $3.8026007 \mathrm{E}-10$ & $4.61356 \mathrm{E}-10$ & $5.10127 \mathrm{E}-10$ & $5.2057947 \mathrm{E}-10$ & $\ldots$ \\
\hline af2D.z & $2.8517805 \mathrm{E}-10$ & $3.8026246 \mathrm{E}-10$ & $4.6131293 \mathrm{E}-10$ & $5.1016247 \mathrm{E}-10$ & $5.2055904 \mathrm{E}-10$ & .. \\
\hline af2E.z & $2.8512878 \mathrm{E}-10$ & $3.8024364 \mathrm{E}-10$ & $4.6132048 \mathrm{E}-10$ & $5.1000265 \mathrm{E}-10$ & $5.2044036 \mathrm{E}-10$ & $\ldots$ \\
\hline af2F.z & $2.851272 \mathrm{E}-10$ & $3.8025072 \mathrm{E}-10$ & $4.6132145 \mathrm{E}-10$ & $5.100972 \mathrm{E}-10$ & $5.204731 \mathrm{E}-10$ & $\cdots$ \\
\hline af2G.z & $2.851396 \mathrm{E}-10$ & $3.8020648 \mathrm{E}-10$ & $4.61258 \mathrm{E}-10$ & $5.0995796 \mathrm{E}-10$ & $5.2044763 \mathrm{E}-10$ & $\cdots$ \\
\hline af2H.z & $2.8513564 \mathrm{E}-10$ & $3.801609 \mathrm{E}-10$ & $4.6121723 \mathrm{E}-10$ & $5.1005666 \mathrm{E}-10$ & $5.2046084 \mathrm{E}-10$ & $\cdots$ \\
\hline af2I.z & $2.8510533 \mathrm{E}-10$ & $3.8013226 \mathrm{E}-10$ & 4.611797E-10 & $5.0999344 \mathrm{E}-10$ & $5.2039545 \mathrm{E}-10$ & $\cdots$ \\
\hline af2J.z & $2.8509747 \mathrm{E}-10$ & $3.8014547 \mathrm{E}-10$ & $4.612215 \mathrm{E}-10$ & $5.099594 \mathrm{E}-10$ & $5.2039245 \mathrm{E}-10$ & $\cdots$ \\
\hline
\end{tabular}

Tabela 4.4: Resultados da aproximação no processo de cálculo de parâmetros $\left(G_{d}, G_{t}, G_{b}, C_{d}, C_{g}, C_{b}\right)$ para o conjunto PAH/PVS

\begin{tabular}{|c|c|c|c|c|c|c|}
\hline Parâmetros & Gd & Gb & Cb & Cg & Cd & Gt \\
\hline \hline af2A.z & $1.15390 \mathrm{E}+04$ & $1.39313 \mathrm{E}+05$ & $7.53970 \mathrm{E}-07$ & $5.72522 \mathrm{E}-08$ & $5.04166 \mathrm{E}-07$ & $1.08826 \mathrm{E}+04$ \\
af2B.z & $1.15876 \mathrm{E}+04$ & $1.39313 \mathrm{E}+05$ & $7.48386 \mathrm{E}-07$ & $5.70931 \mathrm{E}-08$ & $4.99125 \mathrm{E}-07$ & $1.06494 \mathrm{E}+04$ \\
af2C.z & $1.44319 \mathrm{E}+04$ & $1.39313 \mathrm{E}+05$ & $7.48162 \mathrm{E}-07$ & $5.70579 \mathrm{E}-08$ & $4.94133 \mathrm{E}-07$ & $1.00055 \mathrm{E}+04$ \\
af2D.z & $1.44804 \mathrm{E}+04$ & $1.28499 \mathrm{E}+05$ & $7.48087 \mathrm{E}-07$ & $5.70988 \mathrm{E}-08$ & $4.89192 \mathrm{E}-07$ & $1.11490 \mathrm{E}+04$ \\
af2E.z & $1.45210 \mathrm{E}+04$ & $1.18939 \mathrm{E}+05$ & $7.51862 \mathrm{E}-07$ & $5.70522 \mathrm{E}-08$ & $4.88947 \mathrm{E}-07$ & $1.00055 \mathrm{E}+04$ \\
af2F.z & $1.45559 \mathrm{E}+04$ & $1.18904 \mathrm{E}+05$ & $7.51862 \mathrm{E}-07$ & $5.70474 \mathrm{E}-08$ & $4.84252 \mathrm{E}-07$ & $1.09714 \mathrm{E}+04$ \\
af2G.z & $1.81288 \mathrm{E}+04$ & $1.18856 \mathrm{E}+05$ & $7.51862 \mathrm{E}-07$ & $5.70636 \mathrm{E}-08$ & $4.79457 \mathrm{E}-07$ & $1.11102 \mathrm{E}+04$ \\
af2H.z & $1.81696 \mathrm{E}+04$ & $1.18832 \mathrm{E}+05$ & $7.51862 \mathrm{E}-07$ & $5.70009 \mathrm{E}-08$ & $4.74662 \mathrm{E}-07$ & $1.00055 \mathrm{E}+04$ \\
af2I.z & $1.82078 \mathrm{E}+04$ & $1.18832 \mathrm{E}+05$ & $7.51862 \mathrm{E}-07$ & $5.70522 \mathrm{E}-08$ & $4.74520 \mathrm{E}-07$ & $1.05939 \mathrm{E}+04$ \\
af2J.z & $1.82443 \mathrm{E}+04$ & $1.18832 \mathrm{E}+05$ & $7.51862 \mathrm{E}-07$ & $5.70465 \mathrm{E}-08$ & $4.74655 \mathrm{E}-07$ & $1.13988 \mathrm{E}+04$ \\
$\cdots$ & $\ldots$ & $\ldots$ & $\ldots$ & $\ldots$ & $\cdots$ & $\cdots$ \\
\hline
\end{tabular}

Após a conversão de curvas de capacitância em capacitores e resistores, segue o processo de substituição, que será detalhado a seguir.

\subsubsection{Etapa 3: Substituição de sensores}

A última etapa da abordagem visa definir uma forma de encontrar alguma transformação, ou escolha de parâmetros que torne as respostas de dois sensores mais semelhantes. Existem diferentes possibilidades para a execução dessa tarefa, por exemplo, dada uma projeção $P_{i}$ de um sensor $S_{i}$ e uma projeção $P_{j}$ de um sensor $S_{j}$, nominalmente igual a $S_{i}$, pode-se empregar Generalized Procrustes Analysis (GPA) para encontrar uma transformação linear que leve $P_{i}$ a $P_{j}$ distorcendo o mínimo possível os dados. A GPA é uma família de métodos relacionados com a análise de dados procedentes de vários indivíduos (Arabie et al., 1987). O método original da GPA foi descrito por (Gower, 1975) e depois melhorado por (Ten Berge, 1977).

A abordagem GPA é definida como: sejam $k$ configurações de $n$ instâncias no espaço $m$-dimensional, busca-se representar as $k$ configurações em um espaço comum, enquanto 
minimiza o critério de convergência $\sigma_{t}-\sigma_{t-1}<\varepsilon$ usando as 3 transformações básicas para fazer os espaços mais semelhantes possíveis (o valor de $\varepsilon$ usado nos experimentos é 1.0E-05):

1. Traslação: mudar os centroides de cada configuração para uma origem comum

2. Escala isotrópica: encolher ou ampliar cada configuração isotrópica para torná-las o mais semelhantes possíveis

3. Rotação/Reflexão: rotacionar as configurações

O critério de convergência é minimizado usando a seguinte função de perda:

$$
\sigma_{t}=\sum_{i=1}^{k}\left\|\mathbf{X}_{i} \mathbf{T}_{i}-\overline{\mathbf{X}}\right\|
$$

em que $\mathbf{X}$ é uma matriz de $k \times n \times m$ representando as instâncias; $\mathbf{T}$ é a matriz de transformação e $\overline{\mathbf{X}}$ representa a média das matrizes $\mathbf{X}_{\mathbf{i}} \mathbf{T}_{\mathbf{i}}$.

Como mencionado anteriormente, sensores nominalmente idênticos dificilmente produzem a mesma resposta elétrica em toda a curva de impedância capturada (Paulovich et al., 2011b). Portanto, é necessário adaptar as respostas do novo sensor para ser semelhantes às respostas do sensor deficiente. O processo de substituição é definido da seguinte forma: os parâmetros do sensor $S_{N O V O}$ são adaptados aos parâmetros do sensor $S_{D E F}$ usando GPA para cada uma das concentrações analisadas. Logo, as novas curvas da capacitância são geradas para cada concentração e depois as curvas são projetadas usando a técnica IDMAP e o resultado é avaliado calculando o Coeficiente de Silhueta para a projeção gerada. O Coeficiente de Silhueta mede a coesão e a separação entre os diferentes grupos de instâncias. A coesão $a_{x}$ de $x$ é calculada como a média das distâncias entre $x$ e as outras instâncias que formam parte do mesmo grupo de $x$. A separação $b_{x}$ é a distância mínima entre $x$ e o resto de instâncias que formam parte dos grupos diferentes do grupo de $x$. Assim, a silhueta de uma projeção é calculada usando a seguinte equação:

$$
\text { Silh }=\frac{1}{n} \sum_{x \in \mathbf{X}} \frac{\left(b_{x}-a_{x}\right)}{\max \left(a_{x}, b_{x}\right)}
$$

em que $n$ é o número de instâncias. O resultado do cálculo de silhueta é um valor no intervalo $[-1,1]$, em que valor maior de Silh significa uma melhor coesão e separação. Rousseeuw (1987) propôs uma interpretação do coeficiente Silhueta como pode ser visto na Tabela 4.5: 
Tabela 4.5: Interpretação do Coeficiente de Silhueta proposta por Rousseeuw (1987).

\begin{tabular}{|c||l|}
\hline Valor de coeficiente Silhueta & Interpretação \\
\hline \hline $0.71-1.00$ & Uma estrutura forte foi encontrada. \\
\hline $0.51-0.70$ & Uma estrutura razoável foi encontrada \\
\hline $0.26-0.50$ & $\begin{array}{l}\text { A estrutura é fraca e pode ser artificial; é recomendável } \\
\text { testar métodos adicionais nesses dados. }\end{array}$ \\
\hline$<0.25$ & Nenhuma estrutura substancial foi encontrada. \\
\hline
\end{tabular}

A Figura 4.5 apresenta os resultados da substituição de um sensor no conjunto de dados PAH/Phytase. Na esquerda, a Figura 4.5a apresenta a projeção das curvas de capacitância e verifica-se que elas têm um bom grau de separação (Silh: 0.82655245). $\mathrm{Na}$ direita, a Figura 4.5b apresenta a projeção das novas curvas de capacitância geradas a partir dos parâmetros calculados. O Coeficiente de Silhueta da projeção gerada é 0.64841056 e portanto comprova-se que o processo de substituição empregado tem respondido de forma relativamente apropriada (usando a metodologia proposta por Rousseeuw (1987)).

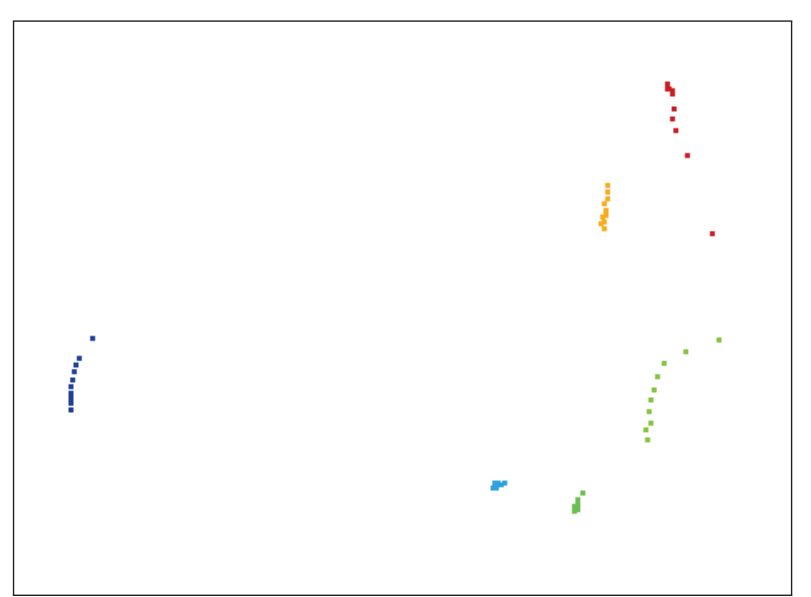

(a) Projeção das curvas de capacitância

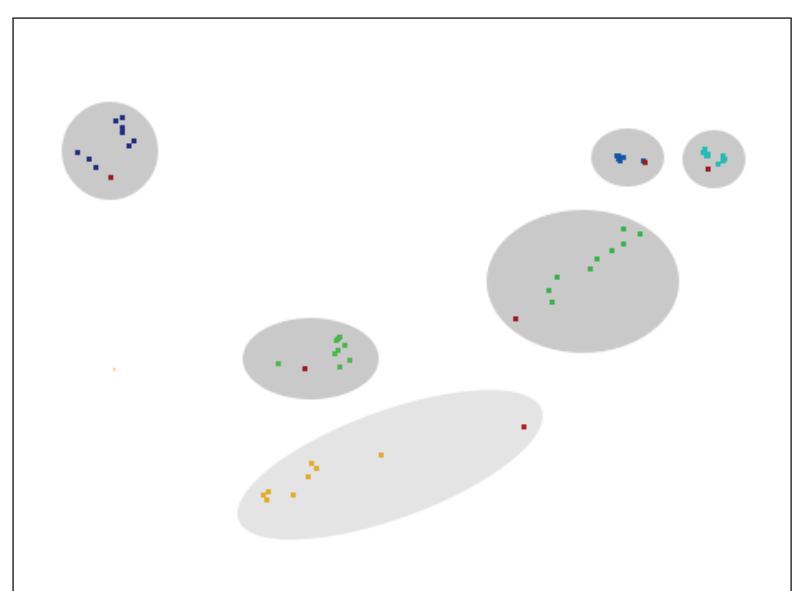

(b) Projeção das curvas de capacitância após a substituicão de um sensor deficiente

Figura 4.5: Projeções do resultado da substituição de um sensor deficiente no conjunto de dados PAH/Fitase. Na Figura (a) representa a projeção dos dados originais em que cada cor representa uma concentração diferente de ácido fítico. Na Figura (b) apresenta o resultado da substituição. Nessa ocasião os pontos vermelhos não representam uma concentração senão representam o novo sensor $S_{N O V O}$ após substituir o sensor deficiente $S_{D E F}$. Para uma melhor interpretação dos resultados, cada concentração é agrupada por um círculo cinza.

Na próxima seção serão expostos os resultados obtidos empregando a abordagem proposta. Os resultados apresentados correspondem às etapas de Conversão em circuito equivalente (Seção 4.1.2) e Substituição de Sensores (Seção 4.1.3), verificando a eficiência de cada uma das etapas. 


\subsection{Resultados}

Os resultados obtidos com a abordagem para avaliar a reprodutibilidade de sensores por meio da transformação e adaptação de componentes eletrônicos foram bastantes promissores. A avaliação da conversão das curvas de capacitância nos valores do circuito equivalente é certamente de grande importância, pois constitui a base da redução da complexidade do problema pois só são analisados os seis valores dos componentes eletrônicos em lugar das centenas de valores complexos de impedância.

A Figura 4.6 apresenta os resultados da etapa de conversão das curvas de capacitância no circuito eletrônico equivalente de Taylor (Seção 4.1.2) para o conjunto de dados PAH/Phytase. Inicialmente os dados apresentaram um bom agrupamento, determinado pelo coeficiente de silhueta da projeção dos dados usando a técnica IDMAP, como apresentado na Figura 4.6a que representa a projeção dos dados de capacitância. A projeção inicial obteve um coeficiente 0.82655245 , o que indica que um agrupamento forte foi encontrado. O ajuste de parâmetros e executado usando a técnica Sequential Linear Squares Programming. O coeficiente da nova projeção gerada (Figura 4.6b) após o ajuste apresentou um coeficiente 0.551106150 e denota que, apesar de ser um valor menor, ainda é apresentado un agrupamento razoável entre os sensores.

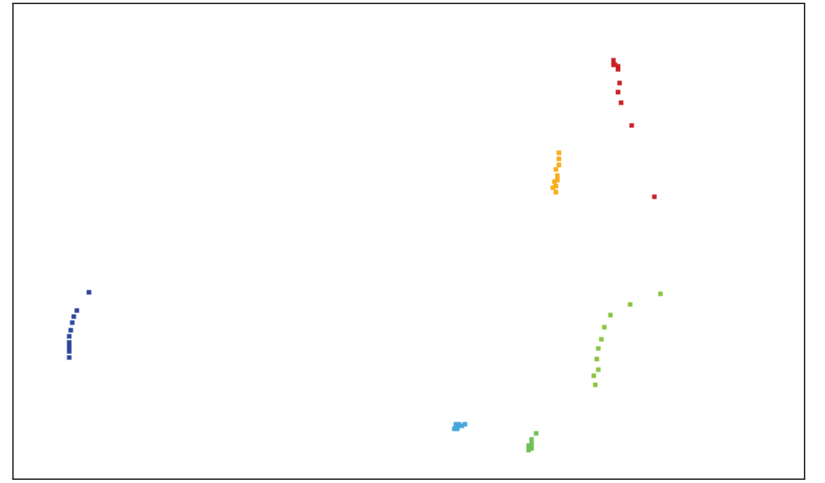

(a) PAH/Phytase - Capacitância

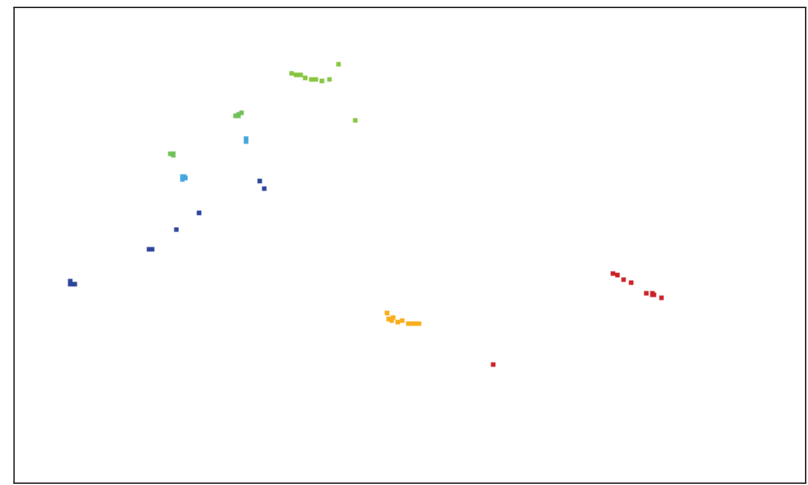

(b) PAH/Phytase - Parâmetros

Figura 4.6: Resultados da etapa de conversão das curvas de capacitância no circuito eletrônico equivalente de Taylor (Seção 4.1.2) para o conjunto de dados PAH/Phytase. A figura (a) apresenta a projeção dos dados originais com um valor de coeficiente de silhueta 0.82655245 . A figura (b) apresenta a projeção dos dados após o cálculo de capacitores e resistores, o novo coeficiente é 0.551106150 . Todas as projeções foram geradas usando a técnica IDMAP e os parâmetros foram calculados com a técnica Sequential Linear Squares Programming.

A Figuras 4.7 e 4.8 apresentam os resultados da conversão para o conjunto de dados PAH/PVS. Da mesma forma que o conjunto Eletrodo Puro, foram geradas as projeções dos dados de capacitância e dos parâmetros calculados a partir delas. A Figura 4.7a exibe a projeção de capacitância do conjunto PAH/PVS com um coeficiente silhueta 0.70707214 
e após o ajuste de parâmetros o coeficiente cai para 0.540498260 como observado na Figura 4.7b. Resultados similares são apresentados na conversão do conjunto Eletrodo Puro. Inicialmente, o coeficiente de silhueta é 0.6353018 (Figuras 4.8a) e após a conversão diminui para 0.488130060 (Figura 4.8b). Nesse caso, o processo de conversão não tem se comportado de forma adequada pois o coeficiente de silhueta apresentou um agrupamento fraco $(\leq 0.50)$ segundo Rousseeuw (1987).

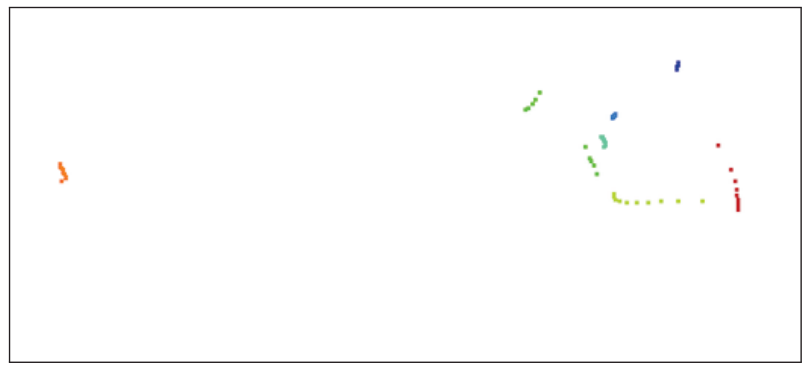

(a) PAH/PVS - Capacitância

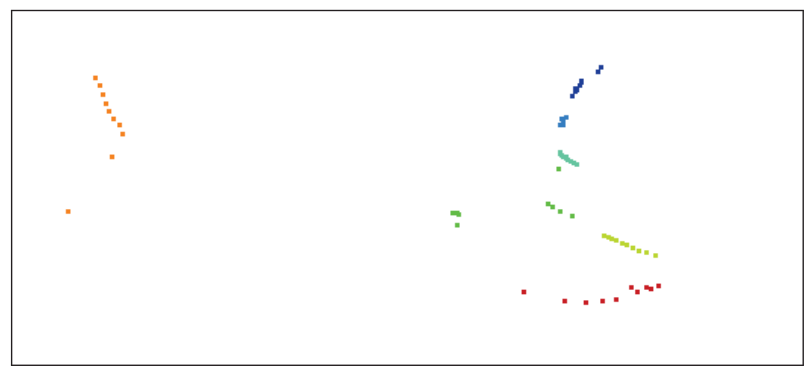

(b) PAH/PVS - Parâmetros

Figura 4.7: Resultados da etapa de conversão das curvas de capacitância no circuito eletrônico equivalente de Taylor (Seção 4.1.2) para o conjunto de dados PAH/PVS. A figura (a) apresenta a projeção dos dados originais com um valor de coeficiente de silhueta 0.70707214. A figura (b) apresenta a projeção dos dados após o cálculo de capacitores e resistores, o novo coeficiente é 0.540498260 . Todas as projeções foram geradas usando a técnica IDMAP e os parâmetros foram calculados com a técnica Sequential Linear Squares Programming.

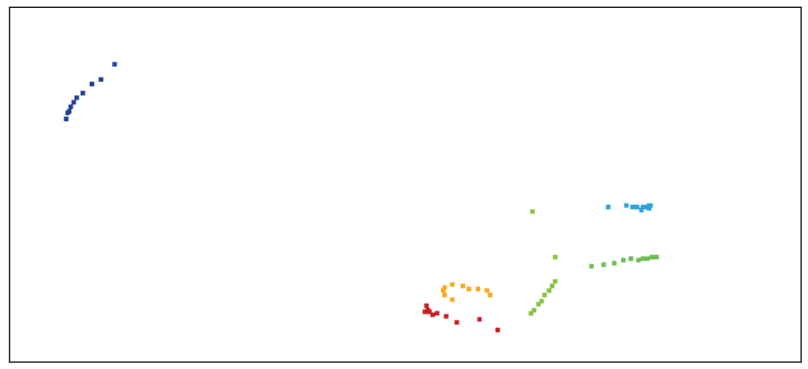

(a) Eletrodo Puro - Capacitância

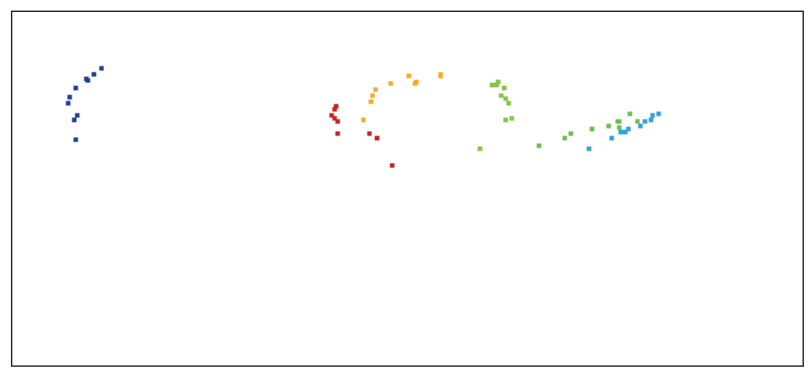

(b) Eletrodo Puro - Parâmetros

Figura 4.8: Resultados da etapa de conversão das curvas de capacitância no circuito eletrônico equivalente de Taylor (Seção 4.1.2) para o conjunto de dados Eletrodo puro. A figura (a) apresenta a projeção dos dados originais com um valor de coeficiente de silhueta 0.6353018. A figura (b) apresenta a projeção dos dados após o cálculo de capacitores e resistores, o novo coeficiente é 0.488130060 . As projeções foram geradas usando a técnica IDMAP e os parâmetros foram calculados com a técnica Sequential Linear Squares Programming.

A última etapa da abordagem, a Substituição de sensores (ver Seção 4.1.3) apresentou resultados satisfatórios usando como critério os valores de coeficiente de silhueta. As projeções expostas na Figura 4.9 apresentam os resultados da substituição de um sensor no conjunto de dados PAH/PVS. Na Figura 4.9a o círculo vermelho representa o sensor 
deficiente $S_{D E F}$. Por outro lado, nas Figuras $4.9 \mathrm{~b}$ e $4.9 \mathrm{c}$, o círculo vermelho representa o sensor $S_{N O V O}$ após a troca e transformação respectivamente. Após a troca inicial do sensor deficiente, o agrupamento apresentado com relação aos outros sensores é regularmente bom, determinado pelo coeficiente de silhueta conseguido 0.4350135. Já depois da transformação para adaptar as características do sensor, o coeficiente silhueta aumenta levemente até 0.45052648 .

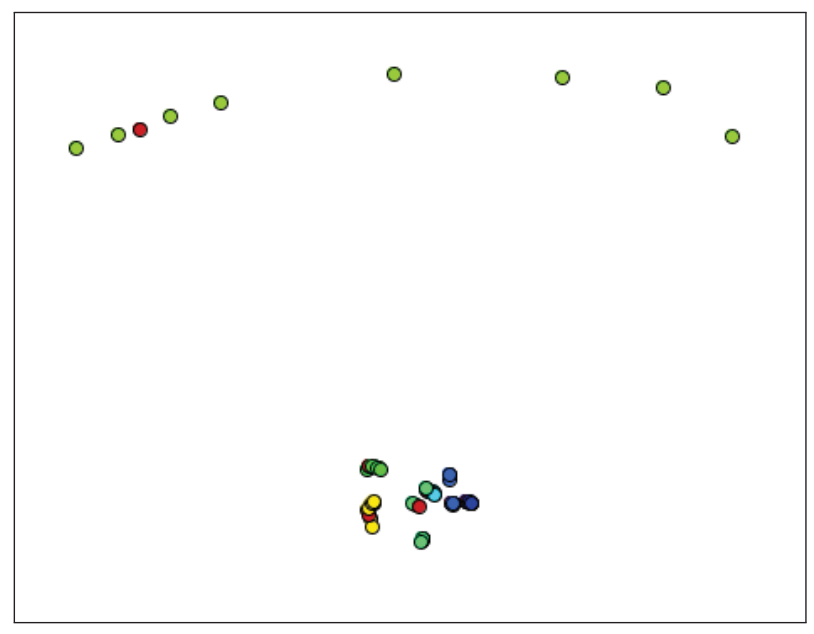

(a) PAH/PVS - Original

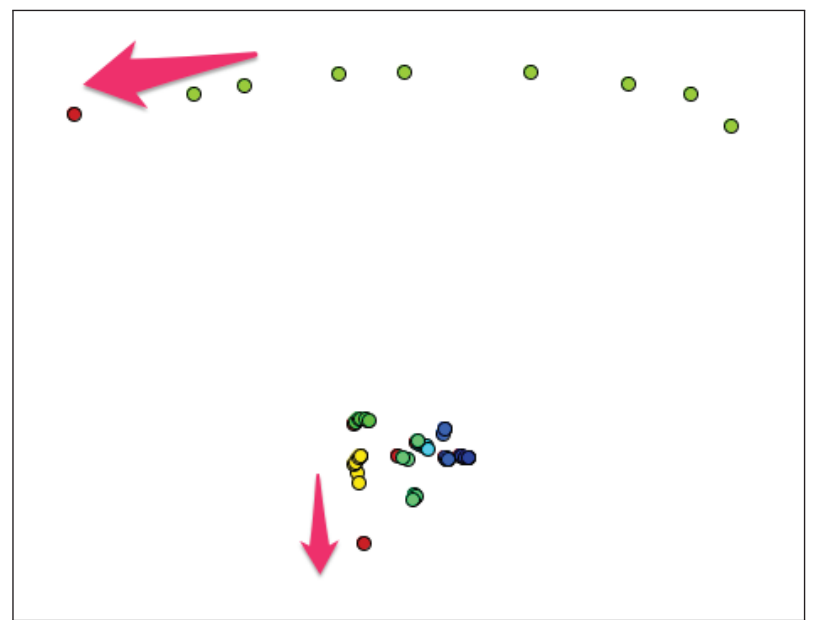

(b) PAH/PVS - Troca

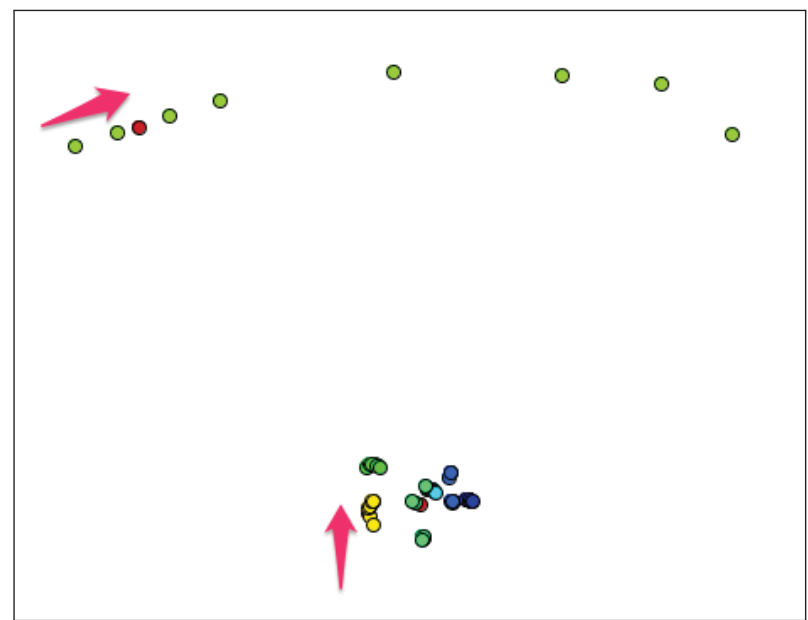

(c) PAH/PVS - Transformação

Figura 4.9: Resultados da etapa de Substituição de sensores (Seção 4.1.3). O ponto vermelho representa o sensor substituído analisado em cada concentração. A Figura (a) exibe a projeção das curvas de capacitância originais. Já a Figura (b) apresenta a nova projeção gerada após a substituição. Observa-se como o novo sensor apresenta uma maior separação comparado com os dados originais. Por fim, a Figura (c) apresenta a projeção depois de aplicar a recalibração do sensor. Os parâmetros do sensor $S_{N O V O}$ são transformados nos parâmetros do sensor $S_{D E F}$. 
Na Figura 4.10 é possível ver com maior detalhe o processo de transformação. As Figuras $4.10 \mathrm{~b}$ e $4.10 \mathrm{c}$ representam o zoom da área determinada pelo quadrado preto na Figura 4.10a. Note que na Figura 4.10b o círculo vermelho, representando o sensor após a troca, apresenta uma separação considerável do resto dos elementos. Aplicando o processo de transformação, o elemento é melhor agrupado com o resto de círculos amarelos, que representam o comportamento do sensor na mesma concentração. Note que para as outras concentrações o círculo vermelho some indicado pela sobreposição com os outros círculos, que indica um comportamento ótimo no agrupamento.

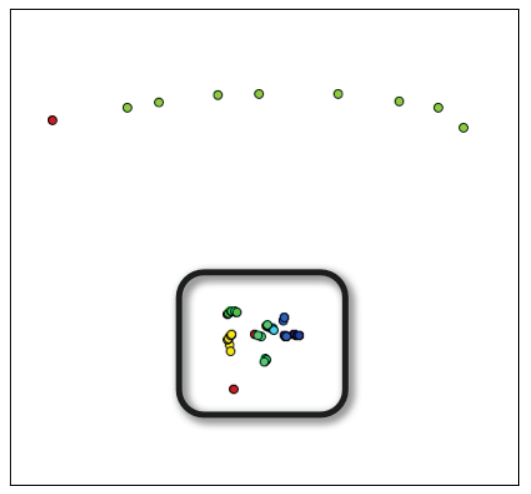

(a) PAH/PVS - Original

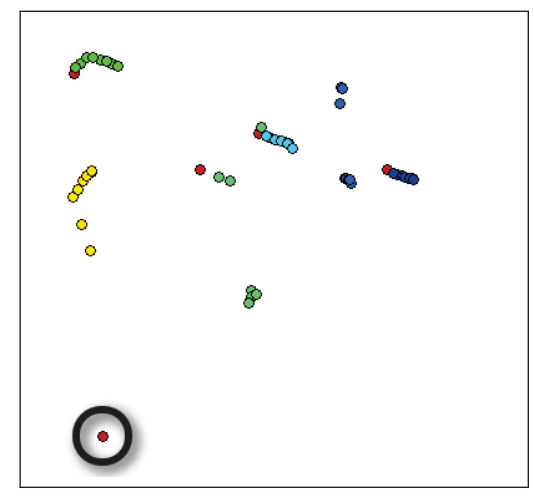

(b) PAH/PVS - Troca

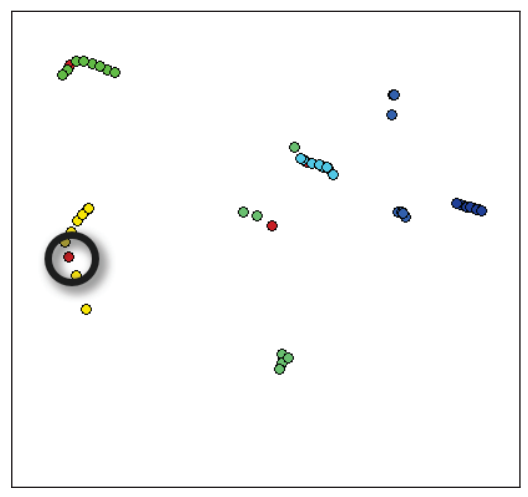

(c) PAH/PVS - Transformação

Figura 4.10: Resultados da etapa de Substituição de sensores na análise do conjunto PAH/PVS. As Figuras (b) e (c) representam o zoom da área indicada pelo retângulo preto na Figura (a). Observa-se como o sensor substituído, representado pelo círculo vermelho, é melhor agrupado após a etapa de transformação.

\subsection{Considerações finais}

Os resultados preliminares da técnica computacional proposta para a substituição de sensores em uma língua eletrônica tem se mostrado razoavelmente bons para se tratar de uma primeira abordagem. A etapa de conversão de curvas de capacitância no circuito de Taylor (Seção 4.1.2) foi de grande importância na análise pois reduziu a complexidade do problema de numerosos valores de impedância coletados ao longo do intervalo de frequências $[1 \mathrm{~Hz}, 1 \mathrm{MHz}]$ à análise de 6 valores (os componentes do circuito eletrônico equivalente de Taylor.

Para o processo de conversão foram analisadas diversas técnicas de ajuste de parâmetros, sendo a técnica Sequential Linear Squares Programming a que apresentou os melhores resultados. Nos experimentos a dissimilaridade encontrada entre a curva de capacitância original $C$ e a curva de capacitância sintética $C^{\prime}$ encontra-se no intervalo [1.0E-12, 1.0E6], sendo que um valor mais próximo de zero indica maior nível de precisão dos ajustes. Assim, os resultados obtidos evidenciam uma boa precisão. Esse processo de conversão 
poderia ser melhorado combinando a técnica atual, SLSQP, com outras técnicas de ajuste e otimização de parâmetros.

Na substituição de sensores, foi empregada uma abordagem que adapta as características de um sensor novo às características de um sensor que apresente deficiências. Essa adaptação é feita usando Generalized Procrustes Analysis, que apresentou bons resultados, mas outras técnicas poderiam ser empregadas, como redes neurais. A avaliação dos resultados foi feita utilizando o Coeficiente de Silhueta combinado com a técnica de projeção Interactive Document Map. Os novos sensores apresentaram uma boa adaptação e as projeções geradas apresentaram bons agrupamentos. 


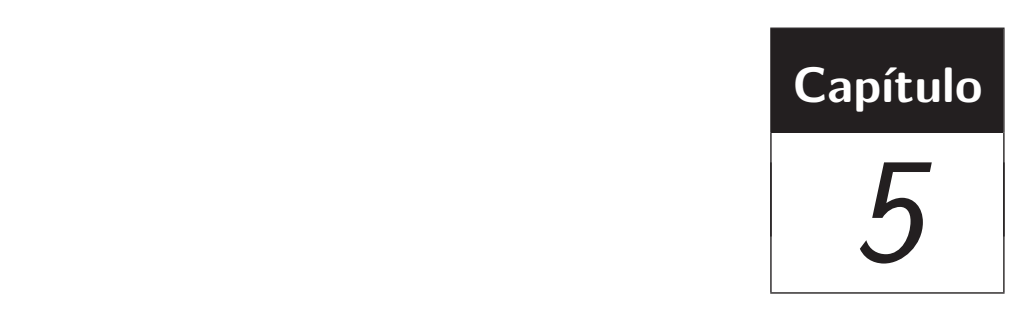

\section{Conclusões}

$\mathrm{N}$ esse capítulo são apresentadas as conclusões sobre o que foi desenvolvido nesse trabalho, bem como as suas limitações. Também são apresentados desenvolvimentos futuros que podem dar continuidade às abordagens propostas, superando algumas limitações e gerando outras contribuições.

O objetivo principal desse trabalho de mestrado foi desenvolver duas abordagens para resolver problemas apresentados na área de sensores e biossensores. Primeiro, o problema de detecção de molécula única apoiada por recursos computacionais (ver Capítulo 3). Segundo, a substituição de sensores em sistemas de língua eletrônica (ver Capítulo 4). É importante ressaltar que em ambos casos foram desenvolvidas abordagens que fizeram uso das técnicas de visualização de informação, já que essas tem se mostrado ferramental importante pois permitem compreender melhor os dados coletados e descobrir relações, padrões e tendências presentes neles.

A seguir apresentamos as conclusões sobre o trabalho desenvolvido para a detecção de molécula única.

\subsection{Detecção de molécula única em sensores do tipo SERS}

Os sensores para detecção de molécula única atuais geram uma grande quantidade de dados dificultando bastante o processo manual de análise. Portanto, o desenvolvimento de ferramental computacional é bastante recomendável. Inicialmente foi desenvolvida uma primeira abordagem que calculava a dissimilaridade entre os espectros analisados e o espectro de referência considerando o espectro como um todo. Os resultados dessa abordagem 
são apresentados em Aoki et al. (2013). Porém, a técnica apresentou algumas deficiências pelo número de falsos positivos encontrados. A fim de corrigir essas deficiências, a técnica computacional sofreu mudanças. Essas mudanças permitiram diminuir o número de falsos positivos encontrados fornecendo uma abordagem mais robusta para resolver o problema de detecção de molécula única. O emprego efetivo da nova abordagem computacional tem apresentado bons resultados em contrapartida à análise manual. O estudo dos conjuntos de dados MB, TRP e R18 demonstra os bons resultados conseguidos. De forma especial, a análise do conjunto R18 exibe o potencial da ferramenta desenvolvida já que o grande número de espectros (37848) que o compõem inviabiliza a análise manual, e sem análise dados têm pouco valor. Nos experimentos foi usado um computador Intel Core it com 24GB de memoria que combinado com um HD de estado sólido (SSD), permitiu analisar o conjunto R18 em aproximadamente $\sim 10$ segundos. Já as análises dos sistemas MB foram quase imediatas, demorando menos de 1 segundo.

A seguir é apresentada uma discussão das conclusões da abordagem proposta para a substituição de sensores em um arranjo de língua eletrônica.

\subsection{Substituição de sensores}

A substituição de sensores em um arranjo de língua eletrônica tem despertado grande interesse tanto na comunidade industrial como na científica. Atualmente, problemas relacionados à reprodutibilidade de sensores tem aparecido. Já que sensores nominalmente iguais dificilmente respondem da mesma forma. Uma inovadora abordagem foi desenvolvida visando resolver esse problema. Essa técnica faz uso da definição do circuito eletrônico equivalente de Taylor para reduzir a complexidade do problema pois as curvas de impedância (geralmente em centenas de valores complexos) foram transformados em 6 valores: 3 capacitores e 3 resistores. Nesse processo de conversão foram usadas diversas técnicas de otimização que conseguiram uma grande aproximação. Na conversão dos conjuntos analisados, o valor de dissimilaridade conseguido foi menor que 5.71899688575E-08, portanto podemos afirmar que uma grande aproximação foi atingida.

Após a conversão, a última etapa troca um sensor deficiente $\left(S_{D E F}\right)$ por um sensor novo $\left(S_{\text {NOVO }}\right)$ de características similares. Essa troca apresentou resultados razoavelmente bons, determinado pelo nível de agrupamento conseguido após a projeção das curvas de capacitância do novo sensor. O uso da abordagem Generalized Procrustes Analysis (GPA) serviu para transformar os parâmetros do sensor $S_{N O V O}$ nos parâmetros do sensor $S_{D E F}$. Após essa transformação, as novas curvas de capacitância foram projetadas outra vez. As novas projeções apresentaram um melhor agrupamento das concentrações analisadas.

A seguir são apresentadas as principais limitações encontradas no desenvolvimento desse trabalho. 


\subsection{Limitações}

O desenvolvimento efetivo de uma ferramenta para analisar dados sensoriais requer certo conhecimento prévio sobre sensores, biossensores e as aplicações deles na vida real. Essa limitação é uma característica presente no momento de trabalhar em áreas multidisciplinares. Por ser multidisciplinar, é aconselhável que os pesquisadores envolvidos trabalhem de forma conjunta durante o desenvolvimento do projeto. Dessa forma, o feedback sobre os resultados e o avanço do projeto pode ser recebido de forma imediata para que as mudanças requeridas possam ser analisadas e aplicadas de forma oportuna .

Por ser uma área nova para a aplicação de abordagens computacionais, não existe um trabalho que possa ser tomado como referência. Assim, o processo de detecção de molécula única apresenta limitações específicas. Uma delas é que não existe uma definição formal para afirmar que um espectro deve ser identificado como molécula única. Dessa forma, os pesos empregados no cálculo de dissimilaridade na Equação 3.6 foram definidos de forma empírica. Durante o desenvolvimento da abordagem, os resultados gerados computacionalmente ainda precisavam ser analisados de forma manual descartando falsos positivos. Essa informação serviu para refinar o processo computacional até atingir bons resultados e tornar o processo de detecção de molécula única em uma análise automática. Adicionalmente, é importante ressaltar que as abordagens tradicionais para análise de sinais não podem ser aplicadas diretamente. Isto porque existem particularidades como a relevância que apresenta a zona Full Width at Half Maximum (FWHM) (ver Seção 3.2) para cada espectro analisado.

Quanto à substituição de sensores, outras limitações foram encontradas. O processo de conversão de curvas de capacitância em resistores e capacitores do circuito de Taylor (ver Seção 4.1.2) consegue resultados razoavelmente bons. Embora, esse processo ainda possa ser melhorado para conseguir uma maior precisão. Existem ferramentas que conseguem melhores resultados para a conversão, uma delas é a ZView http://www.scribner.com/zplot-and-zview-for-windows.html. Porém, por ser ferramenta proprietária, a documentação sobre o processo de conversão não encontra-se disponível.

Apesar dessas limitações, os resultados apresentados se mostraram promissores e abrem espaço para novos campos de pesquisa. A seguir os desenvolvimentos futuros são apresentados. 


\subsubsection{Desenvolvimentos futuros}

Apesar de ter conseguido resultados razoavelmente bons para ambos temas abordados nesse trabalho, é aconselhável estudo de algumas alternativas que poderiam ser aplicadas afim de melhorar a qualidade dos resultados.

No caso da detecção de molécula única, a paralelização do algoritmo representaria um grande avanço pois reduziria ainda mais o tempo de execução da abordagem computacional. Essa é uma tarefa factível já que a análise dos espectros ocorre de forma independente para cada um deles. É importante ressaltar que o ideal seria desenvolver uma técnica para analise em tempo real de dados de sensores e biossensores. Alem disso, é recomendável um maior estudo das particularidades apresentadas nos espectros produzidos por sensores do tipo Surface Enhanced Raman Spectroscopy (SERS), assim como foi feito o estudo da relevância da faixa Full Width at Half Maximum (FWHM).

Quanto a substituição de sensores em línguas eletrônicas, destacam-se duas ações que poderiam ser analisadas com maior aprofundamento para conseguir melhores resultados. Embora o processo de conversão de curvas de capacitância tenha conseguido resultados com grande aproximação, a conversão ainda poderia ser aperfeiçoada até conseguir os resultados atingidos por outras ferramentas, como a ZView. Por outro lado, a etapa de transformação de parâmetros na substituição dos sensores poderia fazer uso de outras técnicas computacionais. Os algoritmos genéticos e as redes neurais constituem duas grandes alternativas para melhorar essa transformação conseguindo um maior agrupamento das concentrações analisadas pelas línguas eletrônicas. 


\section{Bibliografia}

Aoki, P. H. B., Carreon, E. G. E., Volpati, D., Shimabukuro, M. H., Constantino, C. J. L., Aroca, R. F., Oliveira Jr, O. N., e Paulovich, F. V. (2013). Sers mapping in langmuirblodgett films and single molecule detection. Society for Applied Spectroscopy.

Arabie, P., Carroll, J. D., e DeSarbo, W. S. (1987). Three-way scaling and clustering. Sage, Beverly Hills.

Avramoglu, R. K., Basciano, H., e Adeli, K. (2006). Lipid and lipoprotein dysregulation in insulin resistant states. Clinica chimica acta, 368(1-2):1-19.

Barnes, M. D., Whitten, W. B., e Ramsay, J. M. (1995). Detecting single molecules in liquids. Analytical Chemistry, 67(13):418-423.

Barnes, R. J., Dhanoa, M. S., e Lister, S. J. (1989). Standard normal variate transformation and de-trending of near-infrared diffuse reflectance spectra. Applied Spectroscopy, 43(5):772-777.

Card, S. K., Mackinlay, J. D., e Shneiderman, B., editores (1999). Readings in information visualization: using vision to think. Morgan Kaufmann Publishers Inc., San Francisco, CA, USA.

Chinaglia, D., Gozzi, G., Alfaro, R., e Hessel, R. (2008). Espectroscopia de impedância no laboratório de ensino. Revista Brasileira de Ensino de Física, 30(4):4504-1.

Cooley, J. W. e Tukey, J. W. (1965). An Algorithm for the Machine Calculation of Complex Fourier Series. Mathematics of Computation, 19(90):297-301.

Cox, T. F. e Cox, M. A. A. (2000). Multidimensional Scaling. Chapman and Hall/CRC, second ed.

Faloutsos, C. e Lin, K.-I. (1995). Fastmap: a fast algorithm for indexing, data-mining and visualization of traditional and multimedia datasets. In SIGMOD '95: Proceedings of 
the 1995 ACM SIGMOD international conference on Management of data, pp. 163-174, New York, NY, USA. ACM.

Fleischmann, M., Hendra, P., e McQuillan, A. (1974). Raman spectra of pyridine adsorbed at a silver electrode. Chemical Physics Letters, 26(2):163 - 166.

Gil, L., Garcia-Breijo, E., Ibañez, J., Labrador, R. H., Llobet, E., Martínez-Máñez, R., e Soto, J. (2006). Electronic tongue for qualitative analysis of aqueous solutions of salts using thick-film technology and metal electrodes. Sensors, 6(9):1128-1138.

Goldberg, D. E. (1989). Genetic algorithms in search, optimization, and machine learning.

Gorry, P. A. (1990). General least-squares smoothing and differentiation by the convolution method. Analytical Chemistry, 62(6):570-573.

Gower, J. C. (1975). Generalized procrustes analysis. Psychometrika, 40(1):33-51.

Grinstein, G., Trutschl, M., e Cvek, U. (2001). High-dimensional visualizations. In Proceedings of the 7th Data Mining Conference KDD Workshop, pp. 7-19, San Francisco, CA.

Inselberg, A. (1985). The plane with parallel coordinates. The Visual Computer, 1(2):6991.

Inselberg, A. e Dimsdale, B. (1987). Parallel coordinates for visualizing multi-dimensional geometry, pp. 25-44.

Katsube, T., Umetani, S., Shi, L., e Hasegawa, Y. (2005). Sensor fusion for taste sensor and odor sensor. Chemical Senses, 30(suppl 1):i260-i261.

Keim, D. A. (2002). Information visualization and visual data mining. IEEE Transactions on Visualization and Computer Graphics, 8:1-8.

Kim, J.-D., Byun, H.-G., Kim, D.-J., Ham, Y.-K., Jung, W.-S., e Yoon, C.-O. (2006). A simple taste analyzing system design for visual and quantitative analysis of different tastes using multi-array chemical sensors and pattern recognition techniques. Talanta, $70(3): 546-555$.

Kirkpatrick, S., Jr., D. G., e Vecchi, M. P. (1983). Optimization by simulated annealing. science, 220(4598):671-680.

Kneipp, K., Wang, Y., Kneipp, H., Perelman, L. T., Itzkan, I., Dasari, R. R., e Feld, M. S. (1997). Single molecule detection using surface-enhanced raman scattering (sers). Phys. Rev. Lett., 78:1667-1670. 
Kraft, D. (1988). A software package for sequential quadratic programming. Forschungsbericht // Deutsche Forschungs- und Versuchsanstalt für Luft- und Raumfahrt. Wissenschaftliches Berichtswesen der DFVLR [Vertrieb].

Landgrebe, D. (1997). On information extraction principles for hyperspectral data. Purdue University, West Lafayette, IN, USA, page 34.

Legin, A., Rudnitskaya, A., Vlasov, Y., Natale, C. D., Mazzone, E., e D’Amico, A. (2000). Application of electronic tongue for qualitative and quantitative analysis of complex liquid media. Sensors and Actuators B: Chemical, 65(1-3):232 - 234.

Minghim, R., Paulovich, F. V., e Lopes, A. A. (2006). Content-based text mapping using multi-dimensional projections for exploration of document collections. In Erbacher, R. F., Roberts, J. C., Grohn, M. T., e Borner, K., editores, Proceedings of IS and T/SPIE Conference - Visualization and Data Analysis 2006, v. 6060, page 60600S. SPIE.

Mohanty, S. P. e Kougianos, E. (2006). Biosensors: a tutorial review. Potentials, IEEE, $25(2): 35-40$.

Moraes, M., Graciano, W., Olivati, C., Oliveira Jr, O., e Ferreira, M. (2009). Electrical biosensors for triglycerides based on lipase immobilization in layer-by-layer films. In Proceedings of the 11th International Conference in Advanced Materials.

Moraes, M. L., Maki, R. M., Paulovich, F. V., Filho, U. P. R., de Oliveira, M. C. F., Riul, A., de Souza, N. C., Ferreira, M., Gomes, H. L., e Oliveira, O. N. (2010). Strategies to optimize biosensors based on impedance spectroscopy to detect phytic acid using layer-by-layer films. Analytical Chemistry, 82(8):3239-3246.

Moraes, M. L., Petri, L., Oliveira, V., Olivati, C. A., de Oliveira, M. C. F., Paulovich, F. V., Oliveira, O. N., e Ferreira, M. (2012). Detection of glucose and triglycerides using information visualization methods to process impedance spectroscopy data. Sensors and Actuators B: Chemical.

Moré, J. J. (1978). The levenberg-marquardt algorithm: implementation and theory. In Numerical analysis, pp. 105-116. Springer.

Morettin, P. C. e Toloi, C. M. C. (2004). Análise de séries temporais.

Oliveira, M. C. F. e Levkowitz, H. (2003). From visual data exploration to visual data mining: a survey. IEEE Transactions on Visualization and Computer Graphics, 9(3):378394. 
Oliveira Jr, O. N., Pavinatto, F. J., Constantino, C. J., Paulovich, F. V., e de Oliveira, M. C. F. (2012). Information visualization to enhance sensitivity and selectivity in biosensing. Biointerphases, 7(1-4):1-15.

Oliveira Jr, O. N., Zucolotto, V., Ferreira, M., Mattoso, L. H. C., e Riul Jr, A. (2005). Nanostructured films employed in sensors, Cap. Supramolecular Engineering of Conducting Materials. Kerala Research Signpost.

Olsson, D. M. e Nelson, L. S. (1975). The nelder-mead simplex procedure for function minimization. Technometrics, 17(1):45-51.

Parra, V., Hernando, T., R-Méndez, M. L., e de Saja, J. A. (2004). Electrochemical sensor array made from bisphthalocyanine modified carbon paste electrodes for discrimination of red wines. Electrochimica Acta, 49(28):5177 - 5185.

Paulovich, F. V., Maki, R. M., de Oliveira, M. C. F., Colhone, M. C., Santos, F. R., Migliaccio, V., Ciancaglini, P., Daghastanli, K. R., Stabeli, R. G., Perinoto, A. C., Jr, O. N. O., e Zucolotto, V. (2011). Using multidimensional projection techniques for reaching a high distinguishing ability in biosensing. Analytical and Bioanalytical Chemistry.

Paulovich, F. V., Moraes, M. L., Maki, R., Oliveira, M. C. F., e Oliveira Jr, O. N. (2011). Information visualization techniques for sensing and biosensing. Analyst, 136(7):13441350 .

Pejcic, B. e Marco, R. D. (2006). Impedance spectroscopy: Over 35 years of electrochemical sensor optimization. Electrochimica Acta, 51(28):6217 - 6229.

Pieczonka, N. e Aroca, R. (2008). Single molecule analysis by surfaced-enhanced raman scattering. chemical society reviews, 37(5):946-954.

Polder, G. e van der Heijden, G. W. (2001). Visualization of spectral images. In Multispectral Image Processing and Pattern Recognition, pp. 132-137. International Society for Optics and Photonics.

Powell, M. J. (1964). An efficient method for finding the minimum of a function of several variables without calculating derivatives. The computer journal, 7(2):155-162.

Powell, M. J. (1994). A direct search optimization method that models the objective and constraint functions by linear interpolation. Springer.

Quinn, A. (2000). A survey of techniques for preprocessing in high dimensional data clustering. In Proceedings of the Cybernetic and Informatics Eurodays. 
Riul, A., dos Santos, D. S., Wohnrath, K., Di Tommazo, R., Carvalho, A. C. P. L. F., Fonseca, F. J., Oliveira, O. N., Taylor, D. M., e Mattoso, L. H. C. (2002). Artificial taste sensor: Efficient combination of sensors made from langmuir-blodgett films of conducting polymers and a ruthenium complex and self-assembled films of an azobenzenecontaining polymer. Langmuir, 18(1):239-245.

Riul Jr., A., Dantas, C. A. R., Miyazaki, C. M., e Oliveira Jr., O. N. (2010). Recent advances in electronic tongues. Analyst, 135:2481-2495.

ROSSI, A. L. D. (2009). Ajuste de parâmetros de técnicas de classificação por algoritmos bioinspirados. Master's thesis, Instituto de Ciências Matemáticas e de Computação, Universidade de São Paulo, 2009. Dissertação de Mestrado em Ciências de Computação e Matemática Computacional.

Rousseeuw, P. J. (1987). Silhouettes: a graphical aid to the interpretation and validation of cluster analysis. Journal of computational and applied mathematics, 20:53-65.

Sammon, J. (1969). A nonlinear mapping for data structure analysis. IEEE Transactions on Computers, C-18:401 - 409.

Sasic, S., Itoh, T., e Ozaki, Y. (2006). Classification of single-molecule surface-enhanced resonance raman spectra of rhodamine $6 \mathrm{~g}$ from isolated ag colloidal particles by principal component analysis. Vibrational Spectroscopy, 40(2):184 - 191.

Savitzky, A. e Golay, M. J. E. (1964). Smoothing and differentiation of data by simplified least squares procedures. Analytical Chemistry, 36(8):1627-1639.

Solanki, P. R., Dhand, C., Kaushik, A., Ansari, A. A., Sood, K., e Malhotra, B. (2009). Nanostructured cerium oxide film for triglyceride sensor. Sensors and Actuators B: Chemical, 141(2):551-556.

Steinier, J., Termonia, Y., e Deltour, J. (1972). Comments on smoothing and differentiation of data by simplified least square procedure. Analytical Chemistry, 44(11):19061909.

Sun, D. (2008). Infrared Spectroscopy for Food Quality Analysis and Control. Academic Press/Elsevier.

Tan, P.-N., Steinbach, M., e Kumar, V. (2005). Introduction to Data Mining, (First Edition). Addison-Wesley Longman Publishing Co., Inc., Boston, MA, USA.

Taylor, D. M. e Macdonald, A. G. (1987). Ac admittance of the metal/insulator/electrolyte interface. Journal of Physics D: Applied Physics, 20(10):1277. 
Tejada, E., Minghim, R., e Nonato, L. G. (2003). On improved projection techniques to support visual exploration of multidimensional data sets. Information Visualization, $2(4): 218-231$.

Ten Berge, J. M. (1977). Orthogonal procrustes rotation for two or more matrices. Psychometrika, 42(2):267-276.

Vijayalakshmi, A., Tarunashree, Y., Baruwati, B., Manorama, S., Narayana, B., Johnson, R., e Rao, N. (2008). Enzyme field effect transistor (enfet) for estimation of triglycerides using magnetic nanoparticles. Biosensors and Bioelectronics, 23(11):1708-1714.

Young, G. e Householder, A. (1938). Discussion of a set of points in terms of their mutual distances. Psychometrika, 3:19-22. 